\title{
Rearranjo de Genomas \\ por \\ Reversões
}

Francisco Elói Soares de Araújo

\author{
DISSERTAÇÃO APRESENTADA \\ $\mathrm{AO}$ \\ INSTITUTO DE MATEMÁTICA E ESTATÍSTICA \\ DA \\ UNIVERSIDADE DE SÃO PAULO \\ PARA \\ OBTENÇÃO DO GRAU DE MESTRE \\ EM \\ MATEMÁTICA APLICADA
}

\begin{abstract}
Área de Concentração: Ciência da Computação Orientador: Prof. Dr. José Augusto R. Soares
\end{abstract}

Durante a elaboração deste trabalho o autor recebeu apoio financeiro da Capes

- São Paulo — agosto de 1998 - 


\title{
Rearranjo de Genomas por Reversões
}

\author{
Este exemplar corresponde à redação \\ final da dissertaçãoo devidamente corrigida \\ e defendida por Francisco Elói Soares de Araújo \\ e aprovada pela comissão julgadora.
}

São Paulo, 14 de agosto de 1998.

Banca examinadora:

- Prof. Dr. José Augusto R. Soares (orientador) - IME - USP

- Prof. Dr. João Meidanis - DCC - UNICAMP

- Prof $^{a}$. Dr ${ }^{a}$. Nami Kobayashi - IME - USP 
À minha esposa Ione $\mathrm{e}$ aos meus filhos Gabriel, Sarah e Pedro. 
Resumo. O cálculo do número mínimo de eventos de rearranjo de genomas que transformam o genoma de uma espécie em outra é usado para inferir o grau de parentesco entre duas espécies. Devido ao fato da reversão ser, muitas vezes, o único evento de rearranjo de genomas presente em um único cromossomo, o Problema Ordenação por Reversões (MIN-SBR) tem sido estudado, principalmente, nos últimos anos. Nessa dissertação estudamos as duas versōes de MIN-SBR: a versão orientada, representada por uma permutação orientada, isto é, quando conhecemos a orientação dos genes em relação ao cromossomo; e a versão não-orientada, representada por uma permutação não-orientada, quando não conhecemos essa orientação. Para a versão orientada, Hannenhalli e Pevzner [HP95] descreveram um algoritmo polinomial, que, dada uma permutação orientada $\vec{\pi}$ com $n$ elementos, determina uma sequência mínima de reversões que ordenam $\vec{\pi}$ em tempo $O\left(n^{5}\right)$. Posteriormente, uma versão mais eficiente desse algoritmo foi descrita por Kaplan, Shamir e Tarjan [KST97] cujo tempo é $O(n \alpha(n)+n r)$, onde $\alpha(n)$ é o inverso da função de Ackerman e $d$ é o número mínimo de reversōes que ordena $\vec{\pi}$. Descrevemos uma versão para esse algoritmo que gasta tempo $O(n d)$. Mostramos também, resumidamente, os trabalhos de Meidanis, Walter e Dias [MWD97] que determinam o valor do diâmetro por reversões em permutações orientadas; e formalizam a versão orientada do problema em permutações orientadas circulares, modeladas para estudar o número mínimo de reversões que tranformam um cromossomo circular em outro. Para a versão não-orientada do probema, descrevemos o algoritmo polinomial aproximado de Bafna e Pevzner [BP93] que encontra uma seqüência de reversões (que ordenam uma permutação não-orientada $\pi \operatorname{com} n$ elementos) de tamanho menor ou igual a $7 / 4$ do tamanho da seqüência mínima de reversões que ordena $\pi$; e o valor do diâmetro por reversões em permutações não-orientadas. Por fim, descrevemos a prova de Caprara [Cap96] de que a versão não-orientada de MIN-SBR é $N P$-difícil.

\footnotetext{
Abstract. The calculus of the minimal number of genome rearrangements' events that turn the genome of one specie into another is used to infer the level of relationship among two specie. Because the reversal is, many times, the only genome rearrangements' event present in only one chromosome, the problem of sorting by reversals (MIN-SBR) have been studied, mainly, in the last years. In the dissertation, we studied the two MIN-SBR versions: the signed version, represented by a signed permutation, that is, when we know the relationship between the orientation of the genes and the chromosome; and the unsigned version, represented by a unsigned permutation, when we do not know this orientation. For the signed version, Hannenhalli e Pevzner [HP95] described a polinomial algorithm that given a signed permutation $\vec{\pi}$ with $n$ elements determine a minimal sequence of reversals that sorting $\vec{\pi}$ in $O\left(n^{5}\right)$ time. Later, a more efficient version of this algorithm was described by Kaplan, Shamir and Tarjan [KST97], whose time is $O(n \alpha(n)+n r)$, where $\alpha(n)$ is the inverse of Ackerman's function, and $d$ is the minimal number of reversals that sorts $\vec{\pi}$. We describe a version of this algorithm that runs in $O(n d)$ time. We also show, briefly, the work of Meidanis, Walter e Dias [MWD97] that determine the value of reversal diameter of signed permutations; and formalize the signed version of the circular signed permutations problem, modeled to study the minimal number of reversals that turn one circular chromosome into another. For the unsigned version of problem, we describe the approximation polinomial algorithm by Bafna e Pevzner [BP93] that finds a reversal sequence (that sorts a unsigned permutation $\pi$ with $n$ elements) which size is at the most $7 / 4$ of minimal reversals sequence size that sort $\pi$; and the value of reversal diameter in unsigned permutation. Finally, we describe the Caprara's proof [Cap96] of the $N P$-hardness of the MIN-SBR unsigned version.
} 


\section{Agradecimentos}

Ao amigo Professor José Augusto, pela paciência, incentivo, orientação e confiança depositada neste trabalho e nos meus estudos.

À Professora Nami, pela dedicação e dicas que foram muito úteis à redação final desta dissertação.

Ao Professor João Meidanis pelo apoio e incentivo.

A todos do Instituto de Matemática e Estatística da USP, em especial aos colegas, pela amizade; ao Prof. Paulo Feofiloff, pelas sugestões e dicas para a apresentação do trabalho de qualificação; e à Prof ${ }^{a}$ Cláudia Cueva Cândido pelo incentivo constante.

Aos meus queridos sogros Brito e Carmen, que sempre me ajudaram em minha vida particular a fim de que pudessemos ter tempo integral para a dedicação ao mestrado.

$\mathrm{E}$ a todos meus amigos que, de alguma forma, me apoiaram. 


\section{Sumário}

1 Introdução 1

1.1 Modelagem Computacional . . . . . . . . . . . . . . . . . . 3

1.1 .1 Versão Não-Orientada . . . . . . . . . . . . . . . . . . . . 3

1.1 .2 Versão Orientada . . . . . . . . . . . . . . . . . . . . 4

1.2 Organização dos Capítulos . . . . . . . . . . . . . . . . . . . 6

2 Grafo de Pontos de Quebra $\quad 8$

2.1 Introdução . . . . . . . . . . . . . . . . . . . . 8

2.2 Pontos de Quebra . . . . . . . . . . . . . . . . . . . . 8

2.3 Grafo de Pontos de Quebra . . . . . . . . . . . . . . . . . . . . 9

2.4 Circuitos no Grafo de Pontos de Quebra . . . . . . . . . . . . . . . . . . . 9

2.5 Limitante Inferior do Problema MIN-SBR . . . . . . . . . . . . . . . . . 10

3 Permutações Orientadas 13

3.1 Introdução . . . . . . . . . . . . . . . . . . . . . . . . . . 13

3.2 Transformação em Permutações Não-Orientadas . . . . . . . . . . . . . . . 13

3.2.1 Retrato de Permutações Orientadas . . . . . . . . . . . . . . . . 13

3.2.2 Grafo de Pontos de Quebra de Permutações Orientadas . . . . . . . . . 15

3.3 Limitante Inferior . . . . . . . . . . . . . . . . . . . . . . . . . . . 18

3.3.1 Grafo de Entrelaçamento . . . . . . . . . . . . . . . . . . 18

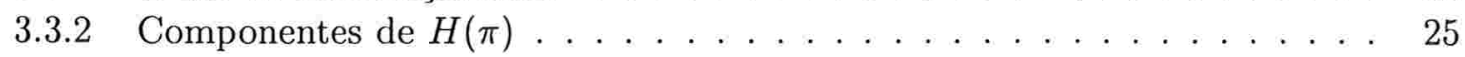

3.3 .3 Limitante Inferior . . . . . . . . . . . . . . . . . . . . . . . . . . 30

3.4 Limitante Superior . . . . . . . . . . . . . . . . . . . . . . . . . . . 34

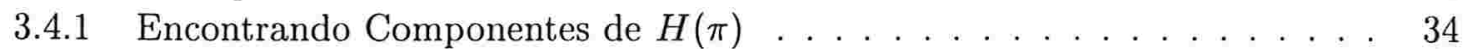

3.4 .2 Eliminando Obstáculos . . . . . . . . . . . . . . . . . . . 40

3.4 .3 Eliminando Componentes Boas . . . . . . . . . . . . . . . . . . 46

3.4 .4 Algoritmo SBR-Orienta . . . . . . . . . . . . . . . . 50

3.5 Diâmetro de Reversões em Permutações Orientadas . . . . . . . . . . . . . . . . . 50

3.6 Permutações Circulares Orientadas . . . . . . . . . . . . . . . . . . . . 53

3.6 .1 Introdução . . . . . . . . . . . . . . . . . . 53

4 Permutações Não-Orientadas $\quad \mathbf{5 7}$

4.1 Algoritmos Aproximados . . . . . . . . . . . . . . . . . . . . . . 57

$4.1 .1 \quad$ Algoritmo $K S \ldots \ldots \ldots \ldots \ldots \ldots \ldots \ldots$ 
$4.1 .2 \quad$ Limitante Inferior $\ldots \ldots \ldots \ldots$. . . . . . . . . . . . . . 60

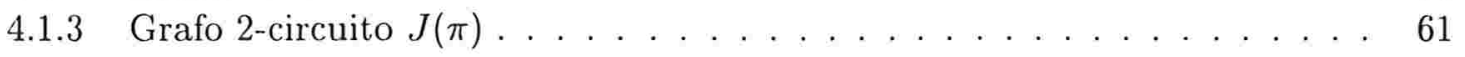

4.1 .4 Explorando 2-reversão . . . . . . . . . . . . . . . . . . . . 62

4.1.5 Encontrando o Candidato Apropriado de uma Permutação . . . . . . . . 64

4.1.6 Ordenando o Retrato de um Candidato Apropriado . . . . . . . . . . . . 65

4.1 .7 Algoritmo AproxMIN-SBR . . . . . . . . . . . . . . 65

4.1 .8 Fator de Aproximação de AproxMIN-SBR . . . . . . . . . . . . . 65

4.1 .9 Complexidade de Tempo de AproxMIN-SBR . . . . . . . . . . . 68

4.2 Diâmetro de Reversão do Grupo Simétrico . . . . . . . . . . . . . . . . . . 68

4.3 Distância Esperada por Reversões . . . . . . . . . . . . . . . . . . 73

5 Complexidade de MIN-SBR $\quad \mathbf{7 4}$

5.1 Introdução . . . . . . . . . . . . . . . . . . . . . . . . . . 74

5.2 Complexidade de MAX-ECD . . . . . . . . . . . . . . . . . . 74

5.3 Complexidade de MAX-ACD . . . . . . . . . . . . . . . 75

5.3.1 Transformando um Grafo Euleriano em um Grafo de Pontos de Quebra . 76

5.4 Complexidade de MIN-SBR . . . . . . . . . . . . . . . . . 80

5.4.1 Determinando uma Permutação a partir de um Grafo de Pontos de Quebra 81

5.4 .2 Procedimento Dupla-Divisão . . . . . . . . . . . . . . . . 81

6 Conclusão $\quad 84$ 


\section{Capítulo 1}

\section{Introdução}

Desde a aceitação pela comunidade científica das teorias de Darwin a respeito da evolução, muitos pesquisadores têm se dedicado a estudar a história evolutiva dos seres vivos atuais e como cada dois desses se relacionam em termos de ancestral comum. Esse estudo normalmente é feito construindo-se árvores cujas folhas representam as espécies atuais e cujos nós internos representam ancestrais hipotéticos. Esses tipos de árvores são ditas árvores filogenéticas ou simplesmente filogenias. Um exemplo de uma árvore filogenética para alguns primatas é mostrado na Figura 1.1 (baseada em [SM97]). De acordo com a mesma, o chimpanzé é geneticamente mais próximo dos seres humanos que o gorila.

Árvores filogenéticas têm sido propostas desde o século passado sendo que os métodos utilizados até 1950 eram baseados em pesquisas experimentais e intuição. Gradualmente, formalismos matemáticos foram introduzidos. Com o desenvolvimento da biologia molecular, os dados para a construção de árvores, que anteriomente eram obtidos das características físicas, químicas e fisiológicas, passaram a ser obtidos também da estrutura molecular dos organismos.

(É claro que, quanto mais diversificadas forem as características observadas na coleta de dados, maiores são as chances de que a árvore construída se aproxime da realidade. Imagine, por exemplo, que um pesquisador use na coleta de dados, para a construção de uma árvore filogenética hipotética, para um grupo de vertebrados, a característica morfológica do tamanho

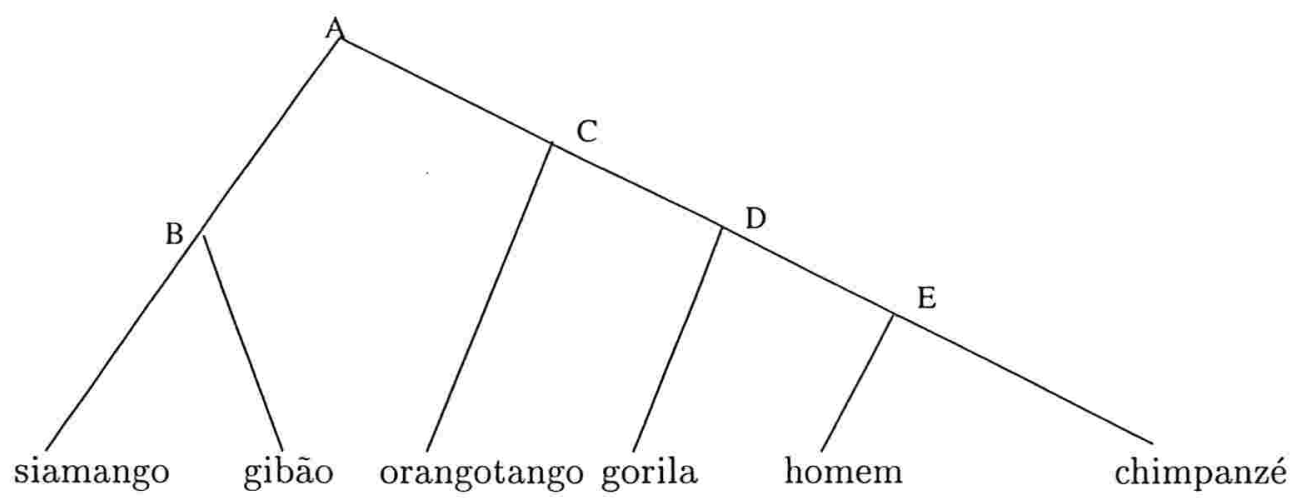

Figura 1.1: Árvore filogenética para alguns primatas 
do pescoço e a característica funcional dos membros para voar de cada animal. Percebemos o conflito que será gerado entre as conclusões desse pesquisador e a comunidade científica atual se o grupo de vertebrados estudado é \{morcego, sabiá, girafa e avestruz\}.)

Uma fonte de dados, que motiva esse trabalho, é a distância evolutiva entre as espécies. O cálculo da distância é baseado em uma métrica definida a partir de um fenômeno observado. A distância determinada nem sempre, infelizmente, corresponde proporcionalmente ao tempo.

Sendo o DNA constituído de uma cadeia dupla de unidades básicas (base nitrogenadas) e, considerando uma mutação como uma operação básica de transformação nessas bases nitrogenadas (remoção, inserção e substituição), uma tentativa em determinar o grau de parentesco entre duas espécies é calcular a distância de edição entre suas moléculas (número mínimo de operações básicas que tranformam uma molécula em outra).

Embora o cálculo da distância de edição pareça ser, à primeira vista, uma modelagem genérica muito boa do problema, intuitivamente, ao conhecermos outros eventos na transformação da molécula de DNA, conhecidos como Rearranjo de Genomas, parece haver a necessidade de reavaliarmos se essa modelagem é realmente genérica.

O rearranjo de genoma é um evento envolvendo um pedaço da molécula de DNA que pode conter uma quantidade muito grande de bases nucleicas. Esse pedaço de DNA pode afetar a "configuração" do genoma de várias maneiras tais como a sua inversão dentro do cromossomo (reversão), remoção e subsequente reinserção em outro local ou no mesmo cromossomo (transposição) ou mesmo em outro cromossomo (translocação), cópia (duplicação), etc.

De fato, esses eventos começaram a ganhar a atenção dos pesquisadores quando a distância de edição entre alguns organismos muito semelhantes (como os vírus da herpes) era tão alta que não fornecia qualquer evidência de ter origem evolutiva comum.

Esse trabalho é dedicado ao estudo da distância de evolução considerando unicamente o evento de reversão e ignorando outros eventos de mutação. Chamamos essa medida de distância por reversões e a entendemos assim. Dadas duas fitas de DNA com o mesmo conjunto de genes, a distância por reversões é o número mínimo de reversões que "transforma" uma fita na outra. Ignorar a existência de outros eventos de mutação não condena o trabalho a residir unicamente no campo teórico já que, quando estudamos o genoma cloroplástico e mitocondrial, por exemplo, a reversão parece ser, praticamente, o único caminho da mudança evolutiva.

Um aspecto importante é sabermos que, basicamente, existem duas técnicas em biologia molecular para obter dados sobre a ordem dos genes em um genoma. Uma delas fornece tão somente a ordem em que os genes aparecem na fita de DNA e a outra, além da ordem dos genes, fornece informações relativas a sua orientação. Entretanto, essa última, apesar de fornecer dados mais ricos, é muito cara (financeiramente falando), o que resulta que, atualmente, são conhecidas muito mais seqüências genômicas curtas do que longas. Por isso, a maior parte dos dados são obtidos através de técnicas que não fornecem a orientação dos genes. A conseqüência de tal fato sobre o estudo do problema de encontrar o número mínimo de reversões é que teremos que. tratar duas versões desse mesmo problema: encontrar a distância por reversões entre duas fitas de DNA, quando não conhecemos a orientação de seus genes, e outra, quando conhecemos a orientação dos mesmos.

Como exemplo do problema onde conhecemos a orientação relativa dos genes, considere o genoma cloroplático da alfafa e da ervilha representados na Figura 1.2 (baseada em [SM97]). Cada flecha rotulada denota um bloco. Um bloco é uma seção da molécula de DNA, possivel- 


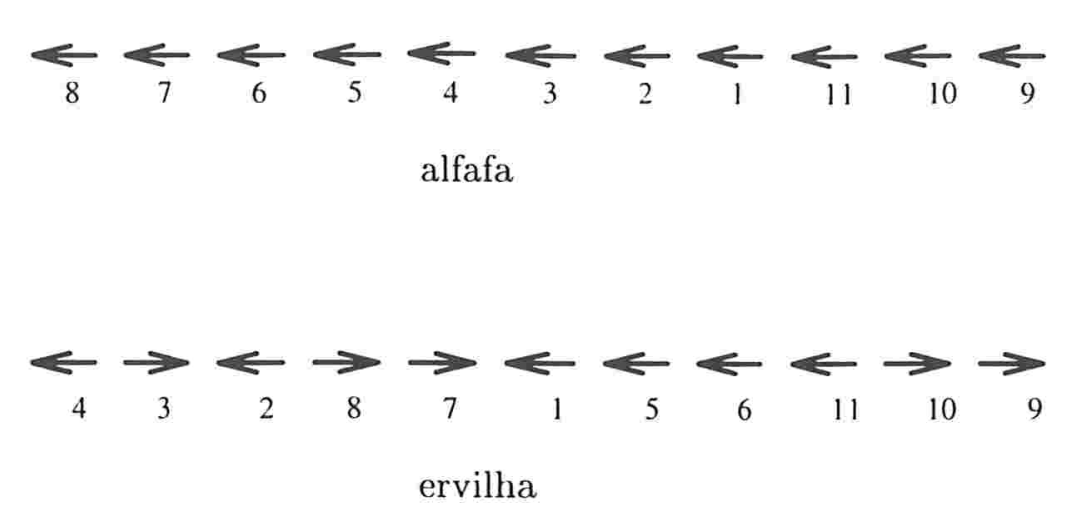

Figura 1.2: Alfafa / ervilha

mente contendo mais de um gene. As setas das flechas denotam o fato de que os blocos têm orientação, isto é, sendo um gene uma sequência de bases nucleicas, elas indicam onde está seu início relativamente ao DNA. Dois blocos em diferentes genomas têm o mesmo rótulo se eles contém a mesma seqüência de genes.

Vale a pena ressaltar que estamos interessados em encontrar o número mínimo de reversões, pois consideramos que a natureza seja parcimoniosa quanto à evolução. Essa pressuposição corresponde à realidade, principalmente, para distâncias pequenas.

\subsection{Modelagem Computacional}

\subsubsection{Versão Não-Orientada}

Uma permutação $\pi$ sobre um inteiro positivo $n$ é uma função

$$
\pi:\{1,2, \ldots, n\} \rightarrow\{1,2, \ldots, n\},
$$

tal que, para todo $i \neq j, \pi(i) \neq \pi(j)$. Dizemos simplesmente permutação $\pi$ se ou $n$ estiver claro ou não for necessário no contexto. Denotamos o elemento $\pi(i)$ por $\pi_{i}$ e a permutação por

$$
\pi=\left(\begin{array}{llll}
\pi_{1} & \pi_{2} & \ldots & \pi_{n}
\end{array}\right) .
$$

Considere, então, um conjunto $\mathcal{A}$ de $n$ blocos de genes rotulados com os números inteiros $1,2, \ldots, n$. Dado um cromossomo $\alpha$ com o conjunto $\mathcal{A}$ de blocos de genes, podemos representar $\alpha$ através de uma permutação da seguinte forma. Se o $i$-ésimo bloco que aparece em $\alpha$ é o bloco $j$, então $\alpha_{i}=j$.

Para $\pi$ e $\sigma$ permutações sobre $n$, aplicar $\sigma$ a $\pi$ é a operação que resulta na permutação

$$
\pi . \sigma=\left(\begin{array}{llll}
\pi_{\sigma_{1}} & \pi_{\sigma_{2}} & \ldots & \pi_{\sigma_{n}}
\end{array}\right) .
$$

A permutação identidade (sobre $n$ ) é a permutação

$$
\iota=\left(\begin{array}{llll}
1 & 2 & \ldots & n
\end{array}\right) .
$$


Denotamos por $\pi^{-1}$, o inverso de $\pi$ no grupo simétrico, ou seja, $\pi^{-1}$ é uma permutação tal que

$$
\pi \cdot \pi^{-1}=\pi^{-1} \cdot \pi=\iota .
$$

Uma reversão $\rho=(i . . j)=(j . . i)$, para $i<j$, é a permutação

$$
\rho=(i . . j)=\left(\begin{array}{llllllllllll}
1 & 2 & \ldots & i-1 & j & j-1 & \ldots & i & j+1 & j+2 & \ldots & n
\end{array}\right) .
$$

Aplicar a reversão $\rho$ a uma permutação $\pi$ é, então, uma operação que transforma $\pi$ na permutação

$$
\pi . \rho=\left(\begin{array}{llllllllllll}
\pi_{1} & \pi_{2} & \ldots & \pi_{i-1} & \pi_{j} & \pi_{j-1} & \ldots & \pi_{i} & \pi_{j+1} & \pi_{j+2} & \ldots & \pi_{n}
\end{array}\right) .
$$

A distância por reversões entre a permutação $\pi$ e a permutação $\sigma$ é o número mínimo $d_{\sigma}(\pi)$ de reversões que aplicadas sucessivamente a $\pi$ transformam $\pi$ em $\sigma$.

A versão não-orientada do problema pode, então, ser formulada da seguinte maneira. Dadas duas permutações $\pi$ e $\sigma$, encontrar uma seqüência mínima de reversões que aplicadas sucessivamente a $\pi$ transformam $\pi$ na permutação $\sigma$.

Dizemos que uma seqüência de reversões ordena uma permutação $\sigma$ se esta, aplicada sucessivamente a $\sigma$, transformam $\sigma$ na permutação identidade.

Note que, sendo $\rho_{1}, \rho_{2}, \ldots, \rho_{d_{\sigma}(\pi)}$ uma seqüência de reversões, tal que

$$
\pi . \rho_{1} . \rho_{2} \ldots . \rho_{d_{\sigma}(\pi)}=\sigma
$$

temos que

$$
\sigma^{-1} \cdot \pi \cdot \rho_{1} \cdot \rho_{2} \ldots . \rho_{d_{\sigma}(\pi)}=\sigma^{-1} \cdot \sigma=\iota .
$$

Por essa razão, tratamos do problema de, dada uma permutação $\pi$. encontrar uma seqüência mínima de reversões que ordena $\pi$ ("sorting a permutation by the minimal number of reversals $M I N-S B R ")$ como segue.

\section{Problema $1 M I N-S B R$}

Instância: Uma permutação $\pi$.

Objetivo: Encontrar uma seqüência de reversões $\rho_{1}, \rho_{2}, \ldots, \rho_{d(\pi)}$, tal que

$$
\pi \cdot \rho_{1} \cdot \rho_{2} \ldots . \rho_{d(\pi)}=\iota
$$

onde $d(\pi)=d_{\iota}(\pi)$.

\subsubsection{Versão Orientada}

Uma permutação orientada $\vec{\pi}$ sobre um inteiro positivo $n$ é uma função

$$
\vec{\pi}:\{1,2, \ldots, n\} \rightarrow\{-n,-n+1,-n+2, \ldots,-1,1,2, \ldots, n\},
$$

tal que, para todo $i \neq j,|\vec{\pi}(i)| \neq|\vec{\pi}(j)|$. Vamos representar um elemento positivo da imagem de $\vec{\pi}$ por $\vec{i}$. Um elemento negativo é representado por $\stackrel{\leftarrow}{i}$. Dizemos, simplesmente, permutação 
orientada $\vec{\pi}$ se ou $n$ estiver claro ou não for necessário no contexto. Denotamos o elemento $\vec{\pi}(i)$ por $\vec{\pi}_{i}$ e a permutação por

$$
\vec{\pi}=\left(\begin{array}{llll}
\vec{\pi}_{1} & \vec{\pi}_{2} & \ldots & \vec{\pi}_{n}
\end{array}\right) .
$$

A versão orientada do problema surge quando conhecemos a orientação de cada bloco de gene (como na Figura 1.2). Além do conjunto $\mathcal{A}$ de $n$ blocos de genes, definimos, para cada elemento de $\mathcal{A}$, uma orientação padrão (ou da esquerda para direita ou vice-versa). Dado um cromossomo $\alpha$ com o conjunto $\mathcal{A}$ de blocos, podemos representar $\alpha$ através de uma permutação orientada da seguinte forma. Se o $i$-ésimo bloco que aparece em $\alpha$ é o bloco $j$, então verificamos o seguinte. Se o bloco $j$ aparece em $\alpha$ com a mesma orientação que aquela definida como padrão, então $\alpha_{i}=j$, senão (se o bloco $j$ aparece em $\alpha$ com a orientação invertida), $\alpha_{i}=-j$.

Para $\vec{\pi}$ e $\vec{\sigma}$ permutações sobre $n$, aplicar $\vec{\sigma}$ a $\vec{\pi}$ é a operação que resulta na permutação $\vec{\pi} . \vec{\sigma}$ tal que

$$
(\vec{\pi} . \vec{\sigma})_{i}= \begin{cases}+\vec{\pi}_{\left|\vec{\sigma}_{i}\right|} & \text { se } \vec{\sigma}_{i}>0, \\ -\vec{\pi}_{\left|\vec{\sigma}_{i}\right|} & \text { caso contrário. }\end{cases}
$$

A permutação identidade orientada (sobre $n$ ) é a permutação

$$
\vec{\iota}=\left(\begin{array}{llll}
\overrightarrow{1} & \overrightarrow{2} & \ldots & \vec{n}
\end{array}\right) .
$$

O inverso de uma permutação $\vec{\pi}$ é a permutação $\vec{\pi}^{-1}$ tal que

$$
\vec{\pi} \cdot \vec{\pi}^{-1}=\vec{\pi}^{-1} \cdot \vec{\pi}=\vec{\iota} \text {. }
$$

Uma reversão orientada $\vec{\rho}=\overrightarrow{(i . . j)}=\overrightarrow{(j . . i)}$, para $i \leq j$, é a permutação

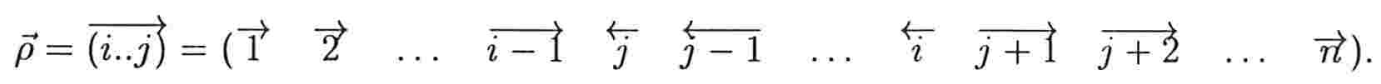

Aplicar a reversão orientada $\vec{\rho}$ a uma permutação orientada $\vec{\pi}$ é, então, a operação que transforma $\vec{\pi}$ na permutação orientada

$$
\vec{\pi} \cdot \vec{\rho}=\left(\begin{array}{llllllllllll}
\vec{\pi}_{1} & \vec{\pi}_{2} & \ldots & \vec{\pi}_{i-1} & -\vec{\pi}_{j} & -\vec{\pi}_{j-1} & \ldots & -\vec{\pi}_{i} & \vec{\pi}_{j+1} & \vec{\pi}_{j+2} & \ldots & \vec{\pi}_{n}
\end{array}\right) .
$$

A distância por reversões orientadas entre a permutação orientada $\vec{\pi}$ e a permutação orientada $\vec{\sigma}$ é o número mínimo $\vec{d}_{\vec{\sigma}}(\vec{\pi})$ de reversões orientadas que aplicadas sucessivamente a $\vec{\pi}$ transformam $\vec{\pi}$ em $\vec{\sigma}$.

A versão orientada do problema pode, então, ser formulada da seguinte maneira. Dadas duas permutações orientadas $\vec{\pi}$ e $\vec{\sigma}$, encontrar uma seqüência mínima de reversões orientadas que aplicadas sucessivamente a $\vec{\pi}$ transformam $\vec{\pi}$ na permutação orientada $\vec{\sigma}$.

Dizemos que uma seqüência de reversões ordena uma permutação orientada $\vec{\sigma}$ se esta, aplicada sucessivamente a $\vec{\sigma}$, transformam $\vec{\sigma}$ na permutação orientada identidade.

Note que, sendo $\vec{\rho}_{1}, \vec{\rho}_{2}, \ldots, \vec{\rho}_{\vec{d}_{\vec{\sigma}}(\vec{\pi})}$ uma seqüência de reversões orientadas, tal que

$$
\vec{\pi} \cdot \vec{\rho}_{1} \cdot \vec{\rho}_{2} \ldots \vec{\rho}_{\vec{d}_{\vec{\sigma}}(\vec{\pi})}=\vec{\sigma}
$$

temos que

$$
\vec{\sigma}^{-1} \cdot \vec{\pi} \cdot \vec{\rho}_{1} \cdot \vec{\rho}_{2} \ldots \vec{\rho}_{\vec{d}_{\vec{\sigma}}(\vec{\pi})}=\vec{\sigma}^{-1} \cdot \vec{\sigma}=\vec{\iota} .
$$

Formalizamos, então, a seguinte versão orientada de MIN-SBR. 


\section{Problema $2 M I N-\overrightarrow{S B R}$}

Instância: Uma permutação orientada $\vec{\pi}$.

Objetivo: Encontrar uma seqüência de reversões orientadas $\vec{\rho}_{1}, \vec{\rho}_{2}, \ldots, \vec{\rho}_{\vec{d}(\vec{\pi})}$, tal que,

$$
\vec{\pi} \cdot \vec{\rho}_{1} \cdot \vec{\rho}_{2} \ldots \vec{\rho}_{\vec{d}(\vec{\pi})}=\vec{\iota}
$$

onde $\vec{d}(\vec{\pi})=\vec{d}_{\vec{\imath}}(\vec{\pi})$.

\subsection{Organização dos Capítulos}

Nesta seção mostramos os pontos principais tratados em cada capítulo desta dissertação.

No Capítulo 2 mostramos o grafo de pontos de quebra de uma permutação que é uma estrutura chave em toda a dissertação. Esse grafo foi definido pela primeira vez por Bafna e Pevzner [BP93] sendo que a sua importância fica evidente quando observamos os avanços significativos nas pesquisas determinados pela obtenção de novas propriedades a partir desse grafo.

O primeiro algoritmo polinomial para MIN-SBR foi apresentado por Hannenhalli e Pevzner [HP95] sendo $O\left(n^{5}\right)$ o seu tempo de execução. Posteriormente, versões mais eficientes desse algoritmo foram descritas: uma, por Berman e Hannenhalli [BH96], que gasta tempo $O\left(n^{2} \alpha(n)\right)$, onde $\alpha(n)$ é o inverso da função de Ackerman; e outra, por Kaplan, Shamir e Tarjan [KST97], que gasta tempo $O(n \alpha(n)+n d)$, onde $d$ é a distância por reversões. No Capítulo 3 descrevemos um algoritmo com complexidade de tempo $O(n d)$.

Ainda no Capítulo 3, descrevemos o trabalho de Meidanis, Walter e Dias [MWD97] que determina, em função de $n$, o valor da distância por reversões orientadas dos elementos do conjunto de permutações orientadas cujas distâncias são máximas, e mostraram como construir um elemento desse conjunto. Nesse artigo, eles apresentam, também, uma formalização do problema de encontrar uma seqüência mínima de reversões que transformam um cromossomo circular em outro, sendo que ambos possuem o mesmo conjunto de blocos de genes e sendo a orientação desses blocos conhecida em cada um dos cromossomos.

No Capítulo 4 tratamos do Problema MIN-SBR. Como veremos, esse problema pertence à classe $N P$-difícil e, a menos que $P=N P$, não existe um algoritmo polinomial que o resolva. Apresentamos, então, dois algoritmos aproximados descritos por Kececioglu e Sankoff [KS95] e Bafna e Pevzner [BP93] que devolvem, dada uma permutação $\pi$, uma seqüência de reversões, de tamanho, comprovadamente, menor ou igual a $2 d(\pi)$ e $\frac{7}{4} d(\pi)$, respectivamente, ambos em tempo $O\left(n^{2}\right)$.

Bafna e Pevzner [BP93] determinaram que a distância máxima para ordenar por reversões uma permutação não-orientada sobre $n$ é $n-1$. Mostraram também que uma particular permutação, chamada de permutação de Gollan, e sua inversa são as únicas permutações que requerem $n-1$ reversões para serem ordenadas. A prova que os autores apresentam desse último resultado contém um erro, embora o resultado seja válido. Mostraremos essa prova com a devida correção. 
Finalmente, no Capítulo 5 descrevemos, resumidamente, a prova de Caprara [Cap96] de que o Problema MIN-SBR pertence à classe $N P$-difícil. 


\section{Capítulo 2}

\section{Grafo de Pontos de Quebra}

\subsection{Introdução}

Bafna e Pevzner [BP93] definiram, a partir de uma permutação não-orientada $\pi$, uma estrutura bastante simples e ao mesmo tempo rica, no sentido de facilitar o estudo da distância por reversões, chamada grafo de pontos de quebra (breakpoints graph). A riqueza dessa estrutura fica evidente quando observamos os avanços significativos nas pesquisas determinados pela obtenção de novas propriedades a partir do grafo de pontos de quebra.

Reservamos este capítulo para definir essa estrutura e para determinar, na Seção 2.5, um limitante inferior da distância a partir do grafo de pontos de quebra. Deixamos, propositadamente, esse assunto a parte do capítulo em que tratamos de permutações não-orientadas pois, como veremos no Capítulo 3, essa estrutura também é essencial para o estudo das permutações orientadas.

A seguir descrevemos como construir essa estrutura.

\subsection{Pontos de Quebra}

Seja $\pi$ uma permutação sobre $n$. Estendemos a permutação para $n+2$ elementos adicionando $\pi_{0}=0$ e $\pi_{n+1}=n+1$. Obtemos o que chamamos de permutação $\pi$ estendida. Observamos que o número mínimo de reversões que ordena $\pi$ é o mesmo número mínimo de reversões que ordena $\pi$ estendida.

Sejam $i$ e $j$ números inteiros. Denotamos por $i \sim j$ o fato de $|i-j|=1$. O caso contrário é denotado por $i \nsim j$.

Um par $\left(\pi_{i}, \pi_{i+1}\right)$ de uma permutação $\pi$ estendida, é chamado de brecha (gap). Classificamos brechas em dois tipos. Uma brecha $\left(\pi_{i}, \pi_{i+1}\right)$ é um ponto de quebra em $\pi$ se $\pi_{i} \nsim \pi_{i+1}$. Caso contrário, dizemos que a brecha é uma adjacência. Os pontos de quebra representam elementos que são consecutivos na permutação $\pi$ mas não são consecutivos na permutação identidade. Isso implica que em algum momento no processo de ordenação os mesmos devem ser separados. Denotamos por $b(\pi)$ o número de pontos de quebra de $\pi$, e por $\Delta b(\pi, \rho)$, ou simplesmente $\Delta b$, se $\pi$ e $\rho$ estiverem claros no contexto, o valor $b(\pi . \rho)-b(\pi)$. 
Do fato de uma única reversão não ser capaz de eliminar mais de 2 pontos de quebra, concluímos que, para qualquer permutação $\pi$ e reversão $\rho$,

$$
\Delta b \geq-2
$$

o que imediatamente nos fornece um limitante inferior para o valor da distância por reversões entre a permutação $\pi$ e a permutação identidade, que é

$$
d(\pi) \geq \frac{b(\pi)}{2} .
$$

Esse limitante inferior é fraco no sentido de que não é difícil encontrar uma permutação $\pi$ tal que $d(\pi)>\lceil b(\pi) / 2\rceil$. Considere, por exemplo, a permutação estendida $\pi=\left(\begin{array}{llllllll}0 & 5 & 6 & 3 & 4 & 1 & 2 & 7\end{array}\right)$. Temos, então, que $b(\pi)=4$ e $d(\pi) \geq 2$. Por outro lado, para que possamos ordenar $\pi$ com duas reversões temos que eliminar dois pontos de quebra por reversão e, observando $\pi$, verificamos que não é possível fazer uma reversão que elimine dois de seus pontos de quebra, o que implica, portanto, que $d(\pi) \geq 3$. Nas próximas seções, mostramos um outro parâmetro que estabelece um limitante inferior mais justo para o valor da distância.

\subsection{Grafo de Pontos de Quebra}

O grafo de pontos de quebra $G(\pi)=(V, R \cup B)$ de uma permutação $\pi$ é um grafo aresta-colorido tal que

$$
\begin{aligned}
& V=\left\{\pi_{0}, \pi_{1}, \ldots, \pi_{n+1}\right\} \\
& R=\left\{\left(\pi_{i}, \pi_{j}\right) \mid \pi_{i} \not \pi_{j} \text { e } i \sim j, \text { isto é, }\left(\pi_{i}, \pi_{j}\right) \text { é um ponto de quebra em } \pi\right\} \\
& B=\left\{\left(\pi_{i}, \pi_{j}\right) \mid i \not j \text { e } \pi_{i} \sim \pi_{j}, \text { isto é, }(i, j) \text { é um ponto de quebra em } \pi^{-1}\right\}
\end{aligned}
$$

Atribuímos a cor vermelha às arestas em $R$ e a cor azul às arestas em $B$.

Veja na Figura 2.1 um exemplo de uma permutação e seu respectivo grafo de pontos de quebra.

\subsection{Circuitos no Grafo de Pontos de Quebra}

Seja $C=x_{0} x_{1} \ldots x_{m-1}$ uma seqüência de vértices em $G(\pi)$. Dizemos que $C$ é um circuito alternante em $G(\pi)$ se $\left(x_{i} \bmod { }_{m}, x_{(i+1)} \bmod m\right)$ é uma aresta em $G(\pi)$ e as cores de todo par de arestas consecutivas são distintas. Neste trabalho estamos interessados somente em circuitos alternantes. Por isso, dizemos simplesmente circuitos para nos referir a circuitos alternantes.

Uma decomposição em circuitos do grafo de pontos de quebra $G(\pi)$ é uma partição das arestas de $G(\pi)$ em circuitos alternantes. Uma decomposição máxima em circuitos do grafo de pontos de quebra $G(\pi)$ é uma decomposição em $t$ circuitos, onde $t$ é máximo.

Veja que se, para um elemento $\pi_{i}$, existe um elemento consecutivo ou $\pi_{i+1}$ ou $\pi_{i-1}$ que com ele forma um ponto de quebra, existe, para cada ponto de quebra, um elemento $\pi_{j}$ em $\pi$, tal que 

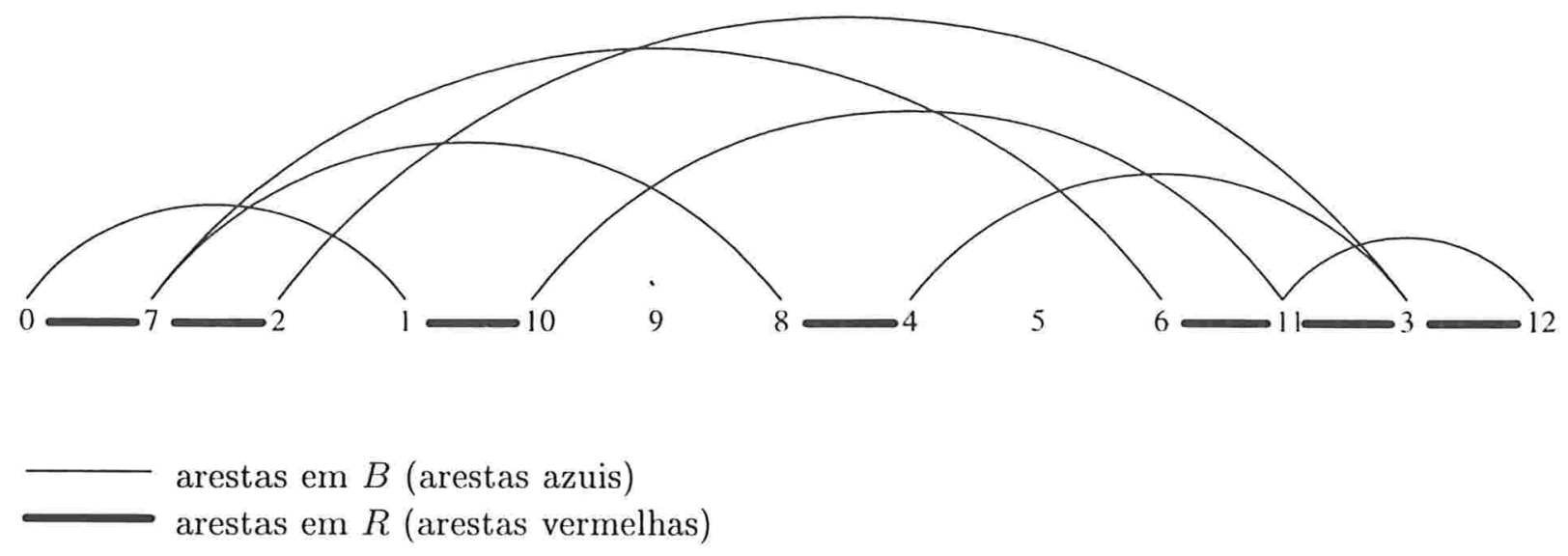

Figura 2.1: Grafo de pontos de quebra $G(\pi)$ da permutação $\pi=\left(\begin{array}{lllllllllll}7 & 2 & 1 & 10 & 9 & 8 & 4 & 5 & 6 & 11 & 3\end{array}\right)$.

$\left(\pi_{i}, \pi_{j}\right)$ é uma aresta azul em $G(\pi)$. Temos, portanto, que o número de arestas vermelhas e azuis incidentes a um vértice $\pi_{i}$ é o mesmo $(0,1$ ou 2$)$. Isto implica que é sempre possível decompor $G(\pi)$ em circuitos. Denotamos por $c(\pi)$ o número de circuitos obtidos em uma decomposição máxima em circuitos de $G(\pi)$ e por $\Delta c(\pi, \rho)$, ou simplesmente $\Delta c$, se $\pi$ e $\rho$ estiverem claros no contexto, o valor $c(\pi . \rho)-c(\pi)$.

\subsection{Limitante Inferior do Problema MIN-SBR}

A seguir, mostramos um limitante inferior, estabelecido por Bafna e Pevzner [BP93], para o valor da distância por reversões envolvendo os parâmetros $b(\pi)$ e $c(\pi)$. Antes, contudo, vejamos o seguinte resultado.

Teorema 2.1 [BP93] Para toda permutação $\pi$ e reversão $\rho$,

$$
|\Delta(b-c)| \leq 1,
$$

onde $\Delta(b-c)=\Delta b-\Delta c$.

Prova. Seja $\hat{G}(\pi)$ o grafo obtido acrescentando arestas em $G(\pi)$ da seguinte forma. Para cada adjacência $\left(\pi_{i}, \pi_{i+1}\right)$, adicione duas arestas, uma vermelha e uma azul, ligando os vértices $\pi_{i}$ e $\pi_{i+1}$. Veja a Figura 2.2, onde obtemos o grafo $\hat{G}(\pi)$ a partir do grafo de pontos de quebra da permutação do exemplo na Figura 2.1, e observe que, na verdade, estamos acrescentando um circuito (alternante) para cada adjacência de $\pi$.

Seja $\hat{c}(\pi)$ o número de circuitos obtido em uma decomposição máxima em circuitos de $\hat{G}(\pi)$. Note que, como o número de adjacências em $\pi$ é $n+1-b(\pi)$, temos que toda decomposição de $G(\pi)$ em $c(\pi)$ circuitos corresponde a uma decomposição de $\hat{G}(\pi)$ em $c(\pi)+(n+1-b(\pi))$ circuitos, isto é, $\hat{c}(\pi) \geq c(\pi)+(n+1-b(\pi))$.

Reciprocamente, uma decomposição de $\hat{G}(\pi)$ em $\hat{c}(\pi)$ circuitos corresponde a uma decomposição de $G(\pi)$ em pelo menos $\hat{c}(\pi)-(n+1-b(\pi))$ circuitos. Para verificar isto, note que existe uma decomposição máxima em circuitos de $\hat{G}(\pi)$, tal que cada adjacência representa um circuito 

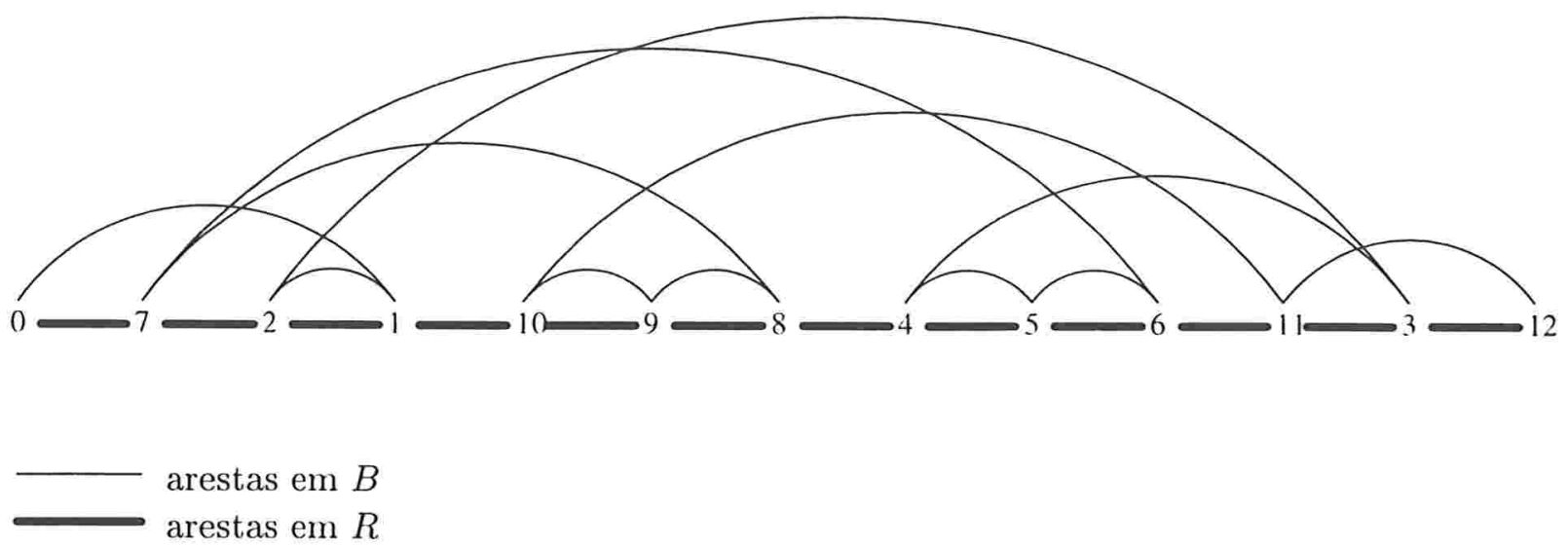

Figura 2.2: Grafo $\hat{G}(\pi)$ da permutação $\pi=\left(\begin{array}{lllllllllll}7 & 2 & 1 & 10 & 9 & 8 & 4 & 5 & 6 & 11 & 3\end{array}\right)$.

de duas arestas (uma vermelha e uma azul), que pode ser obtida a partir de uma decomposição máxima em circuitos de $\hat{G}(\pi)$ qualquer pelo seguinte procedimento. Para cada par de circuitos com mais de duas arestas, $C_{1}$ que possue uma aresta azul de uma adjacência $b=\left(\pi_{i}, \pi_{i+1}\right)$, e $C_{2}$ que possue a aresta vermelha $r=\left(\pi_{i}, \pi_{i+1}\right)$, obtenha uma nova decomposição em circuitos (que também é máxima), substituindo os circuitos $C_{1}$ e $C_{2}$ por $C_{1}^{\prime}$, que possuem as arestas de $C_{1} \backslash\{b\}$ e $C_{2} \backslash\{r\}$, e por $C_{2}^{\prime}$, que possue as arestas $b$ e $r$. Após esse procedimento obtemos a decomposição máxima em circuitos desejada. Segue que $c(\pi) \geq \hat{c}(\pi)-(n+1-b(\pi))$.

Como $\hat{c}(\pi) \geq c(\pi)+(n+1-b(\pi))$ e $c(\pi) \geq \hat{c}(\pi)-(n+1-b(\pi))$, temos que

$$
c(\pi)=\hat{c}(\pi)-(n+1-b(\pi)) .
$$

Como

$$
\begin{aligned}
\Delta(b-c) & =(b(\pi . \rho)-b(\pi))-(c(\pi . \rho)-c(\pi)) \\
& =(b(\pi . \rho)-b(\pi))-(\hat{c}(\pi \cdot \rho)-(n+1-b(\pi . \rho))-(\hat{c}(\pi)-(n+1-b(\pi)))) \\
& =\hat{c}(\pi)-\hat{c}(\pi . \rho),
\end{aligned}
$$

para provar o teorema, basta mostrar que $|\hat{c}(\pi)-\hat{c}(\pi . \rho)| \leq 1$. É o que fazemos a seguir.

Note que uma reversão $\rho=(i . . j)$ envolve 4 vértices de $\hat{G}(\pi)$ e a transformação de $\hat{G}(\pi . \rho)$ em $\hat{G}(\pi)$ pode ser vista como a substituição das arestas vermelhas em $D E L=\left\{\left(\pi_{i-1}, \pi_{j}\right),\left(\pi_{i}, \pi_{j+1}\right)\right\}$ pelas arestas vermelhas em $A D D=\left\{\left(\pi_{i-1}, \pi_{i}\right),\left(\pi_{j}, \pi_{j+1}\right)\right\}$.

Se as arestas em $D E L$ pertencem ao mesmo circuito $C$ em uma decomposição máxima em circuitos de $\hat{G}(\pi . \rho)$, então observe que todas as arestas de $\hat{G}(\pi . \rho)$ que não são arestas de $C$ são arestas de $\hat{G}(\pi)$, implicando que podemos decompor $\hat{G}(\pi)$ em pelo menos $\hat{c}(\pi . \rho)-1$ circuitos. Portanto, $\hat{c}(\pi) \geq \hat{c}(\pi . \rho)-1$.

Se as arestas vermelhas em $D E L$ pertencem a circuitos $C_{1}$ e $C_{2}$ distintos em uma decomposição máxima em circuitos de $\hat{G}(\pi . \rho)$, então observe que todas as arestas de $\hat{G}(\pi . \rho)$ que não são arestas nem de $C_{1}$ e nem de $C_{2}$ são arestas de $\hat{G}(\pi)$, implicando que podemos decompor $\hat{G}(\pi)$ em pelo menos $\hat{c}(\pi . \rho)-2$ circuitos. Por outro lado, note que, no subgrafo de $\hat{G}(\pi)$ induzido pelas arestas em $\left(C_{1} \cup C_{2} \cup A D D\right) \backslash D E L \neq \emptyset$, o número de arestas vermelhas e azuis incidentes a 
cada vértice é o mesmo. Segue que esse subgrafo deve conter pelo menos um circuito. Portanto, $\hat{c}(\pi) \geq \hat{c}(\pi . \rho)-2+1=\hat{c}(\pi . \rho)-1$.

Considerando agora uma transformação do grafo $\hat{G}(\pi)$ em $\hat{G}(\pi . \rho)$ e, usando um raciocínio análogo, concluímos que $\hat{c}(\pi \cdot \rho) \geq \hat{c}(\pi)-1$.

Como $\hat{c}(\pi) \geq \hat{c}(\pi . \rho)-1$ e $\hat{c}(\pi . \rho) \geq \hat{c}(\pi)-1$, temos que $|\hat{c}(\pi)-\hat{c}(\pi . \rho)| \leq 1$.

Com isso, podemos obter um novo limitante inferior para $d(\pi)$. Primeiro observamos que $b(\pi)-c(\pi) \geq 0$, pois cada circuito em $G(\pi)$ possue pelo menos 2 pontos de quebra. Depois, observamos que, sendo $\iota$ permutação identidade, $b(\iota)=0$ e $c(\iota)=0$ o que implica que $b(\iota)-c(\iota)=0$. Finalmente, o Teorema 2.1 nos garante que $\Delta(b-c) \geq-1$. Concluímos, então, o seguinte corolário.

Corolário 2.2 [BP93] Para toda permutação $\pi$,

$$
d(\pi) \geq b(\pi)-c(\pi) .
$$

O exemplo da permutação estendida $\pi=\left(\begin{array}{lllllll}0 & 5 & 6 & 3 & 4 & 1 & 2\end{array}\right)$ nos mostra que esse limitante inferior também é fraco. No exemplo, nenhuma reversão é tal que $\Delta(b-c)=-1$.

Entretanto, não é difícil verificar que esse limitante é melhor do que aquele mostrado na Seção 2.2. Observe que cada circuito em $G(\pi)$ tem, pelo menos, duas arestas vermelhas o que implica, aliado ao fato de que os circuitos em uma decomposição são disjuntos nas arestas, que $2 c(\pi) \leq b(\pi)$ e, imediatamente, concluímos que $b(\pi)-c(\pi) \geq b(\pi)-(1 / 2) b(\pi)=b(\pi) / 2$, que é o limitante inferior anteriormente mostrado. 


\section{Capítulo 3}

\section{Permutações Orientadas}

\subsection{Introdução}

Neste capítulo dissertamos a respeito do Problema MIN- $\overrightarrow{\mathrm{SBR}}$.

Na Seção 3.2 descrevemos uma transformação de uma permutação orientada $\vec{\pi}$ em uma permutação não-orientada $\pi$, tal que, dada uma seqüência de um determinado tipo de reversões (não-orientadas) que transformam a permutação $\pi$ na permutação identidade, podemos calcular uma seqüência de reversões orientadas que transformam a permutação orientada $\vec{\pi}$ na permutação orientada identidade. Além disso, definimos o grafo de pontos de quebra de uma permutação orientada e determinamos algumas de suas propriedades.

$\mathrm{Na}$ Seção 3.3 determinamos um limitante inferior para $\vec{d}(\vec{\pi})$.

Na Seção 3.4 descrevemos um algoritmo polinomial que encontra uma seqüência mínima de reversões orientadas que ordenam uma permutação orientada.

A Seção 3.5 é reservada para determinar o diâmetro de reversões em permutações orientadas, isto é, encontrar o valor da maior distância por reversões entre todas as permutações orientadas sobre $n$.

Finalmente, na Seção 3.6, modelamos um problema semelhante ao Problema MIN-SBR para cromossomos que são encontrados na natureza na forma circular.

A partir de agora, dizemos que os subgrafos conexos maximais de um grafo $G$ são as componentes de $G$, e dizemos que as componentes de $G$ que possuem um único vértice são vértices isolados de $G$. Os demais termos utilizados são os usuais na Teoria dos Grafos.

\subsection{Transformação em Permutações Não-Orientadas}

\subsubsection{Retrato de Permutações Orientadas}

Nesta seção transformamos uma permutação orientada $\vec{\pi}$ em uma permutação não-orientada $\pi$ de modo que o tamanho da seqüência mínima de reversões orientadas que ordenam a permutação $\vec{\pi}$, isto é, que transformam a permutação $\vec{\pi}$ na permutação orientada identidade, é igual ao tamanho da seqüência mínima de reversões não-orientadas, sob certa restrição, que ordenam a permutação $\pi$. 
$\mathrm{Na}$ verdade, tal transformação não é necessária mas simplifica muito o estudo do Problema MIN-SBR. A seguir mostramos, a partir de uma permutação orientada, como construir uma permutação não-orientada, e qual deve ser a restrição às reversões de modo que, juntas, tenhamos as propriedades desejadas.

Seja $\vec{\pi}$ uma permutação orientada sobre $n$. O retrato de $\vec{\pi}$ é uma permutação $\pi$ sobre $2 n$, tal que:

$$
\pi_{i}= \begin{cases}2|j|-1 & \left\{\begin{array}{l}
\text { se } i \text { é ímpar e } j=\vec{\pi}_{\frac{i+1}{2}}>0 \text { ou } \\
\text { se } i \text { é par e } j=\vec{\pi}_{\frac{i}{2}}<0,
\end{array}\right. \\
2|j| & \left\{\begin{array}{l}
\text { se } i \text { é ímpar e } j=\vec{\pi}_{\frac{i+1}{2}}<0 \text { ou } \\
\text { se } i \text { é par e } j=\vec{\pi}_{\frac{i}{2}}>0 .
\end{array}\right.\end{cases}
$$

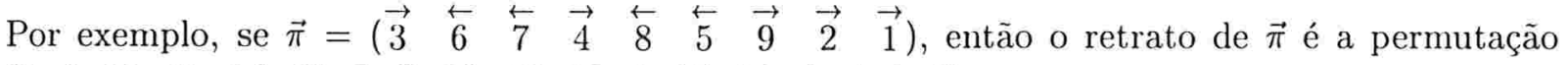
$\left(\begin{array}{llllllllllllllllll}5 & 6 & 12 & 11 & 14 & 13 & 7 & 8 & 16 & 15 & 10 & 9 & 17 & 18 & 3 & 4 & 1 & 2\end{array}\right)$.

A seguir, considere $\pi$ o retrato de $\vec{\pi}$.

Uma reversão par $\rho=(i . . j)$, para $i<j$, é uma reversão onde $i$ é ímpar e $j$ é par.

Uma ordenação par do retrato de $\vec{\pi}$ por reversões pares é uma seqüência finita de reversões pares $\rho_{1}, \rho_{2}, \ldots, \rho_{t}$, tal que

$$
\pi \cdot \rho_{1} \cdot \rho_{2} \ldots . \rho_{t}=\left(\begin{array}{lll}
1 & \ldots & 2 n
\end{array}\right) .
$$

A distância par do retrato de $\vec{\pi}$, denotado por dist par $(\pi)$, é o menor número de reversões pares necessárias para ordenar $\pi$.

Note que, sendo $\pi$ o retrato de $\vec{\pi}$, para quaisquer inteiros $i$ e $j, 1 \leq i \leq j \leq n, \pi \cdot(2 i-1 . .2 j)$ é o retrato de $\vec{\pi} . \overrightarrow{(i . . j)}$. Além disso, o retrato da permutação orientada identidade é a permutação $\left(\begin{array}{lll}1 & \ldots & 2 n\end{array}\right)$, implicando que

$$
\vec{d}(\vec{\pi})=\operatorname{dist}_{\text {par }}(\pi) .
$$

Ademais, conhecendo uma seqüência de $t$ reversões pares que efetua ordenação par de $\pi$, obtemos facilmente uma seqüência de $t$ reversões orientadas que ordena $\vec{\pi}$. Em outras palavras, se

$$
\pi \cdot\left(2 i_{1}-1 . .2 j_{1}\right) \cdot\left(2 i_{2}-1 . .2 j_{2}\right) \ldots .\left(2 i_{t}-1 . .2 j_{t}\right)=\iota,
$$

então

$$
\vec{\pi} \cdot \overrightarrow{\left(i_{1} . . j_{1}\right)} \cdot \overrightarrow{\left(i_{2} . . j_{2}\right)} \ldots . \overrightarrow{\left(i_{t} . . j_{t}\right)}=\vec{\imath} .
$$

É interessante observar que a exigência de que as reversões, na seqüência a ser aplicada ao retrato de uma permutação orientada, sejam pares não é uma restrição meramente didática. $\mathrm{Ou}$ seja, se não exigimos que as reversões são pares, então a igualdade dos valores das distâncias pode não existir. Por exemplo, se $\vec{\pi}=\left(\begin{array}{ll}\overrightarrow{2} & \overrightarrow{1}\end{array}\right)$, então verificamos, por força bruta, que $\vec{d}(\vec{\pi})=3$. Por outro lado, sendo $\pi=\left(\begin{array}{llll}3 & 4 & 1 & 2\end{array}\right)$ o retrato de $\vec{\pi}$, a seqüência de reversões (2..4). (1..3) (que não são reversões pares) ordenam a permutação $\pi$ implicando que $d(\pi) \neq \vec{d}(\vec{\pi})$.

Todo o trabalho aqui desenvolvido com permutações orientadas é feito com os seus retratos. A fim de simplificar a notação, a menos de menção contrária, uma permutação, neste capítulo, 


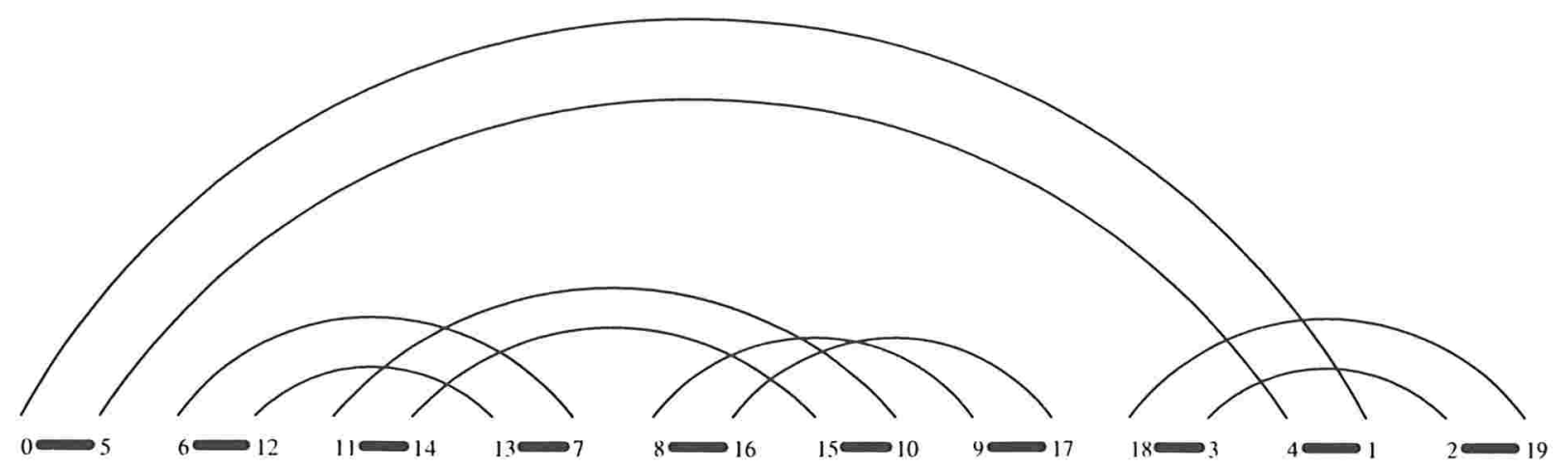

arestas azuis

arestas vermelhas

Figura 3.1: $G(\vec{\pi})$ da permutação $\vec{\pi}=\left(\begin{array}{llllllllll}\overrightarrow{3} & \leftarrow & 6 & \overleftarrow{7} & \overrightarrow{4} & \overleftarrow{8} & \overleftarrow{5} & \overrightarrow{9} & \overrightarrow{2} & \overrightarrow{1}\end{array}\right)$

é o retrato de uma permutação orientada, uma reversão é uma reversão par, uma ordenação de uma permutação $\pi$ é a ordenação par do retrato de uma permutação orientada e a distância da permutação $\pi$, que denotamos daqui para frente como $d(\pi)$. é a distância par do retrato $\pi$ de uma permutação orientada.

\subsubsection{Grafo de Pontos de Quebra de Permutações Orientadas}

O grafo de pontos de quebra de uma permutação orientada $\vec{\pi}$ é o grafo $G(\vec{\pi})=G(\pi)$, onde $\pi$ é o retrato de $\vec{\pi}$.

Deduzimos, pela construção de $\pi$, a seguinte propriedade.

Fato 3.1 Para $\pi_{i}$ e $\pi_{j}$ elementos da permutação $\pi$ (que é o retrato de uma permutação orientada),

$$
\min \left(\pi_{i}, \pi_{j}\right) \text { é ímpar e } \pi_{i} \sim \pi_{j} \Leftrightarrow \min (i, j) \text { é ímpar e } i \sim j \text {. }
$$

Dizemos que $\pi_{i}$ e $\pi_{j}$ são elementos colados em $\pi$ se $\min \left(\pi_{i}, \pi_{j}\right)$ é ímpar e $\pi_{i} \sim \pi_{j}$. Deduzimos que se $\pi_{i}$ e $\pi_{j}$ são colados e se $\rho_{1}, \rho_{2}, \ldots, \rho_{t}$ são reversões pares, então $\pi_{i}$ e $\pi_{j}$ são colados em $\pi . \rho_{1} . \rho_{2} \ldots \ldots \rho_{t}$ o que significa que $\pi_{i}$ e $\pi_{j}$ jamais representarão um ponto de quebra no processo de ordenação.

Segue do Fato 3.1 que, para todo elemento $\pi_{i}$, existe um elemento ou $\pi_{j}=\pi_{i+1}$ ou $\pi_{j}=\pi_{i-1}$ a ele colado. Neste caso, como $i \sim j$ e como $\pi_{i}$ e $\pi_{j}$ não representam um ponto de quebra, segue que em cada vértice do grafo $G(\pi)$ incide no máximo uma aresta vermelha. Como, pelas propriedades dos grafos de pontos de quebra estudadas no Capítulo 2, existe uma decomposição em circuitos de $G(\pi)$, segue que esta é única.

Veja na Figura 3.1 uma permutação orientada $\vec{\pi}$ e seu grafo $G(\vec{\pi})$. 
Em um circuito $C$ de $G(\pi)$, duas arestas vermelhas podem ser comparadas. Imagine por um instante que cada aresta vermelha $\left(\pi_{i}, \pi_{i+1}\right)$ possue orientação de $\pi_{i}$ para $\pi_{i+1}$. Duas arestas vermelhas $p$ e $q$ de $C$ são ditas convergentes, se a orientação das arestas $p$ e $q$ em relação a $C$ coincidem. Caso contrário, dizemos que elas são divergentes. (Note que, na Figura 3.1, as arestas vermelhas $(6,12)$ e $(13,7)$ são convergentes, enquanto as arestas $(8,16)$ e $(9,17)$ são divergentes.)

Determinando o Valor Exato de $\Delta(b-c)$.

O Teorema 2.1 mostra que $|\Delta(b-c)| \leq 1$. Para o retrato $\pi$ de uma permutação orientada, e uma reversão $(i . . j)$, o valor exato de $\Delta(b-c)$ pode ser determinado usando os conceitos de arestas convergentes e de arestas divergentes. É o que mostramos a seguir.

Observe, primeiramente, que sendo $C$ um circuito em $G(\pi)$ e sendo $i<j$, nem $\left(\pi_{i-1}, \pi_{i}\right)$ e nem $\left(\pi_{j}, \pi_{j+1}\right)$ é aresta vermelha de $C$ se, e somente se, $C$ é um circuito em $G(\pi .(i . . j))$. Isto garante que precisamos verificar somente o que ocorre com os circuitos e adjacências contendo os pares $v=\left(\pi_{i-1}, \pi_{i}\right)$ e $w=\left(\pi_{j}, \pi_{j+1}\right)$ em $G(\pi)$, para determinar o que ocorre com os valores de $\Delta b$ e $\Delta c$.

A Figura 3.2 ilustra os 3 casos analisados a seguir.

No Caso $1, v$ e $w$ são arestas divergentes de um mesmo circuito. Observe que, independentemente de $\left(\pi_{i-1}, \pi_{j}\right)$ e $\left(\pi_{i}, \pi_{j+1}\right)$ serem arestas de $G(\pi .(i . . j))$, temos

$$
\Delta(b-c)=-1 .
$$

No Caso 2, $v$ e $w$ são arestas convergentes de um mesmo circuito. Temos $\Delta b=0, \Delta c=0$ e, portanto,

$$
\Delta(b-c)=0 .
$$

No terceiro caso, $v$ e $w$ não são arestas de um mesmo circuito. Neste caso, por sua vez, três casos são possíveis.

No Caso $3 a, v$ e $w$ são arestas de circuitos diferentes em $G(\pi)$. Temos $\Delta b=0, \Delta c=-1$ e, portanto,

$$
\Delta(b-c)=1 .
$$

No Caso $3 b$, um dos pares $v$ ou $w$ é uma adjacência enquanto o outro par é aresta de um circuito. Sem perda de generalidade, na Figura 3.2, supomos $v$ sendo aresta de um circuito e $w$ uma adjacência. Temos $\Delta b=1, \Delta c=0$ e, portanto,

$$
\Delta(b-c)=1 .
$$

No Caso $3 c, v$ e $w$ são adjacências. Temos $\Delta b=2, \Delta c=1 \mathrm{e}$, portanto,

$$
\Delta(b-c)=1 .
$$

Reciprocamente, como nenhum outro caso pode ocorrer e, Caso 1 e Caso 2 e Caso 3 resultam em valores distintos de $\Delta(b-c)$, temos que, para toda permutação $\pi$ e toda reversão $(i . . j)$, $\Delta(b-c)=-1$ implica que $\left(\pi_{i-1}, \pi_{i}\right)$ e $\left(\pi_{j}, \pi_{j+1}\right)$ são arestas divergentes de um mesmo circuito 


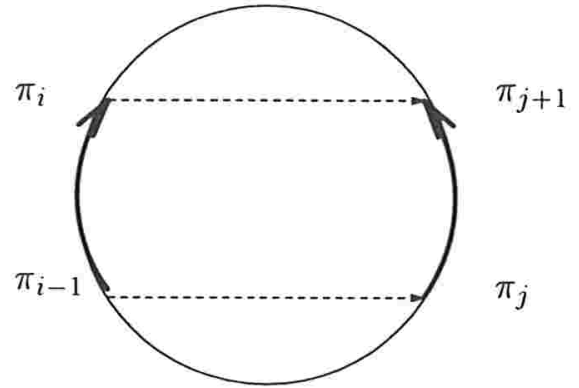

Caso 1

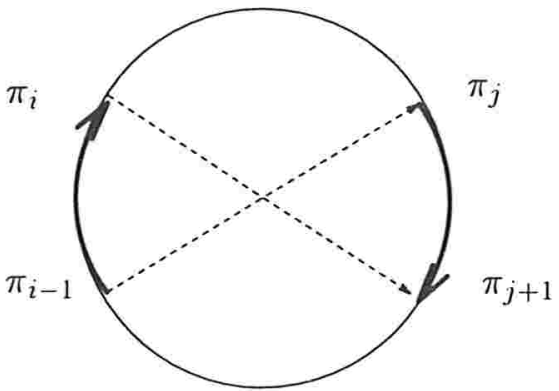

Caso 2

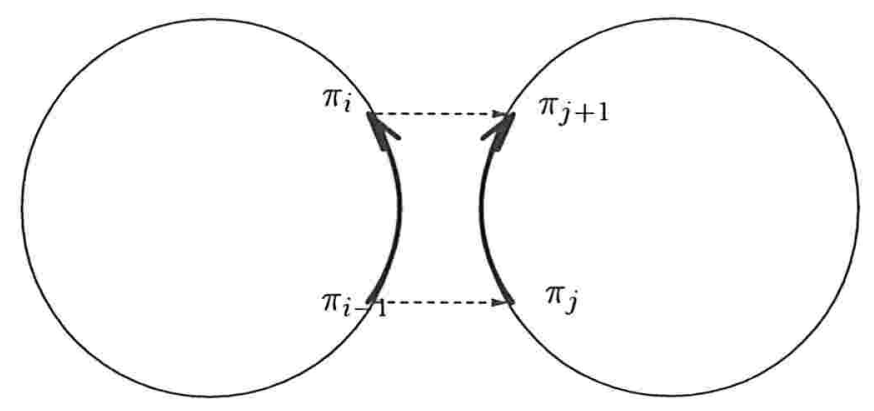

Caso $3 a$

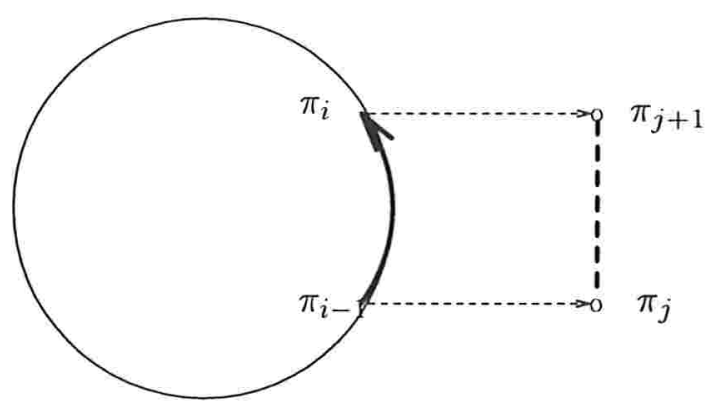

Caso $3 b$

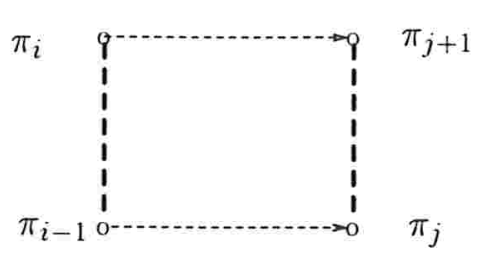

Caso $3 c$

Figura 3.2: Efeitos de uma reversão $(i . . j)$ sobre os circuitos em $G(\pi)$. 
em $G(\pi), \Delta(b-c)=0$ implica que $\left(\pi_{i-1}, \pi_{i}\right)$ e $\left(\pi_{j}, \pi_{j+1}\right)$ são arestas convergentes de um mesmo circuito em $G(\pi)$ e $\Delta(b-c)=1$ implica que $\left(\pi_{i-1}, \pi_{i}\right)$ e $\left(\pi_{j}, \pi_{j+1}\right)$ não são arestas de um mesmo circuito em $G(\pi)$.

É interessante também notar que as arestas $\left(\pi_{i-1}, \pi_{j}\right)$ e $\left(\pi_{i}, \pi_{j+1}\right)$ no circuito resultante em $G(\pi .(i . . j))$, quando $v$ e $w$ não são arestas de um mesmo circuito em $G(\pi)$, são sempre divergentes.

\subsection{Limitante Inferior}

Usando os conceitos de grafos de pontos de quebra, mostramos no Capítulo 2 que um limitante inferior do valor da distância é $d(\pi) \geq b(\pi)-c(\pi)$ (Corolário 2.2). Hannenhalli e Pevzner [HP95] definiram, a partir de uma permutação $\pi$, uma outra estrutura que chamamos de grafo de entrelaçamento $H(\pi)$. Dessa estrutura e do grafo de pontos de quebra, determinamos os parâmetros necessários para estabelecer um limitante inferior mais justo para o valor da distância por reversões.

Nas próximas seções veremos como construir o grafo de entrelaçamento e mostramos alguns resultados intermediários para determinar, na Seção 3.3.3, esse novo limitante inferior.

\subsubsection{Grafo de Entrelaçamento}

Seja $\pi$ uma permutação estendida sobre $2 n$. Definimos

$$
\left.P_{n}=\left\{\left(\pi_{i}, \pi_{j}\right) \mid \min \left\{\pi_{i}, \pi_{j}\right\} \text { é par e } \pi_{i} \sim \pi_{j}\right)\right\},
$$

ou seja, $P_{n}$ representa o conjunto dos pares que representam as adjacências em $\pi$ mas que não são elementos colados, unido ao conjunto das arestas azuis em $G(\pi)$.

Definimos $P_{n}$ como função de $\pi$ apenas para enfatizar quais são os pares de vértices de $G(\pi)$ que são elementos de $P_{n}$. Entretanto, note que $P_{n}$ depende exclusivamente de $n$ e podemos escrever

$$
P_{n}=\{(0,1),(2,3), \ldots,(2 n, 2 n+1)\} .
$$

Para $p=\left(\pi_{i}, \pi_{j}\right) \in P_{n}$, dizemos que $\pi_{i}$ e $\pi_{j}$ são os extremos de $p$.

Definimos o conjunto

$$
P_{\pi}^{+}=\left\{\left(\pi_{i}, \pi_{j}\right) \in P_{n} \mid i \text { e } j \text { têm a mesma paridade }\right\},
$$

isto é, $i$ e $j$ são ambos ou pares ou ímpares. Definimos também o conjunto

$$
P_{\pi}^{-}=\left\{\left(\pi_{i}, \pi_{j}\right) \in P_{n} \mid i \text { e } j \text { têm paridades distintas }\right\} .
$$

Sejam $\pi_{i}, \pi_{j}, \pi_{k}$ e $\pi_{l}$ elementos de $\pi$, onde $i<j$ e $k<l$. Dizemos que $\left(\pi_{i}, \pi_{j}\right)$ entrelaça com $\left(\pi_{k}, \pi_{l}\right)$ em $\pi$, se ou $i \leq k \leq j \leq l$ ou $k \leq i \leq l \leq j$. Denotamos por $\left(\pi_{i}, \pi_{j}\right) \bowtie\left(\pi_{k}, \pi_{l}\right)$ o fato de $\left(\pi_{i}, \pi_{j}\right)$ entrelaçar com $\left(\pi_{k}, \pi_{l}\right)$ em $\pi$. Caso contrário, escreveremos $\left(\pi_{i}, \pi_{j}\right) \bowtie\left(\pi_{k}, \pi_{l}\right)$.

Note que se $\left(\pi_{i}, \pi_{j}\right) \bowtie\left(\pi_{k}, \pi_{l}\right)$, e $\left(\pi_{i}, \pi_{j}\right)$ e $\left(\pi_{k}, \pi_{l}\right)$ são elementos distintos de $P_{n}$, então as desigualdades acima são estritas, isto é, ou $i<k<j<l$ ou $k<i<l<j$. 

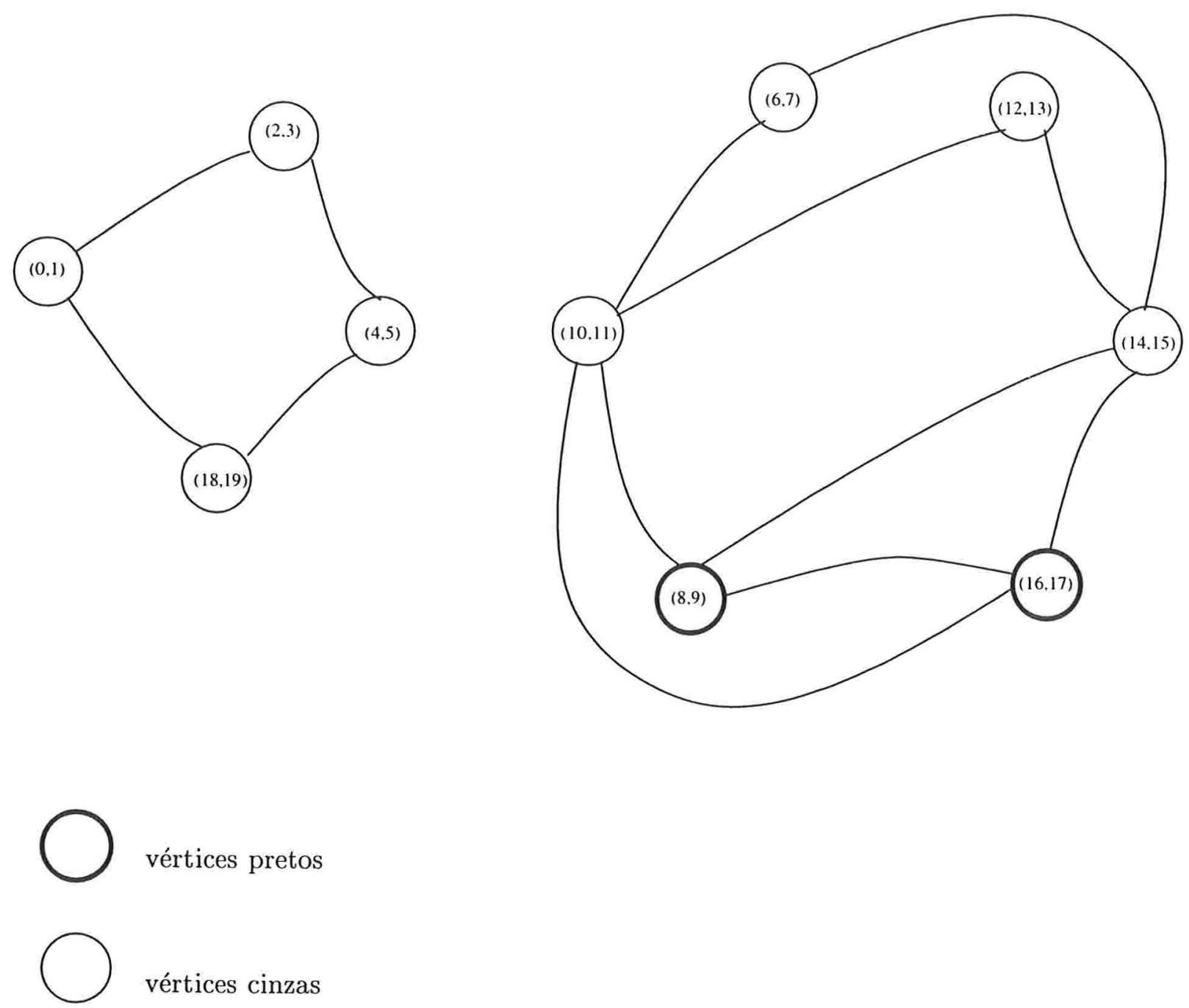

Figura 3.3: $H(\pi)$ do retrato $\left(\begin{array}{llllllllllllllllll}5 & 6 & 12 & 11 & 14 & 13 & 7 & 8 & 16 & 15 & 10 & 9 & 17 & 18 & 3 & 4 & 1 & 2\end{array}\right)$ da

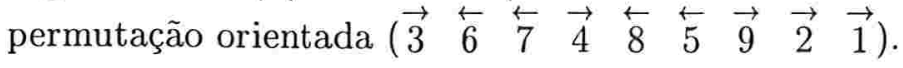


O grafo de entrelaçamento $H(\pi)$ de uma permutação $\pi$ é um grafo vértice-colorido cujo conjunto de vértices contém vértices de cor preta, que são os elementos de $P_{\pi}^{+}$, e vértices de cor cinza, que são os elementos de $P_{\pi}^{-}$, e cujo conjunto de arestas é assim definido. Um par de vértices $p$ e $q$ de $H(\pi)$ são adjacentes, se $p \bowtie q$ em $\pi$. Veja na Figura 3.3 o grafo $H(\pi)$ do retrato $\pi$ de uma permutação orientada, cujo grafo $G(\pi)$ pode ser observado na Figura 3.1.

Mostramos a seguir um resultado que estabelece um conseqüente entrelaçamento de um par $q=\left(\pi_{k}, \pi_{l}\right)$ com algum vértice de uma componente $M$, quando $q \bowtie\left(\pi_{i}, \pi_{j}\right)$ em $\pi$, e $\pi_{i}$ e $\pi_{j}$ são extremos distintos de vértices de $M$.

Lema 3.2 Sejam $\pi_{i}$ e $\pi_{j}$ extremos distintos de vértices (distintos ou não) de uma mesma componente $M$ em $H(\pi)$. Se $q=\left(\pi_{k}, \pi_{l}\right)$ é um par de elementos de $\pi$, tal que $q \bowtie\left(\pi_{i}, \pi_{j}\right)$, então existe um vértice $p$ de $M$, tal que $p \bowtie q$ em $\pi$.

Prova. Sem perda de generalidade, suponha $i<j$ e $k<l$.

Como $q \bowtie\left(\pi_{i}, \pi_{j}\right)$ e $i<j$ e $k<l$, temos que ou $i \leq k \leq j \leq l$ ou $k \leq i \leq l \leq j$. Suponha $i \leq k \leq j \leq l$ (o caso $k \leq i \leq l \leq j$ pode ser analisado de maneira simétrica).

Considere a seguir os conjuntos

$$
\mathcal{R}=\left\{\pi_{k}, \pi_{k+1}, \ldots, \pi_{l}\right\}
$$

$\mathrm{e}$

$\mathcal{P}=\{$ vértices de $M$ que possuem os 2 extremos em $\mathcal{R}\}$,

Note que se $\left(\pi_{s}, \pi_{t}\right) \in \mathcal{P}$ e $s<t$, então $k \leq s<t \leq l$.

Seja

$$
C=v_{1} v_{2} \ldots v_{h}
$$

um caminho em $H(\pi)$, tal que $\pi_{i}$ é extremo de $v_{1}$ e $\pi_{j}$ é extremo de $v_{h}$.

Se nenhum vértice de $C$ é vértice de $\mathcal{P}$, o extremo $\pi_{x} \neq \pi_{j}$ de $v_{h}=\left(\pi_{x}, \pi_{j}\right)$ não pertence a $\mathcal{R}$. Segue que $q \bowtie v_{h}$. Desde que $v_{h}$ é vértice de $M$, basta verificar o caso em que existe um vértice de $C$ que é elemento de $\mathcal{P}$.

Seja $v_{y}=\left(\pi_{w}, \pi_{z}\right)$, com $w<z$, o primeiro vértice de $C$, tal que $v_{y} \in \mathcal{P}$, isto é, $v_{1} v_{2} \ldots v_{y-1}$ não são vértices de $\mathcal{P}$.

Se $y=1$, então ou $i=w$ ou $i=z$. Sendo $i \leq k \leq j \leq l$ e $k \leq w<z \leq l$, temos que $i \neq z$. Segue que $i=w$ e $w=k<z \leq l$. Logo, $q \bowtie v_{1}$.

Para $y>1$, considere $v_{y-1}=\left(\pi_{w^{\prime}}, \pi_{z^{\prime}}\right)$ e $w^{\prime}<z^{\prime}$. Como $\left(v_{y-1}, v_{y}\right)$ é uma aresta em $H(\pi)$, temos que $v_{y-1} \bowtie v_{y}$. Segue que ou $w \leq w^{\prime} \leq z \leq z^{\prime}$ ou $w^{\prime} \leq w \leq z^{\prime} \leq z$.

Suponha $w \leq w^{\prime} \leq z \leq z^{\prime}$. Segue que $\pi_{u^{\prime}} \in \mathcal{R}$ e que $\pi_{z^{\prime}} \notin \mathcal{R}$.

Sendo $\pi_{z^{\prime}} \notin \mathcal{R}$, temos que ou $z^{\prime}<k$ ou $z^{\prime}>l$. Mas, como $\left(\pi_{w}, \pi_{z}\right) \in \mathcal{P}$, temos que $k \leq w<z \leq l$ e, segue, sendo $z \leq z^{\prime}$, que $z^{\prime} \nless k$. Logo, $z^{\prime}>l$. Sendo $k \leq w<z \leq l$ e $w \leq w^{\prime} \leq z \leq z^{\prime}$ e $z^{\prime}>l$, segue que $k \leq w^{\prime} \leq l<z^{\prime}$. Logo, $v_{y-1} \bowtie q$.

Por análise semelhante, supondo $w^{\prime} \leq w \leq z^{\prime} \leq z$, concluímos que $w^{\prime}<k \leq z^{\prime} \leq l$, o que implica que $v_{y-1} \bowtie q$. 
Como todos os vértices de $C$ são vértices de $M$ segue, em todos os casos, que existe vértice $p$ de $M$, tal que $p \bowtie q$.

Deduzimos, como conseqüência do Lema 3.2 , que se $\pi_{i}$ e $\pi_{j}$ são extremos de vértices de uma componente $M_{1}$ em $H(\pi)$ e $\pi_{k}$ e $\pi_{l}$ são extremos de vértices de uma componente $M_{2}$ em $H(\pi)$ e $\left(\pi_{i}, \pi_{j}\right) \bowtie\left(\pi_{k}, \pi_{l}\right)$, então $M_{1}=M_{2}$.

Mostramos a seguir algumas relações importantes entre os grafos $G(\pi)$ e $H(\pi)$ que nos será útil posteriormente.

Fato 3.3 Todas as arestas azuis de un circuito $C$ de $G(\pi)$ são vértices cinzas em $H(\pi)$ se, e somente se, não existe um par de arestas vermelhas $v$ e $w$ de $C$ em $G(\pi)$, tal que $v$ e w são divergentes.

Lema $3.4 U m$ elemento $\left(\pi_{i}, \pi_{j}\right) \in P_{n}$ é uma adjacência em $\pi$ se, e somente se, $\left(\pi_{i}, \pi_{j}\right)$ é um vértice isolado em $H(\pi)$.

Prova. Suponha que $p=\left(\pi_{i}, \pi_{j}\right)$ é uma adjacência em $\pi$ e, sem perda de generalidade, que $i<j$. Portanto, $j=i+1$ e não pode haver vértice $q=\left(\pi_{k}, \pi_{l}\right), k<l$, de $H(\pi)$, tal que ou $i<k<i+1<l$ ou $k<i<l<i+1$. Segue, para todo vértice $q$ de $H(\pi)$, que $p \bowtie q$ em $\pi$, o que implica que $p$ é um vértice isolado.

Reciprocamente, suponha que $p=\left(\pi_{i}, \pi_{j}\right)$ é um vértice isolado em $H(\pi)$ e, novamente, sem perda de generalidade, que $i<j$. Como $\left(\pi_{i}, \pi_{j}\right) \in P_{n}, \min \left\{\pi_{i}, \pi_{j}\right\}$ é par.

Suponha, por contradição, que $\left(\pi_{i}, \pi_{j}\right)$ não é uma adjacência em $\pi$. Segue que $i<j-1$. Seja $\pi_{k}$ o menor elemento do conjunto $I=\left\{\pi_{i+1}, \pi_{i+2}, \ldots, \pi_{j-1}\right\}$. Note que, como $i<j-1, I$ é não-vazio.

Se $\pi_{k}$ é ímpar, então $\left(\pi_{k}, \pi_{k}-1\right) \in P_{n}$. Como $\pi_{k}-1 \notin I,\left(\pi_{k}, \pi_{k}-1\right)$ e $\left(\pi_{i}, \pi_{j}\right)$ se entrelaçam, e, portanto, $p$ não é um vértice isolado em $H(\pi)$. Logo, assumiremos que $\pi_{k}$ é par.

Sendo $\pi_{k}$ par, temos que o elemento colado a $\pi_{k}$ é $\pi_{k}-1$. Pelo fato do elemento colado a $\pi_{k}$ ser ou $\pi_{k-1}$ ou $\pi_{k+1}$ e ao mesmo tempo $\pi_{k}-1 \notin I$, segue que ou $\pi_{i}=\pi_{k}-1$ ou $\pi_{j}=\pi_{k}-1$.

Supondo $\pi_{i}=\pi_{k}-1$, segue, sendo $\pi_{k}$ par, que $\pi_{i}$ é ímpar. Isso implica, como $\left(\pi_{i}, \pi_{j}\right) \in P_{n}$, que $\pi_{j}=\pi_{i}-1$ e é par. Note que, pelo Fato 3.1, nesse caso, $i$ é ímpar.

Se $j$ é ímpar e, sendo $i$ é ímpar, então $|I|$ é ímpar. Observe que, para cada elemento $\pi_{l_{1}}$ em $\pi$, existe um, e somente um, elemento $\pi_{l_{2}}$ em $\pi$, tal que $\left(\pi_{l_{1}}, \pi_{l_{2}}\right) \in P_{n}$, e, como $|I|$ é ímpar, isso implica que existe pelo menos um elemento $\pi_{l_{1}} \in I$ tal que $\pi_{l_{2}} \notin I$ e $\left(\pi_{l_{1}}, \pi_{l_{2}}\right) \in P_{n}$. Portanto, $\left(\pi_{i}, \pi_{j}\right) \bowtie\left(\pi_{l_{1}}, \pi_{l_{2}}\right)$ em $\pi$, o que, por sua vez, implica que $p$ não é um vértice isolado. Logo, assumiremos que $j$ é par.

Sendo $j$ par e $\pi_{j}$ também par, $\pi_{j-1}$ é elemento colado a $\pi_{j}$ e $\pi_{j-1}=\pi_{j}-1$. Como $\pi_{j-1} \in I$ e sendo $\pi_{j-1}=\pi_{j}-1=\pi_{i}-1-1=\pi_{k}-1-1-1<\pi_{k}$, obtemos uma contradição com a minimalidade de $\pi_{k}$.

Supondo $\pi_{j}=\pi_{k}-1$ obteremos, por raciocínio análogo, que $\pi_{i+1}<\pi_{k}$, novamente contradizendo a minimalidade de $\pi_{k}$.

Kaplan, Shamir e Tarjan [KST97] provaram outra importante relação entre o grafo $G(\pi)$ e $H(\pi)$. Eles mostraram que o conjunto de vértices de uma componente que não é um vértice isolado em $H(\pi)$ é a união dos conjuntos de arestas azuis de alguns circuitos de $G(\pi)$. Em outras 
palavras, se $C$ é um circuito em $G(\pi)$ e, $p$ e $q$ são arestas azuis de $C$, então $p$ e $q$ pertencem a uma mesma componente em $H(\pi)$ e, por outro lado, se $M$ não é um vértice isolado em $H(\pi)$, então todo vértice de $M$ é uma aresta azul de (algum circuito em) $G(\pi)$. A seguir mostramos como os autores acima obtiveram esses resultados. Antes, contudo, vejamos mais uma definição.

Seja $M$ o conjunto de vértices de uma componente em $H(\pi)$. O intervalo de $M$. denotado por intervalo $(M)$, é o par não-ordenado $\left(\pi_{i}, \pi_{j}\right)$ tal que, para $i<j$,

$$
i=\min \left\{k \mid \pi_{k} \text { é extremo de um vértice em } M\right\}
$$

e

$$
j=\max \left\{k \mid \pi_{k} \text { é extremo de um vértice em } M\right\} .
$$

Note, como conseqüência do Lema 3.2 , para $M_{1}$ e $M_{2}$ conjuntos de vértices de componentes distintas em $H(\pi)$, que intervalo $\left(M_{1}\right)$ \& intervalo $\left(M_{2}\right)$ em $\pi$.

Lema 3.5 [KST97] Seja X o conjunto de arestas azuis em $G(\pi)$ que correspondem aos vértices de uma componente $M$ em $H(\pi)$. Se intervalo $(X)=\left(\pi_{i}, \pi_{j}\right)$ e $i<j$, então $i$ é par e $j$ é ímpar.

Prova. Suponha, por contradição, que $i$ é impar. Deduzimos do Fato 3.1 que $\pi_{i+1}$ é o elemento colado a $\pi_{i}$ em $\pi$ e é ou $\pi_{i}+1$ ou $\pi_{i}-1$. Por outro lado, ou $\pi_{i}+1$ ou $\pi_{i}-1$ formam, juntamente com $\pi_{i}$ uma aresta azul em $G(\pi)$. Portanto, $\pi_{i}+1$ e $\pi_{i}-1$ devem pertencer a $I=\left\{\pi_{i}, \pi_{i+1}, \ldots, \pi_{j}\right\}$. Segue que $\pi_{i}$ nem é o maior nem é o menor elemento de $I$. Portanto, ou o maior ou o menor elemento de $I$ é $\pi_{k}, i<k<j$.

Suponha que $\pi_{k}$ é o maior elemento em $I$. Então, para $\pi_{l}=\pi_{k}+1$, ou $l<i$ ou $l>j$ e, sendo $i<k<j$, temos conseqüentemente $\left(\pi_{k}, \pi_{k}+1\right) \bowtie\left(\pi_{i}, \pi_{j}\right)$ em $\pi$.

Se $\pi_{k}$ é par, então $\left(\pi_{k}, \pi_{k}+1\right) \in P_{n}$. Segue do Lema 3.2 que $\left(\pi_{k}, \pi_{k}+1\right)$ é também vértice de $M$, contrariando, assim, a definição de intervalo $(X)$. Assumiremos, portanto, que $\pi_{k}$ é ímpar.

Sendo $\pi_{k}$ ímpar e ao mesmo tempo o maior elemento em $I$ e $i<k<j$. temos uma contradição do Fato 3.1 de que ou $\pi_{k-1}=\pi_{k}+1$ ou $\pi_{k+1}=\pi_{k}+1$. Portanto, $\pi_{k}$ não pode ser o maior elemento em $I$.

Por raciocínio análogo, segue que $\pi_{k}$ também não pode ser o menor elemento em $I$.

Portanto, $i$ é par.

A prova de que $j$ é ímpar é similar.

Lema 3.6 [KST97] Toda componente $M$ em $H(\pi)$, que não é um vértice isolado, corresponde ao conjunto de arestas azuis da união de alguns circuitos em $G(\pi)$.

Prova. O conjunto de vértices do grafo $H(\pi)$ é composto por adjacências em $\pi$, que não são elementos colados, e por arestas azuis de $G(\pi)$. Segue do Lema 3.4 que todo vértice de uma componente que não é um vértice isolado em $H(\pi)$ é uma aresta azul de (algum circuito em) $G(\pi)$. Para provar o lema, basta, então, mostrar que se $C$ é um circuito em $G(\pi)$, então as arestas azuis de $C$ são vértices de uma mesma componente em $H(\pi)$.

Suponha, por contradição, que $C$ é um circuito em $G(\pi)$ cujas arestas azuis são vértices de pelo menos duas componentes distintas em $H(\pi)$. Assumiremos serem $M_{1}$ e $M_{2}$ os conjuntos de 
vértices correspondentes a duas dessas componentes, tais que existem duas arestas consecutivas, $\left(\pi_{i}, \pi_{j}\right)$ vértice de $M_{1}$ e $\left(\pi_{j+1}, \pi_{k}\right)$ vértice de $M_{2}$, em $C$.

Desde que intervalo $\left(M_{1}\right)=\left(\pi_{m_{1}}, \pi_{m_{1}^{\prime}}\right) \not$ intervalo $\left(M_{2}\right)=\left(\pi_{m_{2}}, \pi_{m_{2}^{\prime}}\right)$ em $\pi$, para $m_{1}<m_{1}^{\prime} \mathrm{e}$ $m_{2}<m_{2}^{\prime}$, somente dois casos devemos considerar.

- $m_{1}<m_{2}<m_{2}^{\prime}<m_{1}^{\prime}$ (o caso, $m_{2}<m_{1}<m_{1}^{\prime}<m_{2}^{\prime}$ é simétrico). Neste caso, note que $m_{2} \leq j \leq m_{2}^{\prime}$ contradiz o Lema 3.2. Assumiremos, portanto, que ou $j<m_{2}$ ou $j>m_{2}^{\prime}$. Desde que $\pi_{j+1}$ é extremo de um vértice em $M_{2}$, segue que $m_{2} \leq j+1 \leq m_{2}^{\prime}$. Segue que $m_{2}=j+1$. Como $\left(\pi_{j}, \pi_{j+1}\right)$ é uma aresta vermelha, temos que $\pi_{j} \nsim \pi_{j+1}$. Segue, do Fato 3.1 , que $j+1$ é ímpar, contrariando o Lema 3.5 de que $m_{2}$ é par.

- ou $m_{1}<m_{1}^{\prime}<m_{2}<m_{2}^{\prime}$ ou $m_{2}<m_{2}^{\prime}<m_{1}<m_{1}^{\prime}$. Sendo $\pi_{j}$ e $\pi_{j+1}$ extremos de vértices de $M_{1}$ e $M_{2}$ respectivamente, temos que $m_{1} \leq j \leq m_{1}^{\prime}$ e $m_{2} \leq j+1 \leq m_{2}^{\prime}$. Segue, como única possibilidade, que $m_{1}^{\prime}=j$ e $m_{2}=j+1$. Novamente, como $\left(\pi_{j}, \pi_{j+1}\right)$ é uma aresta em $G(\pi)$, segue que $j$ é par e $j+1$ é ímpar, contrariando mais uma vez o Lema 3.5 de que $m_{2}$ é par (e também de que $m_{1}^{\prime}$ é ímpar).

A seguir, estudamos como se comporta uma componente $M$ em $H(\pi)$ frente a uma reversão $\rho$. Dizemos que uma reversão $\rho$ age na componente $M$ em $H(\pi)$ se $M$ não é componente em $H(\pi . \rho)$. Em outras palavras, $\rho$ age na componente $M$ se uma das condições abaixo é satisfeita, para algum vértice $p$ de $M$.

- Ou $p \in P_{\pi}^{+}$e $p \in P_{\pi . \rho}^{-}$ou $p \in P_{\pi}^{-}$e $p \in P_{\pi . \rho}^{+}$, o que significa dizer que as cores do vértice $p$ em $H(\pi)$ e $H(\pi . \rho)$ são distintas.

- Existe vértice $q$ tal que $(p, q)$ é uma aresta em $H(\pi)$ mas não é aresta em $H(\pi . \rho)$.

- Existe vértice $q$ tal que $(p, q)$ não é uma aresta em $H(\pi)$ mas é aresta em $H(\pi . \rho)$.

Dizemos que a reversão $\rho$ age exclusivamente na componente $M$ em $H(\pi)$, se $\rho$ age em $M$ e, para toda componente $M^{\prime} \neq M$ em $H(\pi), \rho$ não age em $M^{\prime}$.

Lema 3.7 Seja $\pi$ uma permutação e $\rho=(i . . j)$ uma reversão. Existe um vértice $p$ da componente $M$ em $H(\pi)$, tal que $p \bowtie\left(\pi_{i}, \pi_{j}\right)$ em $\pi$, se, e somente se, $\rho$ age em $M$.

Prova. Considere, sem perda de generalidade, $i<j$.

Suponha que existe um vértice $p$ da componente $M$ em $H(\pi)$, tal que $p \bowtie\left(\pi_{i}, \pi_{j}\right)$ em $\pi$. Desde que, se existe um vértice $q=\left(\pi_{k}, \pi_{l}\right)$ de $M$, tal que ou $k<i \leq l \leq j$ ou $i \leq k \leq j<l$, então ou $q=\left(\pi_{k}, \pi_{l}\right)=\left((\pi . \rho)_{k},(\pi . \rho)_{i+j-l}\right)$ ou $q=\left(\pi_{k}, \pi_{l}\right)=\left((\pi . \rho)_{i+j-k},(\pi . \rho)_{l}\right)$, respectivamente, $\mathrm{e}$ desde que $i$ é ímpar e $j$ é par, segue que $q \in P_{\pi}^{+} \Leftrightarrow q \in P_{\pi . \rho}^{-}$, o que implica, sendo $q$ vértice de $M$, que $\rho$ age em $M$. Portanto, para provar que $\rho$ age em $M$, basta mostrar que existe um vértice $q$ em $M$, tal que um dos extremos de $q$ é elemento de

$$
I=\left\{\pi_{i}, \pi_{i+1}, \ldots, \pi_{j}\right\}
$$

e um dos extremos de $q$ é elemento de

$$
\bar{I}=\left\{\pi_{0}, \pi_{1}, \ldots, \pi_{i-1}\right\} \cup\left\{\pi_{j+1}, \pi_{j+2}, \ldots, \pi_{2 n+1}\right\} .
$$

Suponha, então, por contradição, que não existe vértice $q$ de $M$, tal que um dos extremos de $q$ é elemento de $I$ e o outro é elemento de $\bar{I}$. 
Desde que $p \bowtie\left(\pi_{i}, \pi_{j}\right)$ em $\pi$ e que não pode ocorrer de um dos extremos de $p$ ser elemento de $I$ e o outro ser elemento de $\bar{I}$, segue que os dois extremos de $p$ são elementos de $I$ e um dos extremos de $p$ ou é $\pi_{i}$ ou é $\pi_{j}$. Suponha que um dos extremos de $p$ é $\pi_{i}$ (o caso um dos extremos de $p$ é $\pi_{j}$ é análisado de maneira análoga). Denotando o vértice $p$ por $\left(\pi_{i}, \pi_{m}\right)$ segue também que $i<m$.

Como $\rho$ é uma reversão par, temos que $i$ é ímpar. Sendo $i<m$ e, $\pi_{i}$ e $\pi_{m}$ não são vértices colados, segue que $i<m-1$, o que implica, pelo Lema 3.4, que $p$ não é um vértice isolado. Segue do Lema 3.6 que $\left(\pi_{i}, \pi_{m}\right)$ é aresta azul de algum circuito em $G(\pi)$ e que, sendo $i$ ímpar, $\pi_{i-1}$ é extremo de um vértice $s$ de $M$, desde que $\left(\pi_{i-1}, \pi_{i}\right)$ é aresta vermelha em $G(\pi)$.

Considere, então, um caminho

$$
C=v_{1} v_{2} \ldots v_{t}
$$

em $M$, tal que $v_{1}=p$ e $v_{t}=s$. Seja $v_{h}$ o primeiro vértice de $C$ que não possue seus dois extremos em $I$, isto é, os vértices $v_{1}, v_{2}, \ldots, v_{h-1}$ possuem os dois extremos em $I$. Note que $p$ possui os dois extremos em $I$ e $s$ possui pelo menos um dos extremos em $\bar{I}$ implicando que $v_{h}$ existe e $h>1$.

Desde que $\left(v_{h}, v_{h-1}\right)$ é uma aresta de $H(\pi)$ temos que $v_{h} \bowtie v_{h-1}$ em $\pi$. Segue que um dos extremos de $v_{h}$ é elemento de $I$, contrariando a hipótese de que não existe vértice $q$ de $M$, tal que um dos extremos de $q$ é elemento de $I$ e o outro é elemento de $\bar{I}$. Com isto, mostramos que se $\rho$ age em $M$, então existe um vértice $q$ em $M$, tal que um dos extremos de $q$ é elemento de $I$ e um dos extremos de $q$ é elemento de $\bar{I}$.

Reciprocamente, suponha que $\rho$ age em $M$. Então, uma das seguintes situações ocorre para algum vértice $p$ de $M$.

- Ou $p \in P_{\pi}^{+}$e $p \in P_{\pi . \rho}^{-}$ou $p \in P_{\pi}^{-}$e $p \in P_{\pi . \rho}^{+}$.

- Existe vértice $q$ tal que $(p, q)$ é uma aresta em $H(\pi)$ mas não é aresta em $H(\pi . \rho)$.

- Existe vértice $q$ tal que $(p, q)$ não é uma aresta em $H(\pi)$ mas é aresta em $H(\pi . \rho)$.

Se existe um vértice $p=\left(\pi_{k}, \pi_{l}\right), k<l$, em $M$, tal que ou $p \in P_{\pi}^{+}$e $p \in P_{\pi . \rho}^{-}$ou $p \in P_{\pi}^{-}$e $p \in P_{\pi . \rho}^{+}$, então as únicas possibilidades são ou $k<i \leq l \leq j$ ou $i \leq k \leq j<l$. De qualquer forma $p \bowtie\left(\pi_{i}, \pi_{j}\right)$ em $\pi$.

Se existe um vértice $p=\left(\pi_{k}, \pi_{l}\right), k<l$, em $M$ e um vértice $q=\left(\pi_{h_{1}}, \pi_{h_{2}}\right), h_{1}<h_{2}$, tais que $p \bowtie q$ em $\pi$, então ou $k<h_{1}<l<h_{2}$ ou $h_{1}<k<h_{2}<l$.

Suponha $k<h_{1}<l<h_{2}$ e $p \bowtie q$ em $\pi$. $\rho$. Segue que as únicas possibilidades para $\rho=(i . . j)$ são ou $i \leq k<h_{1} \leq j<l<h_{2}$ ou $k<i \leq h_{1}<l \leq j<h_{2}$ ou $k<h_{1}<i \leq l<h_{2} \leq j$. De qualquer modo $p=\left(\pi_{k}, \pi_{l}\right) \bowtie\left(\pi_{i}, \pi_{j}\right)$ em $\pi$.

Supondo $h_{1}<k<h_{2}<l$ e $p \not$ 为 $q$ em $\pi$. $\rho$, por raciocínio análogo, segue também que $p \bowtie\left(\pi_{i}, \pi_{j}\right)$ em $\pi$.

Se existe um vértice $p=\left(\pi_{k}, \pi_{l}\right), k<l$, em $M$ e um vértice $q=\left(\pi_{h_{1}}, \pi_{h_{2}}\right), h_{1}<h_{2}$, tais que $p \bowtie q$ em $\pi$, então ou $h_{1}<h_{2}<k<l$ ou $k<l<h_{1}<h_{2}$ ou $h_{1}<k<l<h_{2}$ ou $k<h_{1}<h_{2}<l$.

Suponha $h_{1}<h_{2}<k<l$ e $p \bowtie q$ em $\pi . \rho$. Segue que a única possibilidade para $\rho=(i . . j)$ é $h_{1}<i \leq h_{2}<k \leq j<l$ e, portanto, $p \bowtie\left(\pi_{i}, \pi_{j}\right)$ em $\pi$.

Para ou $k<l<h_{1}<h_{2}$ ou $h_{1}<k<l<h_{2}$ ou $k<h_{1}<h_{2}<l$ e $p \bowtie q$ em $\pi$. $\rho$, verificamos, de forma análoga, todas as possibilidades e concluímos que $p \bowtie\left(\pi_{i}, \pi_{j}\right)$ em $\pi$. 
A seguir, mostramos uma condição necessária e suficiente para uma reversão $\rho$ agir exclusivamente em uma componente de $H(\pi)$.

Lema 3.8 A reversão $\rho=(i . . j)$ age exclusivamente na componente $M$ em $H(\pi)$ se, e somente se, $\pi_{i}$ e $\pi_{j}$ são extremos de vértices de $M$.

Prova. Suponha que $\rho$ age exclusivamente na componente $M$ de $H(\pi)$. Seja $\left(\pi_{i}, \pi_{k}\right)$ vértice de uma componente $M^{\prime}$ em $H(\pi)$. Note que, independente do valor de $k,\left(\pi_{i}, \pi_{j}\right) \bowtie\left(\pi_{i}, \pi_{k}\right)$. Segue do Lema 3.7 que $\rho$ age em $M^{\prime}$. Portanto $M=M^{\prime}$, o que implica que $\pi_{i}$ é extremo de um vértice de $M$. Por raciocínio análogo, concluímos que $\pi_{j}$ também é extremo de um vértice de $M$.

Reciprocamente, suponha que $\pi_{i}$ e $\pi_{j}$ são extremos de vértices de $M$. Seja $M^{\prime}$ uma componente de $H(\pi)$, tal que $\rho$ age em $M^{\prime}$. Segue do Lema 3.7 que existe um vértice $q$ de $M^{\prime}$, tal que $q \bowtie\left(\pi_{i}, \pi_{j}\right)$ em $\pi$. Segue do Lema 3.2 que $M=M^{\prime}$. Portanto, $\rho$ age exclusivamente na componente $M$ de $H(\pi)$.

\subsubsection{Componentes de $H(\pi)$}

Nesta seção fazemos uma classificação das componentes de $H(\pi)$. Para auxiliar o entendimento do significado de nossas definições, podemos pensar no grafo $G(\pi)$ como um diagrama circular. Esse diagrama é construído distribuindo-se uniforme e seqüencialmente os elementos da permutação $\pi$ estendida (vértices de $G(\pi)$ ) em torno de um círculo, e cada aresta $\left(\pi_{i}, \pi_{j}\right)$ em $G(\pi)$ representamos como um segmento de reta unindo $\pi_{i}$ e $\pi_{j}$.

Para $i<j$, um arco de $\pi$ definido pelos elementos $\pi_{i}$ e $\pi_{j}$ é uma das classes de equivalência a seguir:

$$
\begin{gathered}
\text { ou }\left\{\left(\pi_{i}, \pi_{i+1}, \ldots, \pi_{j}\right),\left(\pi_{j}, \pi_{j-1}, \ldots, \pi_{i}\right)\right\} \\
\text { ou }\left\{\left(\pi_{j}, \pi_{j+1}, \ldots, \pi_{2 n+1}, \pi_{0}, \pi_{1}, \ldots, \pi_{i}\right),\left(\pi_{i}, \pi_{i-1}, \ldots, \pi_{0}, \pi_{2 n+1}, \pi_{2 n}, \ldots, \pi_{j}\right)\right\} .
\end{gathered}
$$

Se $y=\left(v_{1}, v_{2}, \ldots, v_{t}\right), t \geq 1$, é um arco de $\pi$, denotamos por $y-v_{1}$ o arco $\left(v_{2}, v_{3}, \ldots, v_{t}\right)$ e por $y-v_{t}$ o arco $\left(v_{1}, v_{2}, \ldots, v_{t-1}\right)$.

Para $x$ e $y=\left(v_{1}, v_{2}, \ldots, v_{t}\right)$ arcos de $\pi$, escrevemos $x \prec y$, se existem inteiros $i \geq 0$ e $j \leq t+1$, tais que $x=y-v_{1}-v_{2}-\ldots-v_{i}-v_{t}-v_{t-1}-\ldots-v_{j}$.

Se $x$ e $y$ são arcos distintos de $\pi$, ambos definidos por $\pi_{i}$ e $\pi_{j}$, dizemos que $y$ é o arco oposto a $x$ em $\pi$. Denotamos o arco oposto a $x$ em $\pi$ por $\bar{x}_{\pi}$.

Note as seguintes propriedades, para $y=\left(\pi_{k}, \ldots, \pi_{l}\right)$ e $x=\left(\pi_{i}, \ldots, \pi_{j}\right)$ arcos de $\pi$.

- Se $y \prec x$, então $\bar{x}_{\pi} \prec \bar{y}_{\pi}$.

- Se $\pi_{i}$ e $\pi_{j}$ são elementos de $y$, então ou $x \prec y$ ou $\bar{y}_{\pi} \prec x$.

- Se nem $\pi_{i}$ e nem $\pi_{j}$ são elementos de $y$, então ou $y \prec x-\pi_{i}-\pi_{j}$ ou $x \prec \bar{y}_{\pi}-\pi_{k}-\pi_{l}$. Veja

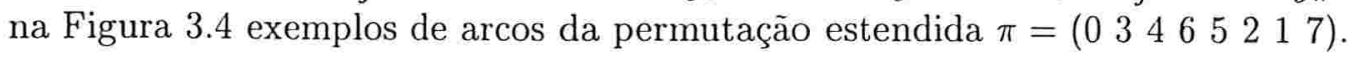

Dizemos que $x$ e $y$ são disjuntos, se $x$ e $y$ não possuem um elemento comum. Note a seguinte condição necessária e suficiente para caracterização de arcos disjuntos.

- Os $\operatorname{arcos} x=\left(\pi_{k}, \ldots, \pi_{l}\right)$ e $y$ de $\pi$ são disjuntos se, e somente se, $y \prec \bar{x}_{\pi}-\pi_{k}-\pi_{l}$. 


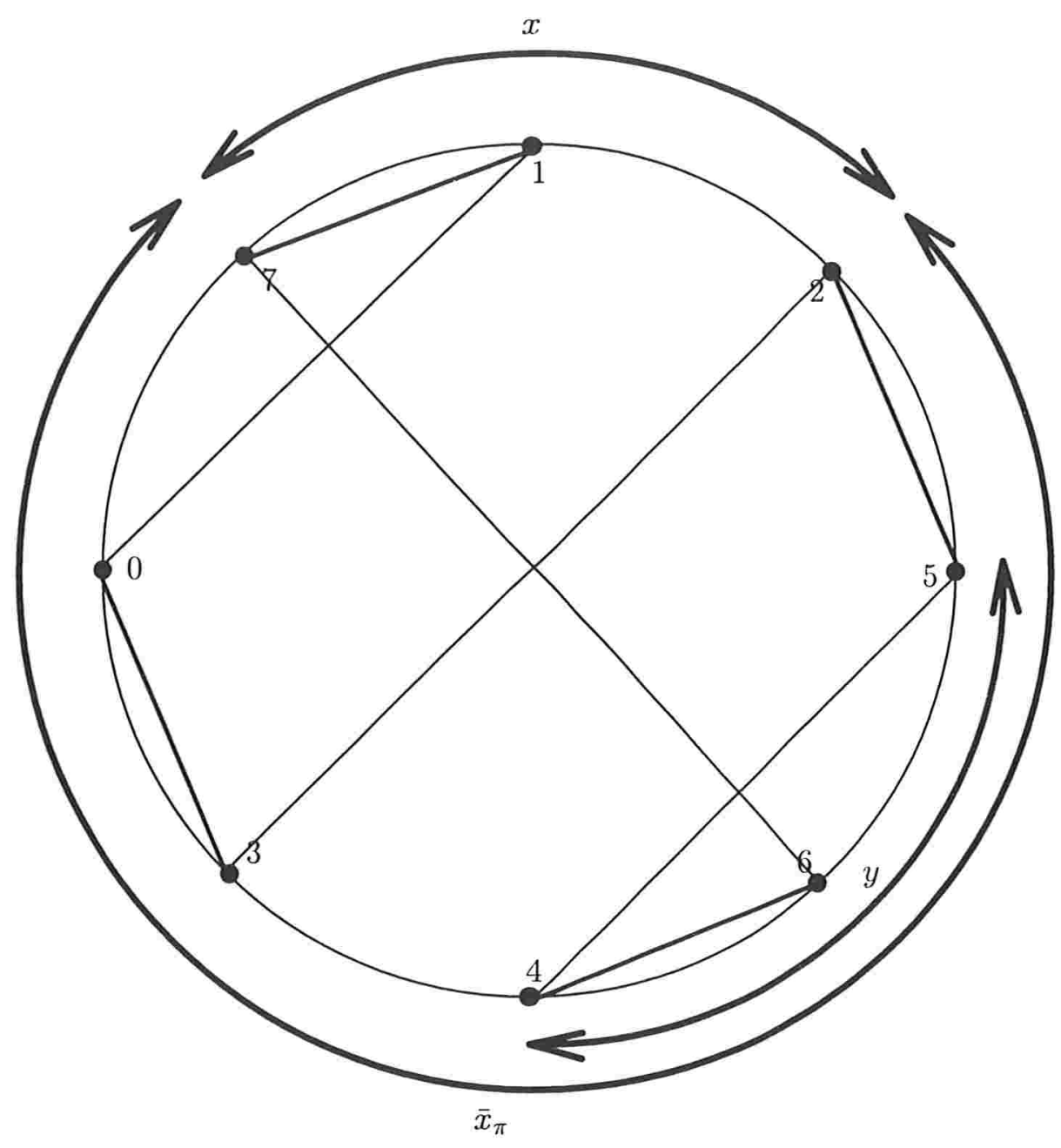

Figura 3.4: $\mathrm{O}$ arco $x=(2,1,7) \equiv(7,1,2)$ é definido por 2 e 7 . O outro arco definido por 2 e 7 é o arco $\bar{x}_{\pi}$ (que é oposto a $x$ em $\pi$ ). Veja também o arco $y=(4,6,5)$ e note que $y \prec \bar{x}_{\pi}$. 
Dizemos que uma reversão $(i . . j)$ cruza o arco $y=\left(\pi_{k}, \ldots, \pi_{l}\right)$, se $\pi_{i}$ e $\pi_{j}$ são elementos de $y$. Neste caso,

- se $y$ é arco de $\pi$, então $\bar{y}_{\pi}-\pi_{k}-\pi_{l}$ é arco de $\pi .(i . . j)$,

- se nem $\pi_{i}$ e nem $\pi_{j}$ são elementos de um arco $x$ de $\pi$, então $x$ é arco de $\pi .(i . . j)$.

Para $y=\left(\pi_{k}, \ldots, \pi_{l}\right)$ um arco de $\pi$, verificamos a seguinte condição de entrelaçamento do par $\left(\pi_{k}, \pi_{l}\right)$ com um par $\left(\pi_{i}, \pi_{j}\right)$ em $\pi$.

$$
\left(\pi_{i}, \pi_{j}\right) \bowtie\left(\pi_{k}, \pi_{l}\right) \Leftrightarrow \text { ou } \pi_{i} \text { é elemento de } y \text { e } \pi_{j} \text { é elemento de } \bar{y}_{\pi} \text { ou vice-versa. }
$$

Se $M$ é uma componente em $H(\pi)$ e a cor de pelo menos um de seus vértices é preta, dizemos que $M$ é uma componente boa. Se $M$ não é um vértice isolado e todo vértice de $M$ possui cor cinza, então dizemos que $M$ é uma componente má.

Para $x$ arco de $\pi$, definimos $C M(x)$ como o conjunto das componentes más em $H(\pi)$, tal que $M \in C M(x)$, se os dois extremos de todo vértice em $M$ são elementos de $x$. Note que, embora a definição de $C M(x)$ dependa de $H(\pi), C M(x)$ independe de $\bar{x}_{\pi}$.

Para $x$ arco de $\pi$, enunciamos, a seguir, algumas propriedades do conjunto $C M(x)$.

- Se $x \prec y$, então $C M(x) \subseteq C M(y)$.

- Se $y$ é arco de $\pi$ e, $x$ e $y$ são disjuntos, então $C M(x) \cap C M(y)=\emptyset$.

- Se $M \in C M(x)$ e, $\pi_{i}$ e $\pi_{j}$ não são elementos de $x$, então $M$ é uma componente má em $H(\pi .(i . . j))$.

Dizemos que $M$ é um obstáculo em $H(\pi)$, se existeum arco $x$ de $\pi$, tal que

$$
C M(x)=\{M\} .
$$

Denotamos por $h(\pi)$ o número de obstáculos em $H(\pi)$, e por $\Delta h(\pi, \rho)$, ou simplesmente $\Delta h$, se $\pi$ e $\rho$ estiverem claros no contexto, o valor $h(\pi . \rho)-h(\pi)$.

Dizemos que o arco $x$ define o obstáculo $M$ em $H(\pi)$, se $C M(x)=\{M\}$ e, para todo arco $y$ de $\pi, y \neq x$ e $y \prec x, C M(y)=\emptyset$.

Note que, se o arco $x$, definido por $\pi_{i}$ e $\pi_{j}$, define o obstáculo $M$, então $\pi_{i}$ e $\pi_{j}$ são extremos de vértices em $M$.

Para $x=\left(\pi_{i}, \ldots, \pi_{j}\right)$ arco de $\pi$ que define o obstáculo $M$, uma componente má $M^{\prime} \neq M$ não pode ter todos os extremos de seus vértices em $x$. Por outro lado, se um dos extremos de um vértice de $M^{\prime}$, digamos $\pi_{k}$, é elemento de $x$ e um dos extremos de um vértice de $M^{\prime}$, digamos $\pi_{l}$, é elemento de $\bar{x}_{\pi}-\pi_{i}-\pi_{j}$, então, $\left(\pi_{i}, \pi_{j}\right) \bowtie\left(\pi_{k}, \pi_{l}\right)$ e segue, como consequiência do Lema 3.2 , que existe um vértice de $M^{\prime}$ adjacente a um vértice de $M$, o que implica que $M^{\prime}=M$; o que é um absurdo. Logo, todo extremo de um vértice de $M^{\prime}$ é elemento de $\bar{x}_{\pi}-\pi_{i}-\pi_{j}$. Dessa discussão, concluímos que

- se $x=\left(\pi_{i}, \ldots, \pi_{j}\right)$ define o obstáculo $M$ em $H(\pi)$ e $M^{\prime}$ é uma componente má em $H(\pi)$, então $M^{\prime} \in C M\left(\bar{x}_{\pi}-\pi_{i}-\pi_{j}\right)$.

Além disso, se $y=\left(\pi_{k}, \ldots, \pi_{l}\right)$ é um arco que define um obstáculo $K \neq M$, como $\pi_{k}$ e $\pi_{l}$ não são elementos de $x$, então ou $x \prec\left(y-\pi_{k}-\pi_{l}\right) \prec y$ ou $y \prec\left(\bar{x}_{\pi}-\pi_{i}-\pi_{j}\right)$. Como $x \prec y$ implica 
que $C M(x) \subseteq C M(y)$ e, portanto, $M \in C M(y)$, contrariando o fato de $y$ definir o obstáculo $K \neq M$, temos que $y \prec\left(\bar{x}_{\pi}-\pi_{i}-\pi_{j}\right)$, o que implica que $y$ e $x$ são disjuntos. Ou seja,

- se $y$ e $x$ são arcos que definem obstáculos distintos em $H(\pi)$, então $y$ e $x$ são disjuntos.

Lema 3.9 Para um arco $x$ de $\pi$, se $C M(x) \neq \emptyset$, então existe $M \in C M(x)$, tal que $M$ é um obstáculo em $H(\pi)$.

Prova. Para $|C M(x)|=1$, a afirmação é verdadeira por definição. Suponha, então, que $\left|C M\left(x=\left(w_{1}, w_{2}, \ldots, w_{t}\right)\right)\right|=k, k \geq 2$, e, para todo arco $z$ de $\pi$, tal que $|C M(z)|=k-1, \mathrm{o}$ lema vale.

Seja $y=x-w_{1}-w_{2}-\ldots-w_{s}$ um arco de $\pi$, tal que todo elemento $w_{1}, w_{2}, \ldots, w_{s}$ não é extremo de um vértice de uma componente em $C M(x)$ e $v=w_{s+1}$ é extremo de um vértice de uma componente, digamos $M^{\prime}$, em $C M(x)$.

Note que o arco $y$ é tal que $C M(y)=C M(x)$.

Por outro lado, observe que $C M(y) \backslash\left\{M^{\prime}\right\}=C M(y-v)$ e, sendo $M^{\prime} \in C M(y)$, temos que

$$
|C M(y-v)|=|C M(y)|-1=|C M(x)|-1=k-1 .
$$

Mas, por hipótese de indução, $C M(y-v)$ deve conter um obstáculo $M$ em $H(\pi)$. Como $C M(y-v) \subseteq C M(x)$, segue que $M \in C M(x)$ e é obstáculo em $H(\pi)$.

Para $M$ uma componente má, se $M$ não é um obstáculo em $H(\pi)$, dizemos que $M$ é um não-obstáculo.

A seguir mostramos uma maneira de identificar um não-obstáculo em $H(\pi)$.

Lema 3.10 Sejam $\pi_{i}$ e $\pi_{j}$ extremos de vértices de uma componente má $K$ em $H(\pi)$ e $x$ um arco de $\pi$ definido por $\pi_{i}$ e $\pi_{j}$. Se

$$
C M\left(x-\pi_{i}\right) \neq \emptyset \text { e } C M\left(\bar{x}_{\pi}-\pi_{i}\right) \neq \emptyset,
$$

então $K$ é um não-obstáculo em $H(\pi)$.

Prova. Suponha, por contradição, que $K$ é um obstáculo. Seja $y$ o arco de $\pi$ que define o obstáculo $K$. Como $y$ deve conter $\pi_{i}$ e $\pi_{j}$ temos que ou $x \prec y$ ou $\bar{x}_{\pi} \prec y$.

Suponha que $x \prec y$. Temos que $x-\pi_{i} \prec x \prec y$ o que implica que $C M\left(x-\pi_{i}\right) \subseteq C M(y)$. Sendo $C M\left(x-\pi_{i}\right) \neq \emptyset$ e $C M(y)=\{K\}$, segue que $C M\left(x-\pi_{i}\right)=\{K\}$, um absurdo pois $\pi_{i}$ é extremo de um vértice de $K$ e não é elemento de $x-\pi_{i}$. Assumiremos, portanto, que $\bar{x}_{\pi} \prec y$.

Mas, por raciocínio análogo, $\bar{x}_{\pi} \prec y$ implica que $C M\left(\bar{x}_{\pi}-\pi_{i}\right)=\{K\}$ o que é, da mesma forma, um absurdo.

Portanto, $K$ é um não-obstáculo em $H(\pi)$.

Dizemos que um obstáculo $M$ protege o não-obstáculo $K$ em $H(\pi)$, se existe um arco $x$ de $\pi$, tal que

$$
C M(x)=\{M, K\} .
$$

Se o obstáculo $M$ protege algum não-obstáculo $K$, dizemos que $M$ é um super-obstáculo. Caso contrário, dizemos que $M$ é um obstáculo simples. 
Dizemos que o arco $x$ define a proteção do obstáculo $M$ sobre o não-obstáculo $K \mathrm{em} H(\pi)$,

$$
C M(x)=\{M, K\} \text { e, para todo arco } y \text { de } \pi, y \neq x, y \prec x, C M(y) \backslash\{M\}=\emptyset .
$$

Note que se $x=\left(\pi_{k}, \ldots, \pi_{l}\right)$ é um arco que define a proteção de $M$ sobre $K$, então $\pi_{k}$ e $\pi_{l}$ são extremos de vértices de $K$, pois se ou $\pi_{k}$ ou $\pi_{l}$ é um extremo de um vértice de uma componente $M^{\prime} \neq M, M^{\prime} \neq K$, então temos, respectivamente, ou $C M\left(x-\pi_{k}\right)=\{M, K\}$ ou $C M\left(x-\pi_{l}\right)=\{M, K\}$ implicando que $x$ não é um arco que define a proteção de $M$ sobre $K$, e se ou $\pi_{k}$ ou $\pi_{l}$ são extremos de vértices de $M$, então temos, respectivamente, ou $C M\left(x-\pi_{k}\right)=\{K\}$ ou $C M\left(x-\pi_{l}\right)=\{K\}$ implicando que $K$ é um obstáculo, o que é um absurdo.

Note que, de maneira similar ao que ocorre com os obstáculos, sendo $x=\left(\pi_{i}, \ldots, \pi_{j}\right)$ o arco que define a proteção de $M$ sobre $K$, como $\pi_{i}$ e $\pi_{j}$ são extremos de vértices em $K$, segue, por raciocínio análogo, os seguintes resultados.

- Se $x=\left(\pi_{i}, \ldots, \pi_{j}\right)$ define a proteção de um obstáculo $M$ sobre um não-obstáculo $K$ em $H(\pi)$ e $M^{\prime}$ é uma componente má, $M^{\prime} \neq M, M^{\prime} \neq K$, em $H(\pi)$, então $M^{\prime} \in C M\left(\bar{x}_{\pi}-\pi_{i}-\pi_{j}\right)$.

- Se $y$ é um arco de $\pi$ que define a proteção de um obstáculo $M$ sobre um não-obstáculo e $x$ é um arco de $\pi$ que define um obstáculo $M^{\prime} \neq M$ em $H(\pi)$, então $y$ e $x$ são disjuntos.

Outro fato importante é que

- Se $x=\left(\pi_{i}, \ldots, \pi_{j}\right)$ define a proteção de um obstáculo $M$ sobre um não-obstáculo $K$ em $H(\pi)$, então $C M\left(\bar{x}_{\pi}-\pi_{i}-\pi_{j}\right) \neq \emptyset$.

Para verificar isto, suponha, por contradição, que $C M\left(\bar{x}_{\pi}-\pi_{i}-\pi_{j}\right)=\emptyset$. Segue que $M$ e $K$ são as únicas componentes más em $H(\pi)$. Se $y=\left(\pi_{k}, \ldots, \pi_{l}\right)$ é o arco de $\pi$ que define o obstáculo $M$, então toda componente má em $H(\pi)$, diferente de $M$, pertence a $C M\left(\bar{y}_{\pi}-\pi_{k}-\pi_{l}\right)$. Segue que $C M\left(\bar{y}_{\pi}-\pi_{k}-\pi_{l}\right)=\{K\}$, uma contradição do fato de $K$ ser um não-obstáculo em $H(\pi)$.

Lema 3.11 Para $x$ arco de $\pi$, se $|C M(x)| \geq 2$ e $M$ é o único elemento de $C M(x)$ que é um obstáculo em $H(\pi)$, então $M$ é um super-obstáculo em $H(\pi)$.

Prova. Para $|C M(x)|=2$ a afirmação é verdadeira por definição. Suponha, então, que $\left|C M\left(x=\left(w_{1}, w_{2}, \ldots, w_{t}\right)\right)\right|=k, k \geq 3$, e, para todo arco $z$ tal que $|C M(z)|=k-1$, o lema vale.

Seja $y=x-w_{1}-w_{2}-\ldots-w_{s}$ um arco de $\pi$, tal que todo elemento $w_{1}, w_{2}, \ldots, w_{s}$ não é extremo de um vértice de uma componente em $C M(x)$, e $v=w_{s+1}$ é extremo de um vértice de uma componente, digamos $M^{\prime}$, em $C M(x)$.

Note que o arco $y$ de $\pi$ é tal que $C M(y)=C M(x)$.

Por outro lado, observe que $C M(y) \backslash\left\{M^{\prime}\right\}=C M(y-v)$ e, sendo $M^{\prime} \in C M(y)$, temos que

$$
|C M(y-v)|=|C M(y)|-1=|C M(x)|-1=k-1 .
$$

Mas, segue do Lema 3.9, que $C M(y-v)$ deve conter pelo menos um obstáculo $M^{\prime \prime}$ em $H(\pi)$. Como $C M(y-v) \subset C M(y)$ e $M$ é o único obstáculo em $C M(y)$, temos que $M^{\prime \prime}=M$ e é o único obstáculo em $C M(y-v)$. Segue, por hipótese de indução, sendo $|C M(y-v)|=k-1$, que $M$ é um super-obstáculo em $H(\pi)$. 
Uma fortaleza é uma permutação $\pi$ tal que $h(\pi)$ é ímpar e todo obstáculo em $H(\pi)$ é um super-obstáculo. Para $\pi$ uma permutação, definimos

$$
f(\pi)= \begin{cases}1 & \text { se } \pi \text { é uma fortaleza } \\ 0 & \text { caso contrário. }\end{cases}
$$

Denotamos por $\Delta f(\pi, \rho)$, ou simplesmente $\Delta f$, se $\pi$ e $\rho$ estiverem claros no contexto, o valor de $f(\pi . \rho)-f(\pi)$.

Note que se $\pi$ é uma fortaleza, então $h(\pi) \geq 3$.

\subsubsection{Limitante Inferior}

Nesta seção, mostramos o seguinte resultado.

Teorema 3.12 Para toda permutação $\pi$ e reversão $\rho$,

$$
\Delta(b-c+h+f) \geq-1 .
$$

Prova. Considere a reversão $\rho=(i . . j)$ e $p$ e $q$ os vértices de $H(\pi)$ com os extremos $\pi_{i}$ e $\pi_{j}$, respectivamente, e $x=\left(\pi_{i-1}, \pi_{i}\right)$ e $y=\left(\pi_{j}, \pi_{j+1}\right)$.

Suponha que $x$ e $y$ são arestas vermelhas de um mesmo circuito $C$ em $G(\pi)$. Claramente, $p$ e $q$ são arestas azuis do circuito $C$. Segue do Lema 3.6 que $p$ e $q$ são vértices de uma mesma componente, digamos $M$, em $H(\pi)$. Segue do Lema 3.8 que $\rho$ age exclusivamente em $M$.

Se $x$ e $y$ são arestas divergentes em $C$, então $\Delta(b-c)=-1$ (Seção 3.2.2) e um dos vértices de $M$, que é uma aresta azul de $C$ em $G(\pi)$, é preto (Fato 3.3), o que implica que $M$ é uma componente boa. Sendo $M$ uma componente boa e a reversão $\rho$ age exclusivamente em $M$, segue do Lema 3.15 que $\Delta(h+f) \geq 0$. Portanto, se $x$ e $y$ são arestas divergentes de um mesmo circuito em $G(\pi)$, então $\Delta(b-c+h+f) \geq-1$.

Se $x$ e $y$ são arestas convergentes em $C$, então $\Delta(b-c)=0$ (Seção 3.2.2). Como a reversão $\rho$ age exclusivamente em $M$, se $M$ é uma componente boa, então $\Delta(h+f) \geq 0$ (Lema 3.15) e se $M$ é uma componente má, então $\Delta(h+f) \geq-1$ (Lema 3.16). Logo, independentemente de $M$ ser uma componente ou boa ou má, $\Delta(h+f) \geq-1$. Portanto, se $x$ e $y$ são arestas convergentes de um mesmo circuito em $G(\pi)$, então $\Delta(b-c+h+f) \geq-1$.

Suponha, então, que $x$ e $y$ não são arestas de um mesmo circuito em $G(\pi)$. Logo, $\Delta(b-c)=1$ (Seção 3.2.2). Como $\Delta(h+f) \geq-2$ (Lema 3.17), segue que $\Delta(b-c+h+f) \geq-1$.

Concluímos que, para toda permutação $\pi$ e reversão $\rho, \Delta(b-c+h+f) \geq-1$.

Corolário 3.13 Para toda permutaçâo $\pi$,

$$
d(\pi) \geq b(\pi)-c(\pi)+h(\pi)+f(\pi) .
$$

Prova. Conforme já observado no Capítulo $2, b(\pi)-c(\pi) \geq 0$ pois cada circuito de $G(\pi)$ possue pelo menos 2 pontos de quebra. Observando que $h(\pi) \geq 0$ e $f(\pi) \geq 0$. temos que $b(\pi)-c(\pi)+h(\pi)+f(\pi) \geq 0$. Por outro lado, sendo $\iota$ a permutação identidade. temos que $b(\iota)=0, c(\iota)=0, h(\iota)=0$ e $f(\iota)=0$. Segue, desde que $\Delta(b-c+h+f) \geq-1$ (Teorema 3.12), que $d(\pi) \geq b(\pi)-c(\pi)+h(\pi)+f(\pi)$. 
A seguir mostramos a prova dos Lemas $3.15,3.16$ e 3.17 que sustentam a demonstração do Teorema 3.12.

Para $\pi$ e $\rho$ permutação e reversão, respectivamente, definimos $T(\pi, \rho)$ como o conjunto de componentes $M$ em $H(\pi)$ que satisfazem as três condições a seguir.

- $M$ é um obstáculo em $H(\pi)$;

- $\rho$ não age em $M$;

- $M$ não é um obstáculo em $H(\pi . \rho)$.

Note, como $\rho$ não age em $M$, que $M$ é uma componente má em $H(\pi . \rho)$. Segue, como $M$ não é obstáculo em $H(\pi . \rho)$, que $M$ é um não-obstáculo em $H(\pi . \rho)$.

Lema 3.14 Para $\pi$ uma permutação e $\rho=(i . . j)$ uma reversão, se $T(\pi, \rho) \neq \emptyset$, então

$$
\Delta(h+f) \geq 0 .
$$

Prova. Sejam $M \in T(\pi, \rho)$ e $y=\left(\pi_{y_{1}}, \ldots, \pi_{y_{2}}\right)$ o arco de $\pi$ que define o obstáculo $M$, e $x=\left(\pi_{x_{1}}, \ldots, \pi_{x_{2}}\right)=\left(\bar{y}_{\pi}-\pi_{y_{1}}-\pi_{y_{2}}\right)$.

Desde que $M$ não é obstáculo em $H(\pi . \rho), y$ não é arco de $\pi . \rho$, o que implica que $\pi_{i}$ e $\pi_{j}$ não podem ser, ao mesmo tempo, elementos de $x$. Por outro lado, sendo $\pi_{y_{1}}$ e $\pi_{y_{2}}$ extremos de vértices de $M$, como $\rho$ não age em $M,\left(\pi_{i}, \pi_{j}\right) \not\left(\pi_{y_{1}}, \pi_{y_{2}}\right)$ em $\pi$ (Lemas 3.2 e 3.7). Segue que $\rho$ cruza $y$ e, portanto, $x$ é arco de $\pi . \rho$.

Note que, como todo extremo de $M$ não é extremo de $x$ e $M$ é uma componente má em $H(\pi . \rho)$, segue que $M \in C M\left(\bar{x}_{\pi . \rho}-\pi_{x_{1}}-\pi_{x_{2}}\right)$.

Seja $M^{\prime} \neq M$ um obstáculo em $H(\pi)$ e $w$ o arco que define $M^{\prime}$. Como $y$ e $w$ definem obstáculos distintos, temos que $y$ e $w$ são disjuntos o que implica que $w \prec x$ e, sendo $x$ arco de $\pi . \rho$, temos que $w$ também é arco de $\pi . \rho$. Segue que $M^{\prime}$ é obstáculo em $H(\pi . \rho)$. Portanto, todo obstáculo $M^{\prime} \neq M$ em $H(\pi)$ é um obstáculo em $H(\pi . \rho)$. Segue, também, que $h(\pi)-1$ elementos de $C M(x)$ são obstáculos em $H(\pi . \rho)$.

Afirmamos que todo não-obstáculo em $H(\pi)$ é um não-obstáculo em $H(\pi . \rho)$. Para verificar essa afirmação, suponha, por contradição, que $K$ é um não-obstáculo em $H(\pi)$ e é um obstáculo em $H(\pi . \rho)$, definido pelo arco $z=\left(\pi_{z_{1}}, \ldots, \pi_{z_{2}}\right)$. Sendo $K$ uma componente má e $K \neq M$, temos que $K \in C M(x)$. Como $\pi_{z_{1}}$ e $\pi_{z_{2}}$ são elementos de $x$, temos que ou $z \prec x$ ou $\bar{x}_{\pi . \rho} \prec z$. Mas $z \prec x$ não pode ocorrer, desde que $x$ é arco de $\pi$ e $K$ é um não-obstáculo em $H(\pi)$. Assumiremos, então, $\bar{x}_{\pi . \rho} \prec z$. Segue, sendo $C M\left(\bar{x}_{\pi \cdot \rho}-\pi_{x_{1}}-\pi_{x_{2}}\right) \subseteq C M(z)$, que $M \in C M(z)$, contrariando a hipótese de que $K$ é um obstáculo em $H(\pi . \rho)$ definido pelo arco $z$. Portanto, todo não-obstáculo em $H(\pi)$ é um não-obstáculo em $H(\pi . \rho)$.

Sejam $M^{\prime} \neq M$ um super-obstáculo em $H(\pi)$ e $v$ o arco que define a proteção de $M^{\prime}$ sobre o não-obstáculo $K$. Segue que $y$ e $v$ são disjuntos o que implica que $v \prec x$. Sendo $C M(v)=\left\{M^{\prime}, K\right\}$ e $K$ um não-obstáculo em $H(\pi . \rho)$, segue dos Lemas 3.9 e 3.11 que $M^{\prime}$ é um super-obstáculo em $H(\pi . \rho)$. Segue que todo super-obstáculo $M^{\prime} \neq M$ em $H(\pi)$ é um super-obstáculo em $H(\pi . \rho)$.

Por outro lado, como $M \in C M\left(\bar{x}_{\pi . \rho}-\pi_{x_{1}}-\pi_{x_{2}}\right)$, segue do Lema 3.9 que existe pelo menos 1 elemento de $C M\left(\bar{x}_{\pi \cdot \rho}-\pi_{x_{1}}-\pi_{x_{2}}\right)$ que é um obstáculo, digamos $M^{\prime \prime}$. Como $M \in T(\pi, \rho)$ segue que $M^{\prime \prime} \neq M$. Segue que $\mid C M\left(\bar{x}_{\pi . \rho}-\pi_{x_{1}}-\pi_{x_{2}} \mid \geq 2\right.$.

Desde que $C M(x)$ contém pelo menos $h(\pi)-1$ obstáculos em $H(\pi . \rho)$ e $C M\left(\bar{x}_{\pi . \rho}-\pi_{x_{1}}-\pi_{x_{2}}\right)$ contém pelo menos um obstáculo em $H(\pi . \rho)$ e $C M(x) \cap C M\left(\bar{x}_{\pi . \rho}-\pi_{x_{1}}-\pi_{x_{2}}\right)=\emptyset$, temos que $h(\pi . \rho) \geq h(\pi)-1+1=h(\pi)$. Logo, $\Delta h \geq 0$. 
Para ou $\Delta h \geq 1$ ou $f(\pi)=0$, então, segue da definição da função $f$ que $\Delta(h+f) \geq 0$.

Basta, então, considerar o caso $\Delta h=0$ e $f(\pi)=1$.

Sendo $f(\pi)=1$, então todo obstáculo em $H(\pi)$ é um super-obstáculo. Segue, sendo todo super-obstáculo $M^{\prime} \neq M$ em $H(\pi)$ um super-obstáculo em $H(\pi . \rho)$, que os $h(\pi)-1$ obstáculos em $C M(x)$ são super-obstáculos em $H(\pi . \rho)$. Por outro lado, segue, sendo $\Delta h=0$, que deve existir no máximo um obstáculo $M^{\prime \prime}$ em $C M\left(\bar{x}_{\pi . \rho}-\pi_{x_{1}}-\pi_{x_{2}}\right)$. Segue dos Lema 3.9 e 3.11 , como $\left|C M\left(\bar{x}_{\pi . \rho}-\pi_{x_{1}}-\pi_{x_{2}}\right)\right| \geq 2$, que $M^{\prime \prime}$ também é um super-obstáculo. Logo, todo obstáculo em $H(\pi . \rho)$ é um super-obstáculo.

Além disso, $f(\pi)=1$ implica que $h(\pi)$ é ímpar e, sendo $\Delta h=0$, segue que $h(\pi . \rho)$ também é ímpar. Como todo obstáculo em $H(\pi . \rho)$ é um super-obstáculo e $h(\pi . \rho)$ é ímpar, temos que $f(\pi \cdot \rho)=1$. Segue que $\Delta f=0$ e, sendo $\Delta h=0$, concluímos que $\Delta(h+f)=0$.

Lema 3.15 Se $\rho=(i . . j)$ não age em qualquer componente má de $H(\pi)$, então

$$
\Delta(h+f) \geq 0 .
$$

Prova. Se $T(\pi, \rho) \neq \emptyset$, então, segue do Lema 3.14, $\Delta(h+f) \geq 0$, verificando, portanto, a veracidade do lema. Basta considerar, então, o caso $T(\pi, \rho)=\emptyset$.

Sendo $T(\pi, \rho)=\emptyset \mathrm{e}$, como $\rho$ não age em uma componente má, temos que todo obstáculo em $H(\pi)$ é um obstáculo em $H(\pi . \rho)$. Consequentemente $\Delta h \geq 0$.

Para ou $\Delta h \geq 1$ ou $f(\pi)=0$, segue da definição da função $f$ que $\Delta(h+f) \geq 0$. Para provar o lema basta, então, verificar o caso $f(\pi)=1$ e $\Delta h=0$ quando $T(\pi, \rho)=\emptyset$.

Note que, sendo todo obstáculo em $H(\pi)$ um obstáculo em $H(\pi . \rho)$ e $\Delta h=0$, temos que todo obstáculo em $H(\pi . \rho)$ é um obstáculo em $H(\pi)$, e sendo $f(\pi)=1$, temos que todo obstáculo em $H(\pi)$ é um super-obstáculo.

Seja $x=\left(\pi_{x_{1}}, \ldots, \pi_{x_{2}}\right)$ o arco que define a proteção de um super-obstáculo $M$ sobre um nãoobstáculo $K$ em $H(\pi)$ e $y=\left(\pi_{y_{1}}, \ldots, \pi_{y_{2}}\right)=\bar{x}_{\pi}-\pi_{x_{1}}-\pi_{x_{2}}$. Desde que $\rho=(i . . j)$ não age em qualquer componente má de $H(\pi)$ e $\pi_{x_{1}}$ e $\pi_{x_{2}}$ são extremos de vértices de $K,\left(\pi_{x_{1}}, \pi_{x_{2}}\right) \bowtie\left(\pi_{i}, \pi_{j}\right)$ (Lemas 3.2 e 3.7). Assumiremos, então, que ou $\rho$ cruza $y$ ou $\rho$ cruza $x-\pi_{x_{1}}-\pi_{x_{2}}$.

Se $\rho$ cruza $y$, então $x$ é arco de $\pi . \rho$ e, sendo $C M(x)=\{M, K\}$ e todo obstáculo em $H(\pi . \rho)$ um obstáculo em $H(\pi)$, segue dos Lemas 3.9 e 3.11 que $M$ é um super-obstáculo em $H(\pi . \rho)$.

Se $\rho$ cruza $x-\pi_{x_{1}}-\pi_{x_{2}}$, então $y$ é arco de $\pi . \rho$. Como todo arco $z$, que define um obstáculo $M^{\prime}$ em $H(\pi)$ é disjunto do arco $x$, temos que $z \prec y$ e, conseqüentemente, $M^{\prime} \in C M(y)$. Como temos $h(\pi)-1$ obstáculos em $H(\pi)$ diferentes de $M$, segue que $C M(y)$ contém $h(\pi)-1$ obstáculos em $H(\pi . \rho)$. Por outro lado, como $\rho$ não age em uma componente má, então $K$ e $M$ são componentes más de $H(\pi . \rho)$. Como nenhum extremo de $M$ e nenhum extremo de $K$ são elementos de $y$, segue que $M$ e $K$ são elementos de $C M\left(\bar{y}_{\pi . \rho}-\pi_{y_{1}}-\pi_{y_{2}}\right)$. Como $C M(y)$ contém $h(\pi)-1$ obstáculos em $H(\pi)$ e $\Delta h=0$, temos que existe no máximo 1 elemento em $C M\left(\bar{y}_{\pi . \rho}-\pi_{y_{1}}-\pi_{y_{2}}\right)$ que é obstáculo. Como $M, K \in C M\left(\bar{y}_{\pi . \rho}-\pi_{y_{1}}-\pi_{y_{2}}\right)$ e $M$ é um obstáculo em $H(\pi . \rho)$, segue do Lema 3.11 que $M$ é um super-obstáculo em $H(\pi . \rho)$.

Sendo todo obstáculo em $H(\pi)$ um super-obstáculo e todo super-obstáculo em $H(\pi)$ um super-obstáculo em $H(\pi . \rho)$ e todo obstáculo em $H(\pi . \rho)$ um obstáculo em $H(\pi)$, temos que todo obstáculo em $H(\pi . \rho)$ é um super-obstáculo. Sendo $f(\pi)=1$, temos que $h(\pi)$ é ímpar. Segue, 
sendo $\Delta h=0$, que $h(\pi . \rho)$ também é ímpar. Segue que $f(\pi . \rho)=1$ e, conseqüentemente, $\Delta f=0$. Portanto, segue, para $\Delta h=0$ e $f(\pi)=1$, que também $\Delta(h+f) \geq 0$.

Lema 3.16 Se $\rho=(i . . j)$ age exclusivamente em uma componente má $M$ de $H(\pi)$, então

$$
\Delta(h+f) \geq-1
$$

Prova. Se $T(\pi, \rho) \neq \emptyset$, então, segue do Lema 3.14, $\Delta(h+f) \geq 0 \geq-1$. Suponha, então, $T(\pi, \rho)=\emptyset$. Isto implica que todo obstáculo $M^{\prime} \neq M$ em $H(\pi)$ é um obstáculo em $H(\pi . \rho)$.

Sendo $T(\pi, \rho)=\emptyset$, se ou $M$ é um não-obstáculo ou $M$ é um obstáculo em $H(\pi)$ e em $H(\pi . \rho)$ ou existe um obstáculo em $H(\pi . \rho)$ que não é obstáculo em $H(\pi)$, então $\Delta h \geq 0$. Como, por definição $\Delta f \geq-1$, segue que $\Delta(h+f) \geq-1$. Suponha, então, que $M$ é um obstáculo em $H(\pi)$ e não é um obstáculo em $H(\pi . \rho)$ e, para todo obstáculo $M^{\prime}$ em $H(\pi . \rho), M^{\prime}$ é um obstáculo em $H(\pi)$. Note que, neste caso, $\Delta h=-1$.

Basta mostrar, então, que nessas condições $f(\pi)=0$ pois, se $f(\pi)=0$, como por definição $f(\pi . \rho) \geq 0$, então $\Delta f \geq 0$ o que implica, sendo $\Delta h=-1$, que $\Delta(h+f) \geq-1$.

Suponha, por contradição, que $f(\pi)=1$. Segue que $M$ é um super-obstáculo. Seja $K$ o não-obstáculo protegido por $M$ em $H(\pi)$ e $y=\left(\pi_{y_{1}}, \ldots, \pi_{y_{2}}\right)$ o arco que define a proteção de $M$ sobre $K$ e $x=\left(\pi_{x_{1}}, \ldots, \pi_{x_{2}}\right)=\bar{y}_{\pi}-\pi_{y_{1}}-\pi_{y_{2}}$.

Segue do Lema 3.8 que $\pi_{i}$ e $\pi_{j}$ são extremos de $M$ o que implica que $\pi_{i}$ e $\pi_{j}$ são elementos de $y$. Segue que a reversão $\rho$ cruza $y$, o que implica que $x$ é um arco de $\pi . \rho$. Sendo todo arco $w$ em $\pi$ que define um obstáculo $M^{\prime} \neq M$ em $H(\pi)$ disjunto de $y$, segue que $w \prec x$, o que implica que, sendo $C M(w)=\left\{M^{\prime}\right\}$, que $M^{\prime}$ é um obstáculo em $H(\pi . \rho)$. Sendo todo obstáculo $M^{\prime} \neq M$ um obstáculo em $H(\pi . \rho)$, segue que $h(\pi)-1$ elementos de $C M(x)$ são obstáculos em $H(\pi . \rho)$. Segue, sendo $\Delta h=-1$, que $C M\left(\bar{x}_{\pi \cdot \rho}-\pi_{x_{1}}-\pi_{x_{2}}\right)=\emptyset$ (Lema 3.9) o que é um absurdo pois, como $\rho$ age exclusivamente em $M$, temos que $K$ é uma componente má em $H(\pi . \rho)$ e como todo extremo de $K$ não é elemento de $x$, segue que $K \in C M\left(\bar{x}_{\pi . \rho}-\pi_{x_{1}}-\pi_{x_{2}}\right)$.

Lema 3.17 Para toda permutação $\pi$ e reversão $\rho=(i . . j)$,

$$
\Delta(h+f) \geq-2 \text {. }
$$

Prova. Desde que os arcos que definem obstáculos em $\pi$ são disjuntos, um elemento $\pi_{l}$ de $\pi$ pode ser elemento de no máximo 1 arco que define algum obstáculo em $\pi$. Isto significa que $h(\pi)-2$ arcos que definem obstáculos em $\pi$ não contém nem $\pi_{i}$ e nem $\pi_{j}$. Seja $x_{k}$, para $1 \leq k \leq h(\pi)-2$, o arco que define o obstáculo $M_{k}$ em $\pi$ que não contém nem $\pi_{i}$ e nem $\pi_{j}$. Segue que $x_{k}$ é arco de $\pi . \rho$ e, sendo $C M\left(x_{k}\right)=\left\{M_{k}\right\}$, temos que $M_{k}$ é um obstáculo em $H(\pi . \rho)$. Segue que $M_{1}, M_{2}, \ldots, M_{h(\pi)-2}$ são obstáculos em $H(\pi . \rho)$ e, portanto, $h(\pi . \rho) \geq h(\pi)-2$.

Para ou $h(\pi . \rho) \geq h(\pi)-1$ ou $f(\pi)=0$, segue da definição da função $f$ que $\Delta(h+f) \geq-2$.

Basta, então, mostrar que o lema vale para $h(\pi . \rho)=h(\pi)-2$ e $f(\pi)=1$. Neste caso, sendo $M_{1}, M_{2}, \ldots, M_{h(\pi)-2}$ obstáculos em $H(\pi)$ e em $H(\pi . \rho)$ e sendo $h(\pi . \rho)=h(\pi)-2$, então, todo obstáculo em $H(\pi . \rho)$ é um obstáculo em $H(\pi)$. Note que, neste caso, $\pi_{i}$ e $\pi_{j}$ são elementos de arcos, digamos $x_{h(\pi)-1}$ e $x_{h(\pi)}$, que definem obstáculos em $\pi$. 
Sendo $M_{k}, 1 \leq k \leq h(\pi)-2$, um super-obstáculo, seja $y$ o arco que define a proteção de $M_{k}$ sobre um não-obstáculo $K$. Desde que tanto $y$ e $x_{h(\pi)-1}$ quanto $y$ e $x_{h(\pi)}$ são disjuntos, $y$ não contém nem $\pi_{i}$ e nem $\pi_{j}$. Segue que $y$ é arco de $\pi . \rho$ e que $\rho$ não age em $K$. Desde que todo obstáculo em $H(\pi . \rho)$ é um obstáculo em $H(\pi)$, temos que $K$ é um não-obstáculo em $H(\pi . \rho)$. Sendo $C M(y)=\left\{M_{k}, K\right\}$, segue dos Lemas 3.9 e 3.11 que $M_{k}$ é um super-obstáculo em $H(\pi . \rho)$.

Sendo $f(\pi)=1$ e todo obstáculo em $H(\pi . \rho)$ é um obstáculo em $H(\pi)$, segue que todo obstáculo em $H(\pi . \rho)$ é um super-obstáculo. Sendo $h(\pi)$ ímpar, temos, sendo $h(\pi . \rho)=h(\pi)-2$, que $h(\pi . \rho)$ também é ímpar. Segue que $f(\pi . \rho)=1$.

Portanto, segue, para $f(\pi)=1$ e $h(\pi . \rho)=h(\pi)-2$, que também $\Delta(h+f) \geq-2$.

\subsection{Limitante Superior}

O limitante superior do valor da distância por reversões em permutações orientadas é determinado, nesta seção, por um algoritmo polinomial, denominado por SBR-Orienta, que recebe uma permutação $\pi$ e devolve uma seqüência de reversões que ordena $\pi$. O número de reversões que SBR-Orienta devolve é $b(\pi)-c(\pi)+h(\pi)+f(\pi)$, implicando que $d(\pi) \leq b(\pi)-c(\pi)+h(\pi)+f(\pi)$.

Como, pelo Corolário 3.13, $d(\pi) \geq b(\pi)-c(\pi)+h(\pi)+f(\pi)$, segue o seguinte resultado.

Teorema 3.18 Para toda permutação $\pi$,

$$
d(\pi)=b(\pi)-c(\pi)+h(\pi)+f(\pi) .
$$

Segue, também, que a seqüência de reversões que SBR-Orienta devolve é mínima.

Dada uma permutação $\pi$, dizemos que uma reversão $\rho$ é segura se essa, aplicada a $\pi$, é tal que $\Delta(b-c+h+f)=-1$. Desde que, pelo Teorema 3.12, $\Delta(b-c+h+f) \geq-1$, segue que saber determinar, para qualquer permutação $\pi$, uma reversão segura é condição necessária e suficiente para descrever um algoritmo que ordena uma permutação usando $b(\pi)-c(\pi)+h(\pi)+f(\pi)$ reversões.

O algoritmo SBR-Orienta pode, basicamente, ser dividido em 2 fases.

A primeira fase, que estudamos na Seção 3.4.2, determina uma seqüência de $\lceil h(\pi) / 2\rceil$ reversões seguras que, aplicadas a $\pi$, resultam em uma permutação $\pi^{\prime}$ tal que $H\left(\pi^{\prime}\right)$ é isenta de componentes más.

A segunda fase, vista na Seção 3.4.3, encontra uma seqüência de $d(\pi)-\lceil h(\pi) / 2\rceil$ reversões seguras que ordena a permutação $\pi^{\prime}$.

\subsubsection{Encontrando Componentes de $H(\pi)$}

O Algoritmo SBR-Orienta, implicitamente requer, como pré-processamento, a computação dos conjuntos de vértices de cada componente em $H(\pi)$.

Para tal, Berman e Hannenhalli [BH96] descrevem um procedimento que, usando a estrutura de "union-find", determina os conjuntos de vértices correspondentes às componentes de $H(\pi)$ em tempo $O(n \alpha(n))$, onde $\pi$ é uma permutação sobre $2 n$ e onde $\alpha(n)$ é o inverso da função 
de Ackerman. O procedimento por nós proposto, que chamamos de ConstróiH, determina o conjunto de componentes de $H(\pi)$ em tempo $O(n)$, sendo, portanto, melhor, assintoticamente, que o anteriormente descrito.

Descrevemos a seguir uma estrutura. definida por Berman e Hannenhalli [BH96], que é utilizada para a descrição de ConstróiH.

O grafo $H(\pi)^{h}, h=0,1, \ldots, 2 n+1$, é um subgrafo de $H(\pi)$ com os seguintes conjuntos de vértices e arestas. O vértice $p=\left(\pi_{i}, \pi_{j}\right)$ de $H(\pi)$ é vértice de $H(\pi)^{h}$, se $\min \{i, j\} \leq h$. A aresta $\left(p=\left(\pi_{i}, \pi_{j}\right), q=\left(\pi_{k}, \pi_{l}\right)\right)$ de $H(\pi)$ é aresta de $H(\pi)^{h}$, se $p$ e $q$ são vértices de $H(\pi)^{h}$ e ou $\max \{i, j\} \leq h$ ou $\max \{k, l\} \leq h$. Note que $H(\pi)^{2 n+1}=H(\pi)$.

Dizemos que o vértice $p=\left(\pi_{i}, \pi_{j}\right)$ de $H(\pi)^{h}$ é ativo, se $\max \{i, j\}>h$. Caso contrário, dizemos que $p$ é um vértice inativo. Dizemos que uma componente $M$ de $H(\pi)^{h}$ é ativa, se pelo menos um de seus vértices é ativo. Caso contrário, dizemos que $M$ é uma componente inativa.

Note, então, sendo $p$ e $q$ vértices de $H(\pi)^{h}$, que $(p, q)$ é aresta de $H(\pi)^{h}$ se, e somente se, $(p, q)$ é aresta de $H(\pi)$ e ou $p$ ou $q$ é um vértice inativo em $H(\pi)^{h}$.

Definimos a função $u:\{0,1,2, \ldots, 2 n+1\} \rightarrow\{0,1,2, \ldots, 2 n+1\}$, para $\pi$ uma permutação estendida sobre $2 n$, tal que $u(i)=j$, se $\left(\pi_{i}, \pi_{j}\right)$ é um vértice de $H(\pi)$. Observe que se $u(i)=j$, então $u(j)=i$.

O grafo $H(\pi)^{h}, h=1, \ldots, 2 n+1$, pode ser construído a partir do grafo $H(\pi)^{h-1}$ através da seguinte operação, para $p=\left(\pi_{h}, \pi_{u(h)}\right)$.

- se $p$ não é vértice de $H(\pi)^{h-1}$ (neste caso, $h<u(h)$ ), então acrescentamos o vértice $p$ e nenhuma aresta ao grafo $H(\pi)^{h-1}$.

- se $p$ é vértice de $H(\pi)^{h-1}$ (neste caso, $u(h)<h$ ), então não acrescentamos vértices mas acrescentamos toda aresta $(p, q)$ tal que $q$ é vértice ativo em $H(\pi)^{h-1}$ e $(p, q)$ é aresta em $H(\pi)$.

Pela maneira com que construímos o grafo $H(\pi)^{h}$ a partir do grafo $H(\pi)^{h-1}$, deduzimos o seguinte resultado.

Fato 3.19 Se $M$ é uma componente inativa em $H(\pi)^{h-1}$, entâo $M$ é uma componente inativa em $H(\pi)^{h}$, ou seja, $M$ é uma componente em $H(\pi)$.

Seja $\mathcal{M}$ um conjunto de vértices de $H(\pi)^{h}$. Definimos indice $(\mathcal{M})$ como sendo o menor inteiro $k$ tal que $\left(\pi_{k}, \pi_{u(k)}\right)$ é elemento de $\mathcal{M}$. Definimos ativo $(\mathcal{M})$ como sendo o número de elementos de $\mathcal{M}$ que são vértices ativos em $H(\pi)^{h}$.

Vejamos alguns resultados que estabelecem uma relação entre componentes ativas de um grafo $H(\pi)^{h}$.

Lema 3.20 Sejam $\mathcal{M}$ e $\mathcal{K}$ os conjuntos de vértices de duas componentes ativas distintas $M$ e $K$ em $H(\pi)^{h-1}$. Se índice $(\mathcal{M})<$ índice $(\mathcal{K}) \leq z \leq h-1$, então $\left(\pi_{z}, \pi_{u(z)}\right)$ não é um vértice de $M$ em $H(\pi)^{h-1}$. 
Prova. Sejam $i=i n \operatorname{dice}(\mathcal{M})$ e $j=i n d i c e(\mathcal{K})$. Segue que $\left(\pi_{i}, \pi_{u(i)}\right)$ e $\left(\pi_{j}, \pi_{u(j)}\right)$ são vértices de $M$ e de $K$, respectivamente.

Suponha, por contradição, que $\left(\pi_{z}, \pi_{u(z)}\right)$ é vértice de $M$ em $H(\pi)^{h-1}$. Então, existe um caminho $C_{M}=v_{1} v_{2} \ldots v_{t}$ em $M$, tal que $v_{1}=\left(\pi_{i}, \pi_{u(i)}\right)$ e $v_{t}=\left(\pi_{z}, \pi_{u(z)}\right)$. Seja $s$ o menor inteiro tal que $v_{s}=\left(\pi_{x}, \pi_{u(x)}\right), x<u(x)$, é um vértice que possui pelo menos um de seus extremos em $\left\{\pi_{j}, \pi_{j+1}, \ldots, \pi_{h-1}\right\}$.

Se $v_{s}$ é um vértice ativo, então $s \neq 1$, pois, do contrário, sendo $i<j \leq h-1$ e $\left(\pi_{i}, \pi_{u(i)}\right)$ um vértice ativo, não pode ocorrer ao mesmo tempo $h-1<u(i)$ e $j \leq u(i) \leq h-1$. Segue que $\left(v_{s-1}, v_{s}\right)$ é aresta de $M$ o que implica, sendo $v_{s}$ um vértice ativo, que $v_{s-1}$ é um vértice inativo. Além disso, $v_{s-1} \bowtie v_{s}$ em $\pi$. Segue que um dos extremos de $v_{s-1}$ pertence a $\left\{\pi_{j}, \pi_{j+1}, \ldots, \pi_{h-1}\right\}$, contrariando a escolha de $v_{s}$. Assumiremos, então, que $v_{s}$ é um vértice inativo.

Sendo $v_{s}$ um vértice inativo, note que $x<j \leq u(x)<h$.

Sendo $K$ uma componente ativa em $H(\pi)^{h-1}$, um dos vértices de $K$, digamos $\left(\pi_{l}, \pi_{u(l)}\right)$, $l<u(l)$, é um vértice ativo de $K$. Sendo $j \leq l$, para $l \leq u(x)$, segue que $\left(\pi_{l}, \pi_{u(l)}\right) \bowtie\left(\pi_{x}, \pi_{u(x)}\right)$ em $\pi$ e, sendo $\left(\pi_{x}, \pi_{u(x)}\right)$ vértice inativo, segue que $\left(\pi_{x}, \pi_{u(x)}\right) \in K$, contrariando a hipótese de $M$ e $K$ serem componentes ativas distintas em $H(\pi)^{h-1}$. Assumiremos, então, que $l>u(x)$ o que implica que $x<j \leq u(x)<l$.

Seja $C_{K}=w_{1} w_{2} \ldots w_{q}$ um caminho em $K$, tal que $w_{1}=\left(\pi_{j}, \pi_{u(j)}\right)$ e $w_{q}=\left(\pi_{l}, \pi_{u(l)}\right)$. Seja $p$ o menor inteiro tal que $w_{p}=\left(\pi_{y}, \pi_{u(y)}\right)$, não possue os dois extremos em $\left\{\pi_{x}, \pi_{x+1}, \ldots, \pi_{u(x)}\right\}$, isto é, $w_{1}, \ldots, w_{p-1}$ possuem os dois extremos em $\left\{\pi_{x}, \ldots, \pi_{u(x)}\right\}$.

Segue que, independentemente de $\left(\pi_{y}, \pi_{u(y)}\right)$ ser vértice ou ativo ou inativo em $H(\pi)^{h-1}$, $\left(\pi_{x}, \pi_{u(x)}\right) \bowtie\left(\pi_{y}, \pi_{u(y)}\right)$ em $\pi$ e, sendo $\left(\pi_{x}, \pi_{u(x)}\right)$ vértice inativo, segue que $\left(\left(\pi_{x}, \pi_{u(x)}\right),\left(\pi_{y}, \pi_{u(y)}\right)\right)$ é aresta de $H(\pi)^{h-1}$, contrariando, novamente, a hipótese de $M$ e $K$ serem componentes ativas distintas em $H(\pi)^{h-1}$.

Portanto, $\left(\pi_{z}, \pi_{u(z)}\right)$ não é vértice de $M$ em $H(\pi)^{h-1}$.

Lema 3.21 Sejam $\mathcal{M}$ e $\mathcal{K}$ os conjuntos de vértices de duas componentes ativas distintas $M$ e $K$ em $H(\pi)^{h-1}$. Para $\left(\pi_{h}, \pi_{u(h)}\right)$ vértice de $M$, existe um vértice ativo de $K$ adjacente a $\left(\pi_{h}, \pi_{u(h)}\right)$ em $H(\pi)^{h}$ se, e somente se, $u(h)<$ indice $(\mathcal{K})$.

Prova. Como $\left(\pi_{h}, \pi_{u(h)}\right)$ é vértice de $H(\pi)^{h-1}$, temos que $u(h) \leq h-1<h$.

Seja $\left(\pi_{i}, \pi_{u(i)}\right), i<u(i)$, um vértice ativo de $K$ em $H(\pi)^{h-1}$. Segue que $i \leq h-1<u(i)$.

Suponha que $\left(\pi_{i}, \pi_{u(i)}\right)$ é adjacente a $\left(\pi_{h}, \pi_{u(h)}\right)$ em $H(\pi)^{h}$. Então, $\left(\pi_{h}, \pi_{u(h)}\right) \bowtie\left(\pi_{i}, \pi_{u(i)}\right)$ em $\pi$ o que implica, sendo $u(h) \leq h-1<h$ e $i \leq h-1<u(i)$, e $\left(\pi_{i}, \pi_{u(i)}\right)$ e $\left(\pi_{h}, \pi_{u(h)}\right)$ vértices distintos em $H(\pi)^{h-1}$, que $u(h)<i<h<u(i)$.

Como índice $(\mathcal{M}) \leq u(h)$ e indice $(\mathcal{K}) \leq i$ e, sendo $K \neq M$, segue que ou

$$
\text { indice }(\mathcal{M})<\operatorname{indice}(\mathcal{K})<u(h)<i
$$

$\mathrm{ou}$

$$
\text { indice }(\mathcal{K})<\operatorname{indice}(\mathcal{M}) \leq u(h)<i
$$

ou

$$
\operatorname{indice}(\mathcal{M}) \leq u(h)<\text { indice }(\mathcal{K}) \leq i \text {. }
$$


Mas tanto indice $(\mathcal{M})<$ indice $(\mathcal{K})<u(h)<i$ quanto indice $(\mathcal{K})<$ indice $(\mathcal{M}) \leq u(h)<i$ contrariam o Lema 3.20. Segue, portanto, que indice $(\mathcal{M}) \leq u(h)<$ indice $(\mathcal{K}) \leq i \mathrm{e}$, em particular, $u(h)<$ indice $(\mathcal{K})$.

Reciprocamente, suponha que $u(h)<$ indice $(\mathcal{K})$. Como $i$ é extremo de um vértice de $K$, sendo indice $(\mathcal{K}) \leq i$, segue que $u(h)<i$. Desde que $i \leq h-1$ e $h \leq u(i)$ e $u(h)<i$, temos que $u(h)<i \leq h-1 \leq u(i)$ e, portanto, $\left(\pi_{h}, \pi_{u(h)}\right) \bowtie\left(\pi_{i}, \pi_{u(i)}\right)$ em $\pi$. Logo, $\left(\left(\pi_{h}, \pi_{u(h)}\right),\left(\pi_{i}, \pi_{u(i)}\right)\right)$ é uma aresta em $H(\pi)$. Sendo $u(h)<h$, temos que $\left(\pi_{h}, \pi_{u(h)}\right)$ é vértice inativo em $H(\pi)^{h}$. Segue que $\left(\left(\pi_{h}, \pi_{u(h)}\right),\left(\pi_{i}, \pi_{u(i)}\right)\right)$ é aresta de $H(\pi)^{h}$ e, portanto, $\left(\pi_{h}, \pi_{u(h)}\right)$ e $\left(\pi_{i}, \pi_{u(i)}\right)$ são adjacentes em $H(\pi)^{h}$.

O Invariante 3.23 mostra que o Procedimento ConstróiH (Figura 3.5) determina, no final de cada iteração $h=0,1, \ldots, 2 n+1$, o conjunto de vértices de cada componente em $H(\pi)^{h}$. Para isto o procedimento mantém duas estruturas de listas para armazenar os vértices das componentes de $H(\pi)^{h}$. Uma delas armazena os conjuntos

$$
\mathcal{M}_{1}, \mathcal{M}_{2}, \ldots, \mathcal{M}_{y}
$$

de vértices, onde cada $\mathcal{M}_{i}$ corresponde ao conjunto de vértices de uma componente ativa em $H(\pi)^{h}$, e a outra armazena os conjuntos

$$
\mathcal{K}_{1}, \mathcal{K}_{2}, \ldots, \mathcal{K}_{x}
$$

de vértices, onde cada $\mathcal{K}_{i}$ corresponde ao conjunto de vértices de uma componente inativa em $H(\pi)^{h}$.

Além disso, para cada conjunto $\mathcal{M}_{i}$, guardamos os valores de índice $\left(\mathcal{M}_{i}\right)$ e ativo $\left(\mathcal{M}_{i}\right)$.

A seguir, escrevemos $y^{h}$ e $x^{h}$ e $\mathcal{M}_{i}^{h}$ e $\mathcal{K}_{j}^{h}$, para denotar os valores de $y$ e $x$, e os conjuntos $\mathcal{M}_{i}$ e $\mathcal{K}_{j}$, respectivamente, no final da iteração $h$.

Por indução em $h$ e pela execução do Procedimento ConstróiH, verificamos a seguinte propriedade.

Invariante 3.22 No final de cada iteração $h=0,1, \ldots, 2 n+1$ :

(a) $\quad$ indice $\left(\mathcal{M}_{1}^{h}\right)<$ indice $\left(\mathcal{M}_{2}^{h}\right)<\ldots<$ indice $\left(\mathcal{M}_{y^{h}}^{h}\right) \leq h$;

(b) indice $\left(\mathcal{M}_{i}^{h}\right), 1 \leq i \leq y^{h}$, corresponde, de fato, ao menor $k$ tal que $\left(\pi_{k}, \pi_{u(k)}\right)$ é elemento de $\mathcal{M}_{i}^{h}$;

(c) ativo $\left(\mathcal{M}_{i}^{h}\right)$ corresponde, de fato, ao número de elementos em $\mathcal{M}_{i}^{h}$ que são vértices ativos em $H(\pi)^{h}$.

O item $(c)$ do Invariante 3.22 não é imediato. Para verificá-lo, basta mostrar que, no final de cada iteração $h,\left(\pi_{h}, \pi_{u(h)}\right)$ é elemento de $\mathcal{M}_{y}$. Por outro lado, este fato segue do seguinte invariante cuja veracidade é verificada por indução em $h$.

Se $\left(\pi_{z}, \pi_{u(z)}\right), z<u(z)$, é um vértice ativo de $H(\pi)^{h}$ e é elemento do conjunto $\mathcal{M}_{i}, i<y$, então $z<$ indice $\left(\mathcal{M}_{i+1}\right)$.

Mostramos abaixo o seguinte resultado.

Invariante 3.23 No final de cada iteração $h=0,1, \ldots, 2 n+1, \mathcal{M}_{1}^{h}, \ldots, \mathcal{M}_{y}^{h}$ e $\mathcal{K}_{1}^{h}, \ldots, \mathcal{K}_{x}^{h}$ correspondem aos conjuntos de vértices das componentes ativas e das componentes inativas, respectivamente, em $H(\pi)^{h}$. 


\section{Procedimento ConstróiH;}

Entrada: Uma permutação $\pi$ sobre $2 n$.

Saída: $\mathcal{K}_{1}, \mathcal{K}_{2}, \ldots, \mathcal{K}_{x}$, tal que, $\mathcal{K}_{j}, 1 \leq j \leq x$, é o conjunto de vértices de uma das $x$ componentes em $H(\pi)$.

calcule a função $u$ para a permutação estendida $\pi$;

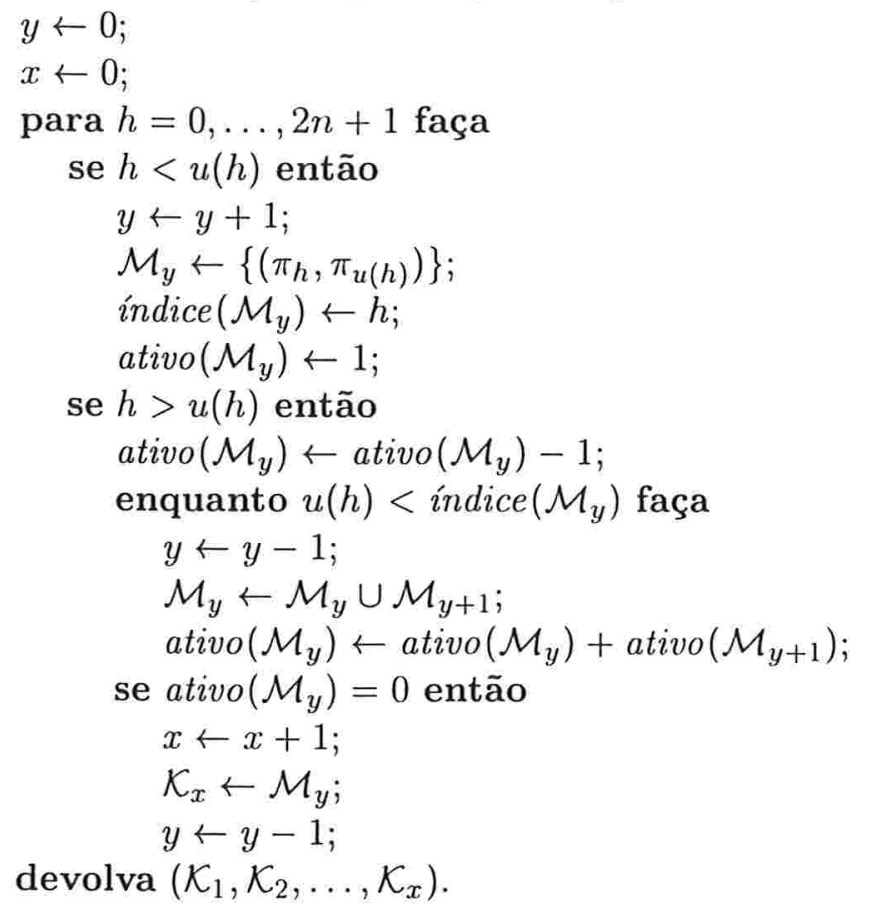

Figura 3.5: Procedimento ConstróiH. 
Prova. A prova é feita por indução em $h$.

Para $h=0$, no final da iteração, temos $y=1, x=0$ e $\mathcal{M}_{1}^{0}=\left\{\left(\pi_{0}, \pi_{u(0)}\right)\right\}$. Segue que o invariante vale para $h=0$.

Suponha que o invariante vale para o final da iteração $h-1, h \geq 1$, e verificamos a seguir que o mesmo vale no final da iteração $h$.

Considere, primeiramente, o caso.de, no início da iteração $h$ (e final da iteração $h-1$ ), $h<u(h)$.

Sendo que, para $h<u(h)$, obter o grafo $H(\pi)^{h}$ a partir do grafo $H(\pi)^{h-1}$ pode ser visto como adicionar um vértice ativo, que é um vértice isolado, e não acrescentar qualquer aresta ao grafo $H(\pi)^{h-1}$ e como, por hipótese de indução, $\mathcal{M}_{1}^{h-1}, \ldots, \mathcal{M}_{y^{h-1}}^{h-1}$ e $\mathcal{K}_{1}^{h-1}, \ldots, \mathcal{K}_{x^{h-1}}^{h-1}$ correspondem aos conjuntos de vértices das componentes ativas e das componentes inativas, respectivamente, em $H(\pi)^{h-1}$ e, pela execução de ConstróiH, $y^{h}=y^{h-1}+1$ e $x^{h}=x^{h-1}$ e $\mathcal{M}_{i}^{h}=\mathcal{M}_{i}^{h-1}$, para $1 \leq i \leq y^{h}-1$ e $\mathcal{K}_{i}^{h}=\mathcal{K}_{i}^{h-1}$, para $1 \leq i \leq x^{h}$ e $\mathcal{M}_{y^{h}}^{h}=\left\{\left(\pi_{h}, \pi_{u(h)}\right)\right\}$, segue que, no final da iteração $h$, o invariante é satisfeito.

Considere, agora, o caso de, no início da iteração $h$ (e final da iteração $h-1), u(h)<h$.

Desde que, por hipótese de indução $\mathcal{M}_{1}^{h-1}, \ldots, \mathcal{M}_{y^{h-1}}^{h-1}$ correspondem aos conjuntos de vértices das componentes ativas em $H(\pi)^{h-1}$ e desde que $y^{h} \leq y^{h-1}$ temos o seguinte.

Para $M_{i}^{h-1}, 1 \leq i \leq y^{h}-1$,

$$
\text { indice }\left(M_{i}^{h-1}\right)<\operatorname{indice}\left(M_{y^{h}}^{h-1}\right)(\text { Invariante } 3.22) \text {, }
$$

implicando, como índice $\left(M_{y^{h}}^{h-1}\right) \leq u(h)$, que nem $\left(\pi_{h}, \pi_{u(h)}\right)$ é vértice de $M_{i}^{h-1}$ (Lema 3.20) e nem $M_{i}^{h-1}$ possui vértices adjacentes a $\left(\pi_{h}, \pi_{u(h)}\right)$ em $H(\pi)^{h}$ (Lema 3.21). Segue que $M_{i}^{h-1}$ corresponde a um conjunto de vértices de uma componente ativa em $H(\pi)^{h}$ conforme executado pelo procedimento.

Para $M_{y^{h}}^{h-1}$, segue como conseqüência do Lema 3.20 que $\left(\pi_{h}, \pi_{u(h)}\right)$ é vértice de $M_{y^{h}}^{h-1}$. Por outro lado, para cada $M_{j}^{h-1}, y^{h}+1 \leq j \leq y^{h-1}$, segue do Lema 3.21 que $\left(\pi_{h}, \pi_{u(h)}\right)$ é adjacente a algum vértice ativo em $M_{j}^{h-1} \mathrm{em} H(\pi)^{h}$. Segue, da execução de ConstróiH, que $M_{y^{h}}^{h}$ corresponde a uma única componente em $H(\pi)^{h}$. Segue do Invariante 3.22 que $M_{y^{h}}^{h}$ é uma componente ou ativa ou inativa se ativo $\left(M_{y^{h}}^{h}\right)=0$ ou ativo $\left(M_{y^{h}}^{h}\right) \neq 0$, respectivamente, conforme executado por ConstróiH.

Finalmente, desde que $K_{1}^{h-1}, \ldots, K_{x^{h-1}}^{h-1}$, correspondem, por hipótese de indução, aos vértices das componentes inativas em $H(\pi)^{h-1}$, segue do Fato 3.19 que $K_{1}^{h-1}, \ldots, K_{x^{h-1}}^{h-1}$ correspondem também aos vértices de componentes inativas em $H(\pi)^{h}$, conforme executado por Constrói $H$.

Como $H(\pi)^{2 n+1}=H(\pi)$ e como $H(\pi)^{2 n+1}$ não possui componentes ativas, segue do Invariante 3.23 o seguinte resultado.

Teorema 3.24 Os conjuntos $\mathcal{K}_{1}, \mathcal{K}_{2}, \ldots, \mathcal{K}_{x}$ que ConstróiH devolve, correspondem, de fato, aos conjuntos de vértices das componentes em $H(\pi)$.

Para determinarmos a complexidade de tempo gasto por ConstróiH, observe que, a menos da rotina para obter a função $u$ para a permutação estendida $\pi$, todas as instruções podem ser executadas em tempo $O(1)$. 
Cada vez que o procedimento executa o laço "enquanto", ocorre união de conjuntos. Como existem $n+1$ vértices em $H(\pi)$, o laço "enquanto" pode ser executado no máximo $n+1$ vezes.

Por outro lado, cada instrução do laço "para", que não é instrução do laço "enquanto", é executada no máximo $2 n+2$ vezes.

Segue que o tempo total gasto no laço "para" é $O(n)$.

A função $u$ pode ser obtida através da seguinte rotina. Calculamos $\pi^{-1}$, fazendo, para cada $i=0,1, \ldots, 2 n+1, \pi_{\pi_{i}}^{-1}=i$. Em seguida, para cada $i=0,1, \ldots, 2 n+1$, calculamos

$$
u(i)= \begin{cases}\pi_{\pi_{\pi}+1}^{-1} & \text { se } \pi_{i} \text { é par, } \\ \pi_{\pi_{i}-1}^{-1} & \text { se } \pi_{i} \text { é ímpar. }\end{cases}
$$

Claramente, obter a função $u$ para a permutação estendida $\pi$ também gasta tempo $O(n)$. Concluímos o seguinte resultado.

Teorema 3.25 A complexidade de tempo gasto por ConstróiH é $O(n)$.

\subsubsection{Eliminando Obstáculos}

Nesta seção descrevemos um procedimento que recebe como entrada uma permutação sobre $2 n$ e determina uma seqüência de $\left\lceil\frac{h(\pi)}{2}\right\rceil$ reversões seguras $\rho_{1}, \rho_{2}, \ldots, \rho_{\left\lceil\frac{h(\pi)}{2}\right\rceil}$, tal que

$$
h\left(\pi \cdot \rho_{1} \cdot \rho_{2} \ldots . \rho_{\left\lceil\frac{h(\pi)}{2}\right\rceil}\right)=0 .
$$

Note que, para $\pi$ uma permutação, $h(\pi)=0$ implica que não existem componentes más em $H(\pi)$, desde que, para todo arco $x$ de $\pi, C M(x)=\emptyset$ (Lema 3.9).

A seguir, vejamos os seguintes conceitos.

Sejam $x_{1}, x_{2}, \ldots, x_{h(\pi)}$ arcos de $\pi$ que definem os obstáculos $M_{1}, M_{2}, \ldots, M_{h(\pi)}$ em $H(\pi)$. Dizemos que $M_{i}$ e $M_{j}, 1 \leq i, j \leq h(\pi)$, são consecutivos, se existe um arco $y$ de $\pi$, tal que $x_{i} \prec y$ e $x_{j} \prec y$ e, para todo $k, k \neq i, k \neq j, 1 \leq k \leq h(\pi), x_{k} \prec \bar{y}_{\pi}$. Caso contrário, dizemos que $M_{i}$ e $M_{j}$, são não-consecutivos.

Dizemos que $\left(M_{1}, M_{2}, \ldots, M_{h(\pi)}\right)$ é uma lista obstáculo-consecutiva de $H(\pi)$, se, para todo $i$, $1 \leq i \leq h(\pi)-1, M_{i}$ e $M_{i+1}$ são consecutivos. Note que, neste caso, se $h(\pi) \geq 4$, então $M_{1}$ e $M_{3}$ são obstáculos não-consecutivos.

A principal propriedade dos obstáculos consecutivos é a seguinte.

Fato 3.26 Sejam $x_{m}$ e $x_{k}$ os arcos que definem os obstáculos não-consecutivos $M$ e $K$, respectivamente, e $\pi_{i}$ elemento de $x_{m}$ e $\pi_{j}$ elemento de $x_{k}$.

Se y é um arco de $\pi$ definido por $\pi_{i}$ e $\pi_{j}$, então $C M(y) \neq \emptyset$ e $C M\left(\bar{y}_{\pi}\right) \neq \emptyset$.

Para $\pi_{i}$ extremo de um vértice de um obstáculo $M$ e $\pi_{j}$ extremo de um vértice de um obstáculo $K \neq M$ em $H(\pi)$, dizemos que a reversão $\rho=(i . . j)$ intercala os obstáculos $M$ e $K$.

Dizemos que a reversão $\rho=(i . . j)$ corta o obstáculo $M$, se $\left(\pi_{i}, \pi_{j}\right)$ é um vértice de $M$. 
Lema 3.27 Sejam $x=\left(\pi_{i} \ldots, \pi_{j}\right)$ e $y=x-\pi_{i}-\pi_{j}$ e $z=\bar{x}_{\pi}-\pi_{i}-\pi_{j}$ arcos de $\pi$. Se $\rho=(i . . j)$ é uma reversão que ou intercala dois obstáculos ou corta um obstáculo, então, para toda componente má $M$ em $H(\pi . \rho)$, ou $M \in C M(y)$ ou $M \in C M(z)$.

Além disso,

- se $\rho$ intercala obstáculos, então $\Delta(b-c)=1$;

- se $\rho$ corta obstáculos, então $\Delta(b-c)=0$.

Prova. Suponha, sem perda de generalidade, que $i<j$. Logo $i$ é ímpar e $j$ é par.

Sendo $\pi_{i}$ e $\pi_{j}$ extremos de vértices de componentes más, segue do Lema 3.4 que $\pi_{i}$ e $\pi_{j}$ não são extremos de vértices em $H(\pi)$ que representam adjacências em $\pi$. Isto implica que, sendo $i$ ímpar e $j$ par, que $\pi_{i-1} \nsim \pi_{i}$ e $\pi_{j} \nsim \pi_{j+1}$. Segue que $\left(\pi_{i-1}, \pi_{i}\right)$ e $\left(\pi_{j}, \pi_{j+1}\right)$ são arestas vermelhas de circuitos, digamos $C_{1}$ e $C_{2}$, em $G(\pi)$.

Se $\rho$ é uma reversão que intercala obstáculos em $H(\pi)$, então $\pi_{i}$ e $\pi_{j}$ são extremos de vértices em componentes distintas em $H(\pi)$. Segue do Lema 3.6 que $C_{1}$ e $C_{2}$ são circuitos distintos. Como vimos na Seção 3.2.2, neste caso, $\Delta(b-c)=1$. Note também (veja Figura 3.2) que $\left(\pi_{i-1}, \pi_{j}\right) \mathrm{e}$ $\left(\pi_{i}, \pi_{j+1}\right)$ são arestas divergentes de um mesmo circuito em $G(\pi . \rho)$. Segue do Lema 3.6 que $\pi_{i}$ e $\pi_{j}$ são extremos de vértices em uma mesma componente, digamos $M^{\prime}$, em $H(\pi . \rho)$ e segue do Fato 3.3 que $M^{\prime}$ é uma componente boa.

Se $\rho$ é uma reversão que corta um obstáculo $K$ em $H(\pi)$, então $\left(\pi_{i}, \pi_{j}\right)$ é vértice de $K$ e, sendo $\left(\pi_{i-1}, \pi_{i}\right)$ e $\left(\pi_{j}, \pi_{j+1}\right)$ arestas vermelhas dos circuitos $C_{1}$ e $C_{2}$ em $G(\pi), C_{1}=C_{2}$. Como vimos na Seção 3.2.2, neste caso, $\Delta(b-c)=0$. Sendo que $K$ é uma componente má, existe um vértice $p \in P_{\pi}^{-}$, tal que $p \bowtie\left(\pi_{i}, \pi_{j}\right)$ em $\pi$. Sendo $\rho=(i . . j)$, segue que $p \in P_{\pi . \rho}^{+}$e que $p \bowtie\left(\pi_{i}, \pi_{j}\right)$ também em $\pi . \rho$. Para $M^{\prime}$ uma componente em $H(\pi . \rho)$ que contém o vértice $\left(\pi_{i}, \pi_{j}\right)$, segue do Fato 3.3 que $M^{\prime}$ é uma componente boa.

Portanto, tanto o caso de $(i . . j)$ ser uma reversão que intercala obstáculos quanto ser uma reversão que corta obstáculos, temos que $\pi_{i}$ e $\pi_{j}$ são extremos de vértices em uma mesma componente boa $M^{\prime}$ em $H(\pi .(i . . j))$.

Como $\rho$ cruza o $\operatorname{arco} x$ e cruza o $\operatorname{arco} \bar{x}_{\pi}$ em $\pi$, temos que $y$ e $z$ são $\operatorname{arcos}$ de $\pi . \rho$.

Desde que todo elemento de $\pi . \rho$ é ou $\pi_{i}$ ou $\pi_{j}$ ou elemento de $z$ ou elemento de $y$ e, $\pi_{i}$ e $\pi_{j}$ são extremos de vértices em uma mesma componente boa $M^{\prime}$, cada extremo de um vértice de uma componente má $M$ em $H(\pi . \rho)$ ou é elemento de $z$ ou é elemento de $y$.

Por outro lado, sendo $\pi_{i}$ e $\pi_{j}$ extremos de vértices da componente boa $M^{\prime}$ em $H(\pi . \rho)$, segue, como conseqüência do Lema 3.2, que não existe componente $X \neq M^{\prime}$ em $H(\pi . \rho)$ que possua um vértice com um de seus extremos em $y$ e um vértice com um de seus extremos em $z$. Como $M^{\prime}$ é uma componente boa, sendo $M$ uma componente má em $H(\pi . \rho)$, temos que $M \neq M^{\prime}$. Segue que ou $M \in C M(y)$ ou $M \in C M(z)$.

Lema 3.28 Se $h(\pi)=2$ e $\rho$ é uma reversão que intercala os obstáculos em $H(\pi)$, então

$$
\Delta(b-c+h+f)=-1 .
$$

Além disso, $H(\pi . \rho)$ é isento de obstáculos.

Prova. Considere $M_{1}$ e $M_{2}$ obstáculos em $H(\pi)$ e $\rho=(i . . j)$. Mostramos, primeiramente, que $H(\pi . \rho)$ é isento de obstáculos. 
Suponha, por contradição, que existe um obstáculo $M \operatorname{em~} H(\pi . \rho)$. Seja $x$ um arco definido por $\pi_{i}$ e $\pi_{j}$ e $y=x-\pi_{i}-\pi_{j}$ e $z=\bar{x}_{\pi . \rho}-\pi_{i}-\pi_{j}$. Segue do Lema 3.27 que ou $M \in C M(y)$ ou $M \in C M(z)$.

Se $M \in C M(y)$, então $C M(y) \neq \emptyset$. Como $y$ também é arco de $\pi$, segue do Lema 3.9 que existe pelo menos um obstáculo $M^{\prime}$ em $H(\pi)$, tal que $M^{\prime} \in C M(y)$. Como ou $\pi_{i}$ é extremo de um vértice de $M_{1}$ e $\pi_{j}$ é extremo de um vértice de $M_{2}$ ou vice-versa e como $y$ não contém nem $\pi_{i}$ e nem $\pi_{j}$, segue que $M^{\prime} \neq M_{1}$ e $M^{\prime} \neq M_{2}$, contrariando a hipótese de $h(\pi)=2$.

Para $M \in C M(z)$, por raciocínio análogo, segue a mesma contradição da hipótese.

Portanto, $H(\pi . \rho)$ é isento de obstáculos. Segue que $h(\pi . \rho)=0$. Como $h(\pi)$ e $h(\pi . \rho)$ são pares, segue que $f(\pi)=f(\pi . \rho)=0$. Por outro lado, segue do Lema 3.27 que $\Delta(b-c)=1$. Concluímos, então, que $\Delta(b-c+h+f)=-1$.

Lema 3.29 Seja $\left(M_{1}, \ldots, M_{h(\pi) \geq 4}\right)$ uma lista obstáculo-consecutiva em $H(\pi)$. Se $\rho=(i . . j)$ é uma reversão que intercala os obstáculos $M_{1}$ e $M_{3}$, então

$$
\Delta h=-2 .
$$

Prova. Considere um arco $x$ de $\pi$ definido por $\pi_{i}$ e $\pi_{j}, y=x-\pi_{i}-\pi_{j}$ e $z=\bar{x}_{\pi}-\pi_{i}-\pi_{j}$.

Seja $x_{k}, k \neq 1, k \neq 3$, um arco de $\pi$ que define o obstáculo $M_{k}$. Como $\rho=(i . . j)$ é uma reversão que intercala os obstáculos $M_{1}$ e $M_{3}$, sendo que os arcos que definem obstáculos em $H(\pi)$ são disjuntos, segue que nem $\pi_{i}$ e nem $\pi_{j}$ são elementos de $x_{k}$. Segue que ou $x_{k} \prec z$ ou $x_{k} \prec y$. Sendo $z$ e $y$ arcos de $\pi . \rho$, segue que $x_{k}$ também é arco de $\pi . \rho$ o que implica que $M_{k}$ é um obstáculo em $H(\pi . \rho)$.

Por outro lado, como nem $\pi_{i}$ e nem $\pi_{j}$ é elemento nem de $y$ e nem de $z$, segue que nem $M_{1}$ nem $M_{3}$ é elemento nem de $C M(z)$ nem de $C M(y)$. Segue do Lema 3.27 que nem $M_{1}$ nem $M_{3}$ é obstáculo em $H(\pi . \rho)$.

Mostramos a seguir que todo obstáculo em $H(\pi . \rho)$ é um obstáculo em $H(\pi)$.

Seja $K$ um obstáculo em $H(\pi . \rho)$. Pelo Lema 3.27, temos que ou $K \in C M(y)$ ou $K \in C M(z)$.

Sem perda de generalidade, supomos $K \in C M(y)$. Seja $w=\left(\pi_{l_{1}}, \ldots, \pi_{l_{2}}\right)$ o arco de $\pi . \rho$ que define $K$. Sendo $\pi_{l_{1}}$ e $\pi_{l_{2}}$ elementos de $y$, temos que ou $w \prec y$ ou $\bar{y}_{\pi . \rho} \prec w$.

Para $w \prec y$, sendo $y$ arco de $\pi$, temos que $w$ é também arco de $\pi$ o que implica que $K$ também é um obstáculo em $H(\pi)$.

Para $\bar{y}_{\pi . \rho} \prec w$, sendo $z$ e $y$ arcos disjuntos em $H(\pi . \rho)$ e, conseqüentemente, $z \prec \bar{y}_{\pi . \rho}$, temos que $z \prec w$. Segue que $C M(z) \subseteq C M(w)$. Por outro lado, como $(i . . j)$ intercala obstáculos não-consecutivos temos, pelo Fato 3.26, que $C M(z) \neq \emptyset$. Segue que $C M(z)=C M(w)=\{K\}$, um absurdo pois, sendo $z$ e $y$ disjuntos, temos que $C M(z) \cap C M(y)=\emptyset$.

Concluímos que se $K$ é obstáculo em $H(\pi . \rho)$, então $K$ é obstáculo em $H(\pi)$, ou seja, todo obstáculo em $H(\pi . \rho)$ é um obstáculo em $H(\pi)$. Como $M_{1}$ e $M_{3}$ são obstáculos em $H(\pi)$ mas não são obstáculos em $H(\pi . \rho)$ e todo obstáculo $M_{k}, M_{k} \neq M_{1}, M_{k} \neq M_{3}$, em $H(\pi)$ é um obstáculo em $H(\pi . \rho)$, segue que $\Delta h=-2$.

Lema 3.30 Seja $\pi$ uma fortaleza e $h(\pi)=3$. Se $\rho=(i . . j)$ é uma reversão que intercala obstáculos em $H(\pi)$, então

$$
\Delta h=-1
$$


Prova. Sejam $M_{1}, M_{2}, M_{3}$ obstáculos em $H(\pi)$ e suponha. sem perda de generlidade, que $\rho$ intercala os obstáculos $M_{1}$ e $M_{2}$.

Considere um arco $x$ de $\pi$ definido por $\pi_{i}$ e $\pi_{j}, y=x-\pi_{i}-\pi_{j}$ e $z=\bar{x}_{\pi}-\pi_{i}-\pi_{j}$.

Como nem $\pi_{i}$ e nem $\pi_{j}$ é elemento nem de $y$ e nem de $z$, segue que nem $M_{1}$ nem $M_{2}$ é elemento nem de $C M(z)$ e nem de $C M(y)$. Segue do Lema 3.27 que nem $M_{1}$ e nem $M_{2}$ é obstáculo em $H(\pi . \rho)$.

Seja $x_{3}=\left(\pi_{k}, \ldots, \pi_{l}\right)$ o arco de $\pi$ que define o obstáculo $M_{3}$. Como $\rho=(i . . j)$ é uma reversão que intercala os obstáculos $M_{1}$ e $M_{2}$, sendo que os arcos que definem obstáculos em $H(\pi)$ são disjuntos, segue que nem $\pi_{i}$ e nem $\pi_{j}$ são elementos de $x_{3}$. Segue que ou $x_{3} \prec z$ ou $x_{3} \prec y$. Sendo $z$ e $y$ arcos de $\pi . \rho$, segue que $x_{3}$ também é arco de $\pi . \rho$ o que implica que $M_{3}$ é um obstáculo em $H(\pi . \rho)$.

Seja $x_{3}^{\prime}$ o arco que define a proteção do obstáculo $M_{3}$ sobre algum não-obstáculo $K$. Por análise análoga àquela feita para o arco $x_{3}$, segue que $x_{3}^{\prime}$ também é arco de $\pi . \rho$, o que implica que $K$ também é componente má em $H(\pi . \rho)$. Como $x_{3}$ define $M_{3} \neq K, K \in C M\left(\left(\bar{x}_{3}\right)_{\pi . \rho}-\pi_{k}-\pi_{l}\right)$. Segue do Lema 3.9 que existe pelo menos um elemento em $C M\left(\left(\bar{x}_{3}\right)_{\pi . \rho}-\pi_{k}-\pi_{l}\right)$ que é obstáculo em $H(\pi . \rho)$, digamos $Q$. Como $C M\left(\left(\bar{x}_{3}\right)_{\pi . \rho}-\pi_{k}-\pi_{l}\right) \cap C M\left(x_{3}\right)=\emptyset$, segue que $Q \neq M_{3}$. Sendo que $M_{1}$ e $M_{2}$ não são obstáculos em $H(\pi . \rho)$, segue que $Q$ não é obstáculo em $H(\pi)$ o que implica que existe pelo menos um obstáculo em $H(\pi . \rho)$ que não é obstáculo em $H(\pi)$.

Pelo Lema 3.27, ou $Q \in C M(y)$ ou $Q \in C M(z)$. Suponha, sem perda de generalidade, que $Q \in C M(y)$. Sendo $x_{q}$ o arco que define $Q$ em $\pi . \rho$, segue que ou $x_{q} \prec y$ ou $\bar{y}_{\pi . \rho} \prec x_{q}$. Mas $x_{q} \prec y$, implica que $x_{q}$ é arco de $\pi$ e, sendo $C M\left(x_{q}\right)=\{Q\}$, temos uma contradição com o fato de $Q$ não é obstáculo em $H(\pi)$. Logo, temos que $\bar{y}_{\pi . \rho} \prec x_{q}$ o que implica que $\pi_{i}$ e $\pi_{j}$ são elementos de $x_{q}$. Desde que os arcos que definem obstáculos são disjuntos e, para todo obstáculo $Q \neq M_{3}$ em $H(\pi . \rho), \pi_{i}$ e $\pi_{j}$ são elementos do arco que define $Q$, deduzimos que existe no máximo 1 obstáculo em $H(\pi . \rho)$ que não é obstáculo em $H(\pi)$.

Portanto, sendo $M_{3}$ obstáculo em $H(\pi . \rho)$ e $M_{1}$ e $M_{2}$ não são obstáculos em $H(\pi . \rho)$ e existe exatamente um obstáculo em $H(\pi . \rho)$ que não é obstáculo em $H(\pi)$, segue que $\Delta h=-1$.

Lema 3.31 Se $\rho=(i . . j)$ corta um obstáculo simples em $H(\pi)$, então

$$
\Delta h=-1
$$

Prova. Sejam $M_{1}, \ldots, M_{h(\pi)}$ obstáculos em $H(\pi)$ e suponha, sem perda de generalidade, que $\rho$ corta o obstáculo simples $M_{h(\pi)}$.

Considere um arco $x$ de $\pi$ definido por $\pi_{i}$ e $\pi_{j}, y=x-\pi_{i}-\pi_{j}$ e $z=\bar{x}_{\pi}-\pi_{i}-\pi_{j}$.

Sendo que $\pi_{i}$ nem é elemento de $y$ e nem elemento de $z$ e $\pi_{i}$ é extremo de um vértice de $M_{h(\pi)}$, segue do Lema 3.27 que $M_{h(\pi)}$ não é obstáculo em $H(\pi . \rho)$.

Seja $w_{k}$ o arco de $\pi$ que define o obstáculo $M_{k}, 1 \leq k \leq h(\pi)-1$. Como os arcos de $\pi$ que definem obstáculos são disjuntos e $\pi_{i}$ e $\pi_{j}$ são extremos de vértices de $M_{h(\pi)}$, temos que nem $\pi_{i}$ e nem $\pi_{j}$ são elementos de $w_{k}$. Logo, ou $w_{k} \prec y$ ou $w_{k} \prec z$. Segue, sendo $y$ e $z$ arcos de $\pi . \rho$, que $w_{k}$ também é arco de $\pi . \rho$ o que implica que $M_{k}$ também é obstáculo em $H(\pi . \rho)$.

Mostramos a seguir que todo obstáculo em $H(\pi . \rho)$ é um obstáculo em $H(\pi)$. Para verificar esse fato, suponha, por contradição, que existe um obstáculo $K \mathrm{em} H(\pi . \rho)$ que não é obstáculo em $H(\pi)$. 
Pelo Lema 3.27, ou $K \in C M(y)$ ou $K \in C M(z)$. Sem perda de generalidade, suponha $K \in C M(y)$. Seja $w^{\prime}=\left(\pi_{l_{1}}, \ldots, \pi_{l_{2}}\right)$ arco de $\pi . \rho$, tal que $w^{\prime}$ define $K$. Sendo que nem $\pi_{l_{1}} \mathrm{e}$ nem $\pi_{l_{2}}$ são elementos de $z$, temos que ou $w^{\prime} \prec y$ ou $\bar{y}_{\pi . \rho} \prec w^{\prime}$.

Se $w^{\prime} \prec y$, sendo $y$ arco de $\pi$, então $w^{\prime}$ é arco de $\pi$ e, sendo $C M\left(w^{\prime}\right)=\{K\}$, segue uma contradição da hipótese de $K$ não é obstáculo em $H(\pi)$. Assumiremos, então, $\bar{y}_{\pi . \rho} \prec w^{\prime}$. Isto implica $\bar{w}_{\pi . \rho}^{\prime} \prec y$.

Seja $v=\bar{w}_{\pi . \rho}^{\prime}$. Sendo $M_{k}, 1 \leq k \leq h(\pi)-1$, obstáculo em $H(\pi . \rho) . M_{k} \in C M\left(v-\pi_{l_{1}}-\pi_{l_{2}}\right)$.

Sendo $v \prec y$ e $y$ arco de $\pi$, temos que $v$ também é arco de $\pi$. Como todo extremo de todo vértice de $K$ não é elemento de $v-\pi_{l_{1}}-\pi_{l_{2}}$ então $K \in C M\left(\bar{v}_{\pi}\right)$ e, portanto, $C M\left(\bar{v}_{\pi}\right) \neq \emptyset$. Segue do Lema 3.9 que existe um elemento de $C M\left(\bar{v}_{\pi}\right)$ que é um obstáculo. Segue que $M_{h(\pi)}$ é o único obstáculo em $C M\left(\bar{v}_{\pi}\right)$. Como o não-obstáculo $K$ também pertence a $C M\left(\bar{v}_{\pi}\right)$, temos que $\left|C M\left(\bar{v}_{\pi}\right)\right| \geq 2$, contrariando o Lema 3.11 , desde que, por hipótese, $M_{h(\pi)}$ é um obstáculo simples.

Desde que $M_{h(\pi)}$ não é um obstáculo em $H(\pi . \rho)$ e $M_{1} \ldots M_{h(\pi)-1}$ são obstáculos em $H(\pi . \rho)$ e todo obstáculo em $H(\pi . \rho)$ é um obstáculo em $H(\pi)$, temos que $\Delta h=-1$.

Teorema 3.32 Para $\pi$ uma permutação, existe uma seqüência de $\lceil h(\pi) / 2\rceil$ reversões seguras que eliminam obstáculos em $H(\pi)$.

Prova. Considere $\mathcal{L}=\left(M_{1}, \ldots, M_{h(\pi)}\right)$ uma lista obstáculo-consecutiva de $H(\pi)$.

Para $f(\pi)=0$ e $h(\pi)$ ímpar, escolhemos em $\mathcal{L}$ um obstáculo simples $M$ e determinamos uma reversão $\rho$ que corta o obstáculo $M$. Segue do Lema 3.31 que $\Delta h=-1$ implicando que $h(\pi . \rho)$ é par e, conseqüentemente, $f(\pi . \rho)=0$. Como, pelo Lema 3.27, $\Delta(b-c)=0$, segue que $\Delta(b-c+h+f)=-1$.

Para $h(\pi) \geq 4$ par, temos que, $f(\pi)=0$. Neste caso, escolhemos os obstáculos nãoconsecutivos $M_{1}$ e $M_{3}$ em $\mathcal{L}$ e determinamos uma reversão que intercala $M_{1}$ e $M_{3}$. Segue do Lema 3.29 que $\Delta h=-2$ implicando que $h(\pi . \rho)$ é par e, conseqüentemente, $f(\pi . \rho)=0$. Como, pelo Lema 3.27, $\Delta(b-c)=1$, segue que $\Delta(b-c+h+f)=-1$.

Para $h(\pi)=2$, temos que $f(\pi)=0$. Determinamos uma reversão $\rho$ que intercala os elementos de $\mathcal{L}$. Segue que $h(\pi . \rho)=0$ e que $\Delta(b-c+h+f)=-1$ (Lema 3.28).

Do exposto até aqui, segue que, para $f(\pi)=0$, podemos determinar ou

$$
1+\frac{h(\pi)-1}{2}-1+1=\frac{h(\pi)+1}{2}=\left\lceil\frac{h(\pi)}{2}\right\rceil
$$

ou

$$
\frac{h(\pi)}{2}-1+1=\frac{h(\pi)}{2}=\left\lceil\frac{h(\pi)}{2}\right\rceil
$$

reversões seguras para ou $h(\pi)$ ímpar ou $h(\pi)$ par, respectivamente. Essa seqüência de reversões aplicadas a $\pi$ transformam $\pi$ na permutação $\pi^{\prime}$ tal que $h\left(\pi^{\prime}\right)=0$.

Para $f(\pi)=1$ e $h(\pi) \geq 5$ ímpar, escolhemos em $\mathcal{L}$ os dois obstáculos não-consecutivos $M_{1}$ e $M_{3}$ e determinamos a reversão $\rho$ tal que $\rho$ intercala $M_{1}$ e $M_{3}$. Segue do Lema 3.29 que $\Delta h=-2$ implicando, como o Lema 3.27 garante que, neste caso, $\Delta(b-c)=1$, que $\Delta(b-c+h)=-1$. Sendo $f(\pi . \rho) \leq 1$, segue que $\Delta f \leq 0$ e, portanto, $\Delta(b-c+h+f) \leq-1$. Como, pelo Teorema 3.12, $\Delta(b-c+h+f) \geq-1$, concluímos que $\Delta(b-c+h+f)=-1$. 
Para $f(\pi)=1$ e $h(\pi)=3$, escolhemos em $\mathcal{L}$ dois obstáculos $M$ e $K$ e determinamos uma reversão $\rho$ tal que $\rho$ intercala $M$ e $K$. Segue do Lema 3.30 que $\Delta h=-1$ e, sendo $h(\pi . \rho)=2$, que $f(\pi . \rho)=0$. Como, pelo Lema 3.27, $\Delta(b-c)=1$, segue que $\Delta(b-c+h+f)=-1$.

Do exposto até aqui, segue que, para $f(\pi)=1$, sendo $h(\pi)$ ímpar, determinamos

$$
\frac{h(\pi)-1}{2}-1+1+1=\frac{h(\pi)+1}{2}=\left\lceil\frac{h(\pi)}{2}\right\rceil
$$

reversões seguras, que aplicadas a $\pi$ transformam $\pi$ na permutação $\pi^{\prime}$ tal que $h\left(\pi^{\prime}\right)=0$.

A prova do Teorema 3.32 é uma descrição de um procedimento que encontra uma seqüência de reversões seguras que eliminam obstáculos de $H(\pi)$.

Kaplan, Shamir e Tarjan [KST97] mostraram como encontrar uma seqüência de $\lceil h(\pi) / 2\rceil$ reversões seguras que eliminam os obstáculos em $H(\pi)$ em tempo $O(n)$.

Mostramos a seguir como podemos executar esta tarefa em tempo a $O(n d)$, onde $d=d(\pi)$, a partir do retrato $\pi$ de uma permutação orientada. (Felizmente, isto não interfere na complexidade total do Algoritmo SBR-Orienta já que encontrar uma seqüência de reversões que ordenam uma permutação $\pi$ tal que $h(\pi)=0$, como segue na próxima seção, também é $O(n d)$.) Para isto, vejamos como podemos determinar uma reversão segura em tempo $O(n)$.

Primeiramente, vejamos como determinar a lista $\mathcal{L}$ e os valores de $h(\pi)$ e $f(\pi)$.

Determinamos os conjuntos de vértices $K_{1}, K_{2}, \ldots, K_{x}$ que correspondem às componentes de $H(\pi)$ e a permutação $\pi^{-1}$. Na Seção 3.4.1 vimos que este passo pode ser executado em tempo $O(n)$.

Em seguida, removemos os conjuntos, entre $K_{1}, K_{2}, \ldots, K_{x}$, que não representam uma componente má, isto é, removemos cada conjunto $K_{j}$ tal que ou $\left|K_{j}\right|=1$ (vértice isolado) ou existe um vértice $\left(\pi_{i}, \pi_{u(i)}\right)$ em $K_{j}$, tal que $i$ e $u(i)$ são ou ambos pares ou ambos ímpares (componentes boas). (Note que $i$ e $u(i)$ são os valores de $\pi_{\pi_{i}}^{-1}$ e $\pi_{\pi_{u(i)}}^{-1}$, respectivamente). Note que tanto para decidir se uma componente é um vértice isolado quanto verificar se um vértice de $H(\pi)$ é ou preto ou cinza gasta tempo constante. Como o número de vértices de $H(\pi)$ é proporcional a $n$, segue que determinar os conjuntos correspondentes às componentes más em $H(\pi)$, a partir dos conjuntos correspondentes a todas as componentes em $H(\pi)$ e da permutação $\pi^{-1}$, gasta tempo $O(n)$.

Considere, então, $\left\{K_{1}^{\prime}, K_{2}^{\prime}, \ldots, K_{t}^{\prime}\right\}$ os conjuntos de vértices que correspondem às componentes más em $H(\pi)$. Definimos uma função

$$
c p:\{0,1, \ldots, 2 n+1\} \rightarrow\left\{K_{1}^{\prime}, \ldots, K_{t}^{\prime}\right\},
$$

tal que se $\pi_{i}$ é extremo de uma componente má $K_{j}^{\prime}$ em $H(\pi)$, então $c p(i)=K_{j}^{\prime}$. Se $\pi_{i}$ não é extremo de um vértice de uma componente má em $H(\pi)$, então $c p(i)=\emptyset$. Para construir a função $c p$, fazemos primeiramente $c p(i)=\emptyset$, para $0 \leq i \leq 2 n+1$, e em seguida, para cada vértice $\left(\pi_{i}, \pi_{u(i)}\right)$ de cada componente má $K_{j}^{\prime}$, fazemos $c p(i)=c p(u(i))=K_{j}^{\prime}$. Note que, cada uma das operações aqui descritas gasta tempo constante. Sendo que no máximo $4 n+4$ operações são executadas, a definição da função $c p$ também gasta tempo $O(n)$.

Percorrendo a função $c p$ a partir de $c p(0)$ não mais do que duas vezes podemos determinar os obstáculos de $H(\pi)$ detectando os arcos de $\pi$ que definem os mesmos. Uma lista inicialmente 
vazia $\mathcal{L}$ é criada e a medida em que descobrimos novos obstáculos em $H(\pi)$ os mesmos são inseridos no final da lista $\mathcal{L}$. Após determinarmos todos os obstáculos em $H(\pi), \mathcal{L}$ é uma lista obstáculo-consecutiva. De modo similar, percorrendo novamente a função $c p$ não mais do que duas vezes podemos determinar se cada obstáculo em $H(\pi)$ é ou um obstáculo simples ou um super-obstáculo. Conhecendo a lista $\mathcal{L}$ e sabendo se todos os obstáculos em $H(\pi)$ são superobstáculos, determinamos os valores de $h(\pi)$ e de $f(\pi)$. Novamente, o tempo gasto nessa fase é $O(n)$.

Vejamos a seguir como determinar uma reversão segura.

Note que, baseado nos valores de $h(\pi)$ e de $f(\pi)$, podemos determinar os obstáculos a serem intercalados ou o obstáculo a ser cortado percorrendo a lista $\mathcal{L}$, cujo tamanho não é maior que $n$, uma única vez. Feito isto, com o auxílio da permutação $\pi^{-1}$ podemos determinar a reversão segura necessária em tempo constante. (Vejamos, por exemplo, se buscamos uma reversão que intercala os obstáculos $M$ e $K$ em $H(\pi)$, escolha um extremo de um vértice qualquer de $M$, digamos $\pi_{m}$, e um extremo de um vértice qualquer de $K$, digamos $\pi_{k}$. Verificamos se $m\left(=\pi_{\pi_{m}}^{-1}\right)$ é ou par ou ímpar. Suponha que $m$ é par. Então $\pi_{m+1}$ é o extremo de um vértice de $M$ e $m+1$ é ímpar. De maneira análoga, verificamos a paridade de $k\left(=\pi_{\pi_{k}}^{-1}\right)$. Suponha que $k$ seja ímpar. Então, $\pi_{k-1}$ é extremo de um vértice de $K$ e $k-1$ é ímpar. Verificamos, então, se ou $k<m$ ou $k>m$. No exemplo, suponha que $k<m$. Uma reversão segura que intercala os obstáculos $M$ e $K$ é $(k . . m)$.

Da discussão acima, enunciamos o seguinte resultado.

Teorema 3.33 Eliminar obstáculos em $H(\pi)$ gasta tempo $O(n d)$, onde $d=d(\pi)$.

\subsubsection{Eliminando Componentes Boas}

Esta seção é fortemente baseada no trabalho de Kaplan, Shamir e Tarjan [KST97]. Nela, mostramos um procedimento que recebe uma permutação $\pi$ tal que $h(\pi)=0$, e devolve uma reversão segura $\rho$ tal que $h(\pi . \rho)=0$. Esse procedimento pode ser usado para encontrar uma reversão segura para a permutação $\pi . \rho$ e, assim, sucessivamente $d(\pi)$ vezes, determinar uma seqüência de reversões seguras que ordenam a permutação $\pi$.

Primeiramente, introduzimos algumas notações. Seja $p$ um vértice de $H(\pi)$. Denotamos por $A_{\pi}(p)$ o conjunto de vértices adjacentes a $p$ incluindo o próprio $p$, por $A_{\pi}^{+}(p)$ o subconjunto de vértices de $A_{\pi}(p)$ que contém todos os vértices pretos e por $A_{\pi}^{-}(p)$ o subconjunto de vértices de $A_{\pi}(p)$ que contém todos os vértices cinzas. Se $p=\left(\pi_{i}, \pi_{u(i)}\right)$ é um vértice preto, denotamos por $r(p)$ a reversão tal que $p$ é um vértice isolado em $H(\pi \cdot r(p))$. Note que, para $i<u(i)$, se $i$ é ímpar, então $r(p)=(i . . u(i)-1)$, e se $i$ é par, então $r(p)=(i+1 . . u(i))$. Além disso, para $\pi$ uma permutação e $r(p)$ uma reversão, temos que $\Delta(b-c)=-1$ (Seção 3.2.2), o que implica, caso $h(\pi)=h(\pi \cdot r(p))=0$, que $r(p)$ é uma reversão segura.

Para $p$ um vértice preto de $H(\pi)$, observe que o grafo $H(\pi . r(p))$ pode ser obtido através das seguintes operações.

- para todo par de elementos $x$ e $y$ de $A_{\pi}(p)$, se $(x, y)$ é aresta em $H(\pi)$, então removemos a aresta $(x, y)$, e se $(x, y)$ não é aresta em $H(\pi)$, então acrescentamos a aresta ao grafo $H(\pi \cdot r(p))$; 
- para todo elemento $x$ de $A_{\pi}(p)$, trocamos a cor de $x$, isto é. se $x$ é preto em $H(\pi)$, então atribuímos a cor cinza a $x$ em $H(\pi . r(p))$ e vice-versa.

Note que, se $M$ é uma componente de $H(\pi)$ que não contém o vértice $p$, então $M$ é uma componente em $H(\pi \cdot r(p))$. Por outro lado, se $p$ é um vértice preto da componente $M$ em $H(\pi)$, os vértices de $M$ são vértices de duas ou mais componentes em $H(\pi \cdot r(p))$. Denotamos por $M_{1}^{\prime}(p), \ldots, M_{k}^{\prime}(p)$, onde $k \geq 0$, os conjuntos de vértices das componentes que nem são vértices isolados de $H(\pi . r(p))$ e nem componentes em $H(\pi)$. Denotamos, simplesmente, por $M_{i}^{\prime}$ a componente $M_{i}^{\prime}(p)$, se $p$ estiver claro no contexto.

Seja $C$ o conjunto de vértices pretos que determinam um clique em $H(\pi)$. Dizemos que $C$ é um clique feliz se, para todo vértice preto $p \notin C$ e todo vértice (preto) $q \in C$, tal que $(p, q)$ é aresta em $H(\pi)$, existe um vértice preto $g \notin C$, tal que $(g, p)$ é uma aresta mas $(g, q)$ não é uma aresta em $H(\pi)$.

Teorema 3.34 [KST97] Sejam $C$ o conjunto de vértices pretos que determinam um clique feliz em um grafo isento de obstáculos $H(\pi)$ e $p \in C$, tal que $\left|A_{\pi}^{-}(p)\right| \geq\left|A_{\pi}^{-}(q)\right|$, para todo $q \in C$. Então, $h(\pi \cdot r(p))=0$.

Prova. Seja $M$ a componente em $H(\pi)$ que contém o vértice $p$.

Sendo $p$ vértice de $M$, desde que, para toda componente $M^{\prime} \neq M, M^{\prime}$ é componente em $H(\pi . \rho)$, para mostrar que $h(\pi . r(p))=0$ basta mostrar que, para todo $M_{i}^{\prime}(p), 1 \leq i \leq k, M_{i}^{\prime}$ corresponde a uma componente boa em $H(\pi . r(p))$.

Suponha, por contradição, que $M_{i}^{\prime}$ é o conjunto que representa uma componente má, para algum $i, 1 \leq i \leq k$. Observando que pelo menos um elemento de $C$ é vértice $M_{i}^{\prime}$, temos que $A_{\pi}(p) \cap M_{i}^{\prime} \neq \emptyset$.

Suponha que existe $y \in A_{\pi}(p) \cap M_{i}^{\prime}$, tal que $y \notin C$. Sendo $(y, p)$ aresta em $H(\pi)$, desde que $y$ é vértice cinza em $H(\pi \cdot r(p)), y$ é um vértice preto em $H(\pi)$, e desde que $C$ é o conjunto de vértices pretos que determinam um clique feliz em $H(\pi)$, existe um vértice preto $y^{\prime}$ adjacente a $y$, tal que $\left(y^{\prime}, p\right)$ não é aresta em $H(\pi)$. Segue que $y^{\prime}$ permanece preto e adjacente a $y \mathrm{em}$ $H(\pi . r(p))$, contrariando a hipótese de $M_{i}^{\prime}(p)$ ser o conjunto que representa uma componente má. Assumiremos, portanto, que $A_{\pi}(p) \cap M_{i}^{\prime} \subseteq C$.

Seja $y \in A_{\pi}(p) \cap M_{i}^{\prime}$ e seja $z \in A_{\pi}^{-}(p)$. O vértice $z$ é preto em $H(\pi . r(p))$ e, desde que $y \in M_{i}^{\prime}$, $(z, y)$ não pode ser aresta em $H(\pi \cdot r(p))$ o que implica que $z$ é adjacente a $y$ em $H(\pi)$. Segue que $A_{\pi}^{-}(p) \subseteq A_{\pi}^{-}(y)$. Como $M_{i}^{\prime}$ não é um vértice isolado, considere $x$ um vértice adjacente a $y$ em $M_{i}^{\prime}$. Desde que $A_{\pi}(p) \cap M_{i}^{\prime} \subseteq C$, e, observando que os vértices de $C$ são 2 -a-2 não-adjacentes em $H(\pi \cdot r(p))$, segue que o vértice $x$ não é adjacente a $p$ em $H(\pi)$. Portanto, segue que $(x, y)$ é aresta em $H(\pi)$, que $(x, p)$ não é aresta em $H(\pi)$, e que $x$ é cinza em $H(\pi)$. Desde que já provamos que $A_{\pi}^{-}(p) \subseteq A_{\pi}^{-}(y)$, isto implica que $A_{\pi}^{-}(p) \subset A_{\pi}^{-}(y)$, contrariando a escolha de $p$.

Teorema 3.35 [KST97] Seja $p$ um vértice preto de uma componente $M$ em $H(\pi)$. Existe um vértice $q \in A_{\pi}^{+}(p)$, tal que $M_{1}^{\prime}(q), \ldots, M_{k}^{\prime}(q)$ são todas componentes boas em $H(\pi . r(q))$.

Prova. Segue do Teorema 3.34 que é suficiente mostrar que existe $C \subseteq A_{\pi}^{+}(p)$ que corresponde aos vértices de um clique feliz em $H(\pi)$. 
Seja $\operatorname{Ext}(p)=\left\{x \in A_{\pi}^{+}(p) \mid\right.$ existe $y \in A_{\pi}^{+}(x)$, tal que $\left.y \notin A_{\pi}^{+}(p)\right\}$. Isto ć, $\operatorname{Ext}(p)$ contém todos os vértices pretos adjacentes a $p$ que têm vértices adjacentes não pertencentes a $A_{\pi}^{+}(p)$.

Caso 1: $\operatorname{Ext}(p)=A_{\pi}^{+}(p) \backslash\{p\}$. Neste caso, considere $C=\{p\}$.

Caso 2: $\operatorname{Ext}(p) \subset A_{\pi}^{+}(p) \backslash\{p\}$. Neste caso, seja $D^{0}=A_{\pi}^{+}(p) \backslash \operatorname{Ext}(p)$. Para $j \geq 0$, enquanto $D^{j}$ não é um clique, seja $K^{j}$ um clique maximal em $D^{j}$ e defina $D^{j+1}=D^{j} \backslash K^{j}$. Seja $D^{k}$, para algum $k \geq 0$, um clique. Considere $C=D^{k}$.

Observe que, em cada um dos dois casos, $C$, de fato, é um clique feliz.

Note que o grafo $H(\pi)$ possui $n+1$ vértices. Entretanto, o número de arestas de $H(\pi)$ pode ser não linear em $n$. Portanto, construir o grafo $H(\pi)$ pode gastar um tempo não-proporcional a $n$. A seguir, descrevemos como encontrar, dado uma permutação $\pi$ tal que $H(\pi)$ é isento de obstáculos, um vértice preto $p$ em $H(\pi)$ em tempo $O(n)$, tal que todas as componentes, que não são vértices isolados em $H(\pi . r(p))$, são componentes boas.

\section{Encontrando um Clique Feliz}

Vejamos como encontrar um clique feliz em $H(\pi)$.

Para $p=\left(\pi_{i}, \pi_{u(i)}\right), i<u(i)$, vértice em $H(\pi)$, definimos $L(p)=i$ e $R(p)=u(i)$. Considere $P=\left(p_{1}, \ldots, p_{k}\right)$ uma lista de todos os vértices pretos de $H(\pi)$, tal que $L\left(p_{1}\right)<\ldots<L\left(p_{k}\right)$. Esta lista pode ser construída em tempo proporcional a $n$ usando as permutações $\pi$ e $\pi^{-1}$.

Para encontrar um clique feliz percorremos a lista $P$. Após percorrer $p_{1}, \ldots, p_{i}$, o procedimento mantém uma lista de vértices $C_{i}=\left(p_{i_{1}}, \ldots, p_{i_{j}}\right), j \leq i$, que corresponde a um conjunto de vértices de um clique feliz no subgrafo induzido pelos vértices $p_{1}, \ldots, p_{i}$, e $i_{1}<i_{2}<\ldots<i_{j}$. Seja $t_{i} \notin C_{i}$ um elemento de $P$, tal que, para todo $p \in C_{i}, L\left(t_{i}\right)<L(p)<R(p)<R\left(t_{i}\right)$. Note que nem sempre existe um vértice $t_{i}$ que satisfaz as condições acima. Dizemos, neste caso, que $t_{i}$ é indefinido. O conjunto $C_{i}$ e o vértice $t_{i}$ (se existir) satisfazem o seguinte invariante.

Invariante 3.36 [KST97] Para todo vértice $p_{l} \notin C_{i}, l \leq i$,

- se $L\left(p_{i_{1}}\right)<L\left(p_{l}\right)$, então $p_{l}$ deve ser adjacente a $t_{i}$, isto é, $R\left(t_{i}\right)<R\left(p_{l}\right)$.

- se $L\left(p_{i_{1}}\right)>L\left(p_{l}\right)$ e $p_{l}$ é adjacente a um elemento de $C_{i}$, então $p_{l}$ ou é adjacente a um vértice preto $q$ tal que $R(q)<L\left(p_{i_{1}}\right)$ ou é adjacente a $t_{i}$.

O fato de que a lista $C_{i}$ corresponde aos vértices de um clique feliz no subgrafo induzido por $p_{1}, \ldots, p_{i}$ segue desse invariante. Inicializamos o procedimento fazendo $C_{1} \leftarrow\left(p_{1}\right)$. Inicialmente, $t_{i}$ é indefinido. Considere $p_{i+1}$ o vértice corrente. Se $R\left(p_{i_{j}}\right)<L\left(p_{i+1}\right)$, então $C_{i}$ corresponde a lista de vértices de um clique feliz em $H(\pi)$, desde que nenhum vértice $p_{i+1}, p_{i+2}, \ldots, p_{k}$ é adjacente a algum vértice em $C_{i}$. Portanto, o procedimento pára e devolve $C_{i}$.

Agora, assumiremos que $R\left(p_{i_{j}}\right)>L\left(p_{i+1}\right)$ e mostramos como obter $C_{i+1}$ e $t_{i+1}$. Devemos considerar os seguintes casos.

Caso 1. O vértice $t_{i}$ não é indefinido e $R\left(p_{i+1}\right)>R\left(t_{i}\right)$.

Neste caso, $C_{i+1} \leftarrow C_{i}$ e $t_{i+1} \leftarrow t_{i}$.

Caso 2. Ou vértice $t_{i}$ é indefinido ou $R\left(p_{i+1}\right)<R\left(t_{i}\right)$.

(a) $R\left(p_{i+1}\right)>R\left(p_{i_{j}}\right)$ e $L\left(p_{i+1}\right)<R\left(p_{i_{1}}\right)$.

Obtenha $C_{i+1}$ acrescentando $p_{i+1}$ ao final da lista $C_{i}$ e $t_{i+1} \leftarrow t_{i}$.

(b) $R\left(p_{i+1}\right)>R\left(p_{i_{j}}\right)$ e $L\left(p_{i+1}\right)>R\left(p_{i_{1}}\right)$. 
Neste caso, $C_{i+1} \leftarrow\left(p_{i+1}\right)$ e $t_{i+1} \leftarrow t_{i}$.

(c) $R\left(p_{i+1}\right)<R\left(p_{i_{j}}\right)$.

Neste caso, $C_{i+1} \leftarrow\left(p_{i+1}\right)$ e $t_{i+1} \leftarrow p_{i_{j}}$.

A seguir mostramos o seguinte resultado.

Teorema 3.37 [KST97] A lista $C=C_{i}$ que o procedimento acima devolve quando pára, corresponde a uma lista de vértices de um clique feliz em $H(\pi)$.

Prova. Por indução em $i$, verificamos que $C_{i}$ e $t_{i}$ satifazem Invariante 3.36 .

O procedimento pára ou quando $R\left(p_{i_{j}}\right)<L\left(p_{i+1}\right)$ ou quando $i=k$, onde $k$ é o número de vértices pretos em $H(\pi)$. Em ambos os casos, desde que $C_{i}$ corresponde aos vértices de um clique feliz induzidos por $p_{1}, p_{2}, \ldots, p_{i}, C_{i}$ deve corresponder aos vértices de um clique feliz em $H(\pi)$.

Procurando um vértice preto $p$ em $H(\pi)$, tal que $H(\pi \cdot r(p))$ é isento de obstáculos

Após determinarmos a lista $C$, que corresponde a uma lista de vértices de um clique feliz em $H(\pi)$, devemos procurar o elemento $p$ de $C$ que corresponde ao vértice que possue o maior número de vértices cinzas a ele adjacentes. Ou seja, procuramos o elemento $p$ de $C$, tal que, $r(p)$ é uma reversão segura (Seção 3.2.2) e $h(\pi . r(p))=0$ (Teorema 3.34). A seguir, mostramos como executar esta tarefa.

Considere agora $C=\left(p_{1}, \ldots, p_{j}\right)$. Como $L\left(p_{1}\right)<\ldots<L\left(p_{j}\right)$ e $C$ corresponde a lista de vértices de um clique, temos que $L\left(p_{1}\right)<\ldots<L\left(p_{j}\right)<R\left(p_{1}\right)<\ldots<R\left(p_{j}\right)$. Considere, então, os seguintes conjuntos disjuntos. $I_{0}=\left\{0,1, \ldots, L\left(p_{1}\right)\right\}, I_{l}=\left\{L\left(p_{l}\right)+1, \ldots, L\left(p_{l+1}\right)\right\}$, para $1 \leq l<j, I_{j}=\left\{L\left(p_{j}\right)+1, \ldots, R\left(p_{1}\right)\right\}, I_{l}=\left\{R\left(p_{l-j}\right)+1, \ldots, R\left(p_{l-j+1}\right)\right\}$, para $j<l<2 j$, e $I_{2 j}=\left\{R\left(p_{j}\right)+1, \ldots, 2 n+1\right\}$. O procedimento consiste nos seguintes três estágios.

Estágio 1: Determine a função intervalo : $\{0,1, \ldots, 2 n+1\} \rightarrow\{0,1, \ldots, 2 n+1\}$, tal que intervalo $(i)=j$, se $i \in I_{j}$.

Estágio 2: Determine a função $o:\{1, \ldots, j\} \rightarrow\{0,1, \ldots, 2 n+1\}$, tal que $\sum_{i=1}^{l} o(i)$ é o número de vértices cinzas adjacentes ao vértice preto $p_{i} \in C$. Para proceder essa tarefa, fazemos o seguinte. Inicialize cada $o(i)$ com zero. Para cada vértice cinza $q$ tal que ou $L\left(p_{1}\right)<L(q)$ ou $R(q)<R\left(p_{j}\right)$, alteramos no máximo quatro valores da imagem de $o$, como segue. Seja intervalo $(L(q))=l$ e intervalo $(R(q))=r$. Podemos assumir que $l<r$ desde que, para $l=r, q$ não é adjacente a qualquer elemento de $C$, podendo, então, ser ignorado. Verificamos qual dos casos a seguir ocorre.

Caso 1: $r \leq j$.

Os vértices $p_{l+1}, p_{l+2}, \ldots, p_{r}$ são adjacentes a $q$. Portanto, incrementamos $o(l+1)$ e decrementamos $o(r+1)($ se $r<j)$.

Caso 2: $l \geq j$.

Os vértices $p_{l-j+1}, p_{l-j+2}, \ldots, p_{r-j}$ são adjacentes a $q$. Portanto, incrementamos $o(l-j+1) \mathrm{e}$ decrementamos $o(r-j+1)$.

Caso 3: $l<j$ e $j<r$.

Seja $m=\min \{l, r-j\}$. Se $m>0$, então os vértices $p_{1}, p_{2}, \ldots, p_{m}$ são adjacentes a $q$ e, portanto, 
Algoritmo SBR-Orienta;
Entrada: O retrato $\pi$ de uma permutação orientada.
Saída: Uma seqüência de reversões $\rho_{1}, \ldots, \rho_{d(\pi)}$, tal que $\pi \cdot \rho_{1} \ldots \rho_{d(\pi)}=\iota$.

Determine uma seqüência de reversões seguras $\rho_{1}, \ldots, \rho_{\left\lceil\frac{h(\pi)}{2}\right\rceil}$, que eliminam obstáculos em $H(\pi)$;

Determine uma seqüência de reversões seguras $\rho_{\left\lceil\frac{h(\pi)}{2}\right\rceil+1}, \ldots, \rho_{d(\pi)}$ que ordenam a permutação $\pi \cdot \rho_{1} \ldots \ldots \rho_{\left\lceil\frac{h(\pi)}{2}\right\rceil}$;

Devolva $\rho_{1}, \ldots, \rho_{d(\pi)}$.

Figura 3.6: Algoritmo SBR-Orienta.

incrementamos $o(1)$ e decrementamos $o(m+1)$. De maneira análoga, seja $m^{\prime}=\max \{l, r-j\}$. Se $m^{\prime}<j$, então os vértices $p_{l+1}, p_{l+2}, \ldots, p_{j}$ são adjacentes a $q$ e, portanto, incrementamos $o(l+1)$.

Estágio 3: Compute $f=\max _{l}\left\{\sum_{i=1}^{l} o(i) \mid 1 \leq l \leq j\right\}$ e devolva $p_{f}$.

Teorema 3.38 [KST97] Dada uma lista $C=\left(p_{1}, p_{2}, \ldots, p_{j}\right)$ de vértices pretos do grafo $H(\pi)$, tal que $L\left(p_{1}\right)<L\left(p_{2}\right)<\ldots<L\left(p_{j}\right)$ e $\left\{p_{1}, p_{2}, \ldots, p_{j}\right\}$ corresponde ao conjunto de vértices em um clique feliz em $H(\pi)$, o procedimento acima devolve o vértice $p \in C$, tal que $p$ possui o maior número de vértices cinzas a ele adjacentes entre todos os vértices de $C$.

\subsubsection{Algoritmo SBR-Orienta}

A Figura 3.6 resume o algoritmo que ordena uma permutação orientada usando um número mínimo de reversões.

Pelos resultados referentes às complexidades dos algoritmos encontrados nesta Seção 3.4, segue o seguinte resultado.

Teorema 3.39 O Algoritmo SBR-Orienta encontra uma seqüência de reversões que ordenam uma permutação $\pi$ sobre $2 n$ em tempo $O(n r)$, onde $r=d(\pi)$.

Prova. Encontrar uma seqüência de reversões seguras que elimina obstáculos em $H(\pi)$ gasta tempo $O(n d)$ (Teorema 3.33). Encontrar uma seqüência de reversões seguras que ordenam uma permutação $\pi$ tal que $h(\pi)=0$, pode ser executado em tempo $O(n d)$, conforme discutido na Seção 3.4.3.

\subsection{Diâmetro de Reversões em Permutações Orientadas}

Nesta seção mostramos o resultado obtido por Meidanis, Walter e Dias [MWD97] determinando a distância máxima entre uma permutação orientada $\vec{\pi}$ e a permutação orientada identidade. 
Denotamos por

$$
\vec{S}_{n}=\{\text { permutações orientadas sobre }\{1,2, \ldots, n\}\} \text {. }
$$

Definimos o diâmetro por reversôes de permutações orientadas com $n$ elementos, $\vec{D}_{n}$, como

$$
\vec{D}_{n}=\max _{\vec{\pi} \in \vec{S}_{n}} d(\vec{\pi})
$$

Teorema 3.40 [MWD97] Para todo n,

$$
\vec{D}_{n}= \begin{cases}n & \text { se } n=1 \text { ou } n=3 \\ n+1 & \text { caso contrário. }\end{cases}
$$

Prova. A prova se baseia em 3 pontos.

Primeiramente, o valor $\vec{D}_{n}=n$ pode ser verificado por força bruta para os casos $n=1 \mathrm{e}$ $n=3$.

O segundo ponto a ser observado é que, para todo $n, \vec{D}_{n} \leq n+1$. Para verificar a veracidade dessa afirmação, note que segue do Lema 3.6 que, para $\vec{\pi}$ uma permutação sobre $n$ e $\pi$ o retrato de $\vec{\pi}$, sendo $M_{1}, M_{2}, \ldots, M_{k}$ componentes que não são vértices isolados em $H(\pi)$, podemos associar a cada $M_{i}$ o conjunto não-vazio

$$
C\left(M_{i}\right)=\left\{C \mid C \text { é um circuito em } G(\pi) \text { cujas arestas azuis são vértices em } M_{i}\right\},
$$

onde, para $i \neq j, C\left(M_{i}\right) \cap C\left(M_{j}\right)=\emptyset$.

Como $C\left(M_{i}\right)$ é não-vazio e $C\left(M_{i}\right) \cap C\left(M_{j}\right)=\emptyset$, temos que em $G(\pi)$ existem pelo menos $k$ circuitos, ou seja, $k \leq c(\pi)$. Como temos $k$ componentes que não são vértices isolados em $H(\pi)$, segue que $h(\pi) \leq k \leq c(\pi)$.

Se $f(\pi)=0$, como $h(\pi) \leq c(\pi)$, então $f(\pi)+h(\pi) \leq c(\pi)$.

Se $f(\pi)=1$, notando que pelo menos uma componente má é um não-obstáculo, então $h(\pi) \leq k-1$ o que implica que $f(\pi)+h(\pi)=1+h(\pi) \leq k \leq c(\pi)$. Logo, temos $f(\pi)+h(\pi) \leq c(\pi)$, independentemente de $\pi$ ser uma fortaleza.

Por outro lado, pelo Teorema 3.18, temos que $d(\vec{\pi})=b(\pi)-c(\pi)+h(\pi)+f(\pi)$. Sendo $f(\pi)+h(\pi) \leq c(\pi)$, segue que $d(\vec{\pi}) \leq b(\pi)$.

Observando que $b(\pi) \leq n+1$, temos que $d(\vec{\pi}) \leq n+1$. Como a afirmação vale para um $\vec{\pi}$ arbitrário, segue que $\vec{D}_{n} \leq n+1$.

Finalmente, o último ponto a ser observado é que, para $n \neq 1, n \neq 3$, existem permutações cuja distância por reversão é $n+1$. Mostraremos, a seguir, como construir uma tal permutação $\vec{\pi}$.

Para $n$ par, seja $\vec{\pi}^{n}$ uma permutação tal que, para $1 \leq i \leq n$,

$$
\vec{\pi}_{i}^{n}=\vec{a}, \text { onde } a= \begin{cases}i+1 & \text { se } i \text { é ímpar, } \\ i-1 & \text { se } i \text { é par. }\end{cases}
$$

A Figura 3.7 mostra exemplos do grafo $G\left(\vec{\pi}^{n}\right)$ para $n=2, n=4$ e $n=6$. Note que, sendo $\pi^{n}$ retrato de $\vec{\pi}^{n}$, todas as arestas azuis de $G\left(\pi^{n}\right)$ são arestas de um único circuito $\left(c\left(\pi^{n}\right)=1\right)$ e que são vértices de uma única componente $M$ em $H\left(\pi^{n}\right)$. Desde que todas as arestas vermelhas 
(a)

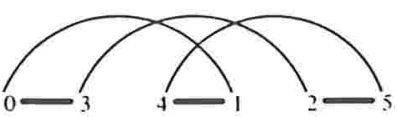

(b)

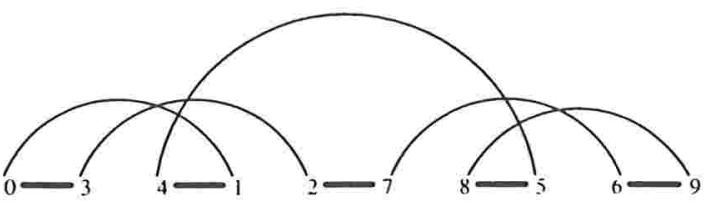

(c)

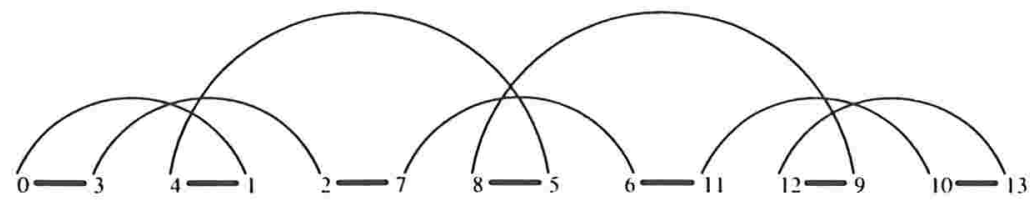

(d)
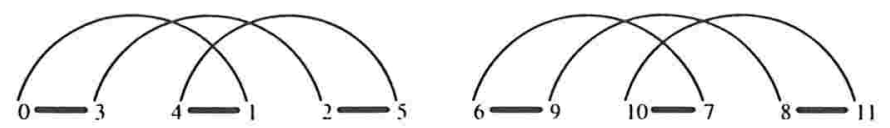

(e)
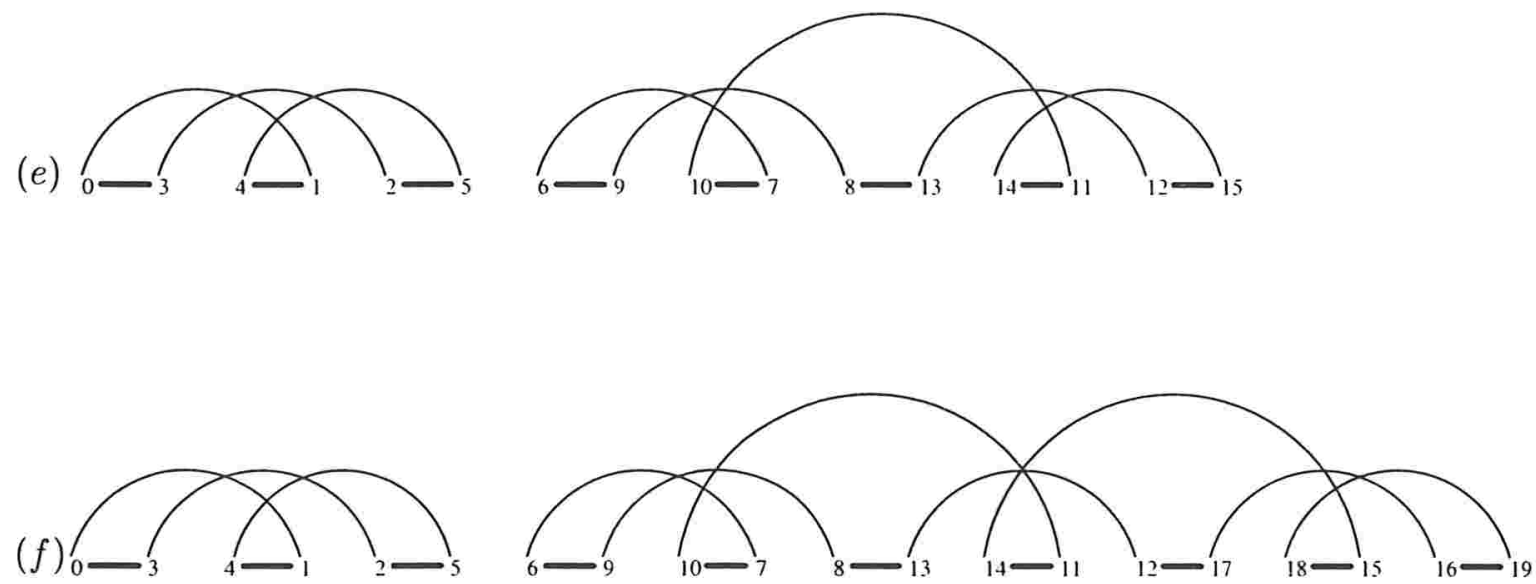

Figura 3.7: Grafo de Pontos de Quebra das permutações $(a) \vec{\pi}^{2}=\left(\begin{array}{ll}\overrightarrow{2} & \overrightarrow{1}\end{array}\right) ;(b) \vec{\pi}^{4}=\left(\begin{array}{llll}2 & \overrightarrow{1} & \overrightarrow{4} & \overrightarrow{3}\end{array}\right)$; (c) $\vec{\pi}^{6}=\left(\begin{array}{llllllll}2 & \overrightarrow{1} & \overrightarrow{4} & \overrightarrow{3} & \overrightarrow{6} & \overrightarrow{5}\end{array}\right) ;(d) \vec{\pi}^{5}=\left(\begin{array}{llllll}\overrightarrow{2} & \overrightarrow{1} & \overrightarrow{3} & \overrightarrow{5} & \overrightarrow{4}\end{array}\right) ;(e) \vec{\pi}^{7}=\left(\begin{array}{lllllll}\overrightarrow{2} & \overrightarrow{1} & \overrightarrow{3} & \overrightarrow{5} & \overrightarrow{4} & \overrightarrow{7} & \overrightarrow{6}\end{array}\right) ;(f)$ $\vec{\pi}^{9}=\left(\begin{array}{lllllllll}\overrightarrow{2} & \overrightarrow{1} & \overrightarrow{3} & \overrightarrow{5} & \overrightarrow{4} & \overrightarrow{7} & \overrightarrow{6} & \overrightarrow{9} & \overrightarrow{8}\end{array}\right)$. 
de $G\left(\pi^{n}\right)$ são convergentes, segue que $M$ é obstáculo e $h\left(\pi^{n}\right)=1$. Note também que $\pi^{n}$ possue $n+1$ pontos de quebra. Portanto,

$$
d\left(\vec{\pi}^{n}\right)=b\left(\pi^{n}\right)-c\left(\pi^{n}\right)+h\left(\pi^{n}\right)+f\left(\pi^{n}\right)=(n+1)-1+1+0=n+1 .
$$

Para $n \geq 5$ ímpar, seja $\vec{\pi}^{n}$ uma permutação tal que

$$
\vec{\pi}_{i}^{n}=\vec{a}, \text { onde } a= \begin{cases}2 & \text { se } i=1, \\ 1 & \text { se } i=2, \\ 3 & \text { se } i=3, \\ i+1 & \text { se } i \text { é par e } i \geq 4 \\ i-1 & \text { se } i \text { é ímpar e } i \geq 5\end{cases}
$$

A Figura 3.7 mostra exemplos do grafo $G\left(\vec{\pi}^{n}\right)$ para $n=5, n=7$ e $n=9$. Por verificação análoga, para $n \geq 5$ ímpar e $\pi^{n}$ retrato de $\vec{\pi}^{n}$, segue que $c\left(\pi^{n}\right)=2, h\left(\pi^{n}\right)=2$ e $f\left(\pi^{n}\right)=0$ Portanto,

$$
d\left(\vec{\pi}^{n}\right)=b\left(\pi^{n}\right)-c\left(\pi^{n}\right)+h\left(\pi^{n}\right)+f\left(\pi^{n}\right)=(n+1)-2+2+0=n+1 .
$$

Segue da análise dos 3 pontos acima a prova do teorema.

A permutação $\vec{\pi}^{n}$ mostrada na prova do Teorema 3.40 é apenas um exemplo de um elemento de $\vec{S}_{n}$ com distância máxima. De modo geral, para que uma permutação $\vec{\pi}$ sobre $n \geq 4$ tenha distância máxima, sendo $\pi$ retrato de $\vec{\pi}$, é necessário e suficiente que $b(\pi)=n+1$ e $c(\pi)=h(\pi)$.

\subsection{Permutações Circulares Orientadas}

\subsubsection{Introdução}

Existem na natureza cromossomos de alguns organismos que são circulares e que, assim como os cromossomos lineares, sofrem muitos eventos de rearranjo de genomas, sendo, entre eles, o mais comum, o evento de reversão.

Nesta seção, estudamos, dados dois cromossomos circulares que possuem o mesmo conjunto de genes, uma maneira de determinar uma seqüência mínima de reversões que transforma um cromossomo em outro. Pressupomos aqui que conhecemos a ordem e a orientação relativa dos genes nos dois cromossomos. Esse estudo mostra resumidamente o trabalho de Meidanis, Walter e Dias [MWD97].

Um cromossomo circular pode ser visto como um arranjo circular de $n$ blocos de genes, onde cada bloco possue uma orientação. Cada um desses blocos possue um rótulo que o identifica. Esse rótulo é um inteiro entre $0,1, \ldots, n-1$. A Figura 3.8, baseada em [MWD97], nos mostra exemplos de cromossomos circulares de duas espécies de plantas, onde cada rótulo representa um bloco composto por um ou mais genes e as flechas indicam a orientação dos blocos de uma espécie em relação à outra.

Escolha um bloco inicial de um cromossomo circular $A$ com $n$ blocos, e podemos representar $A$ por uma permutação orientada

$$
\vec{\pi}=\left(\begin{array}{llll}
\vec{\pi}_{0} & \vec{\pi}_{1} & \cdots & \vec{\pi}_{n-1}
\end{array}\right),
$$




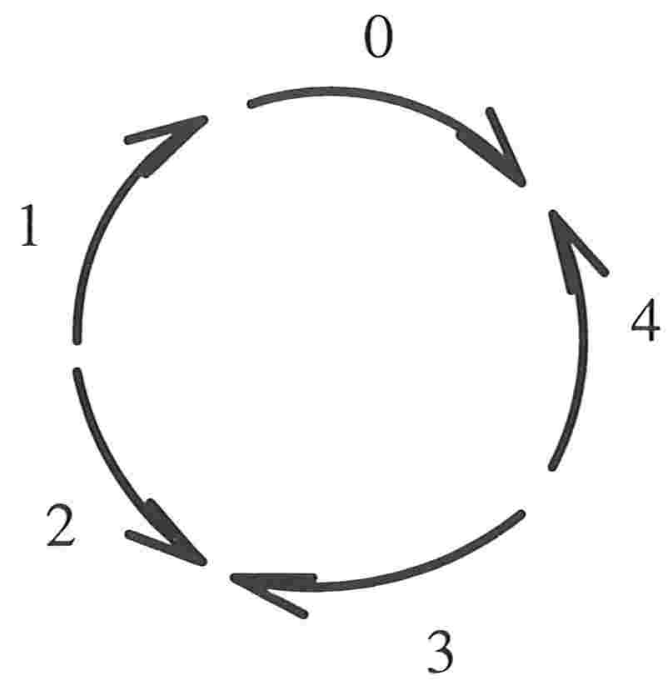

Brassica oleracea (repolho)

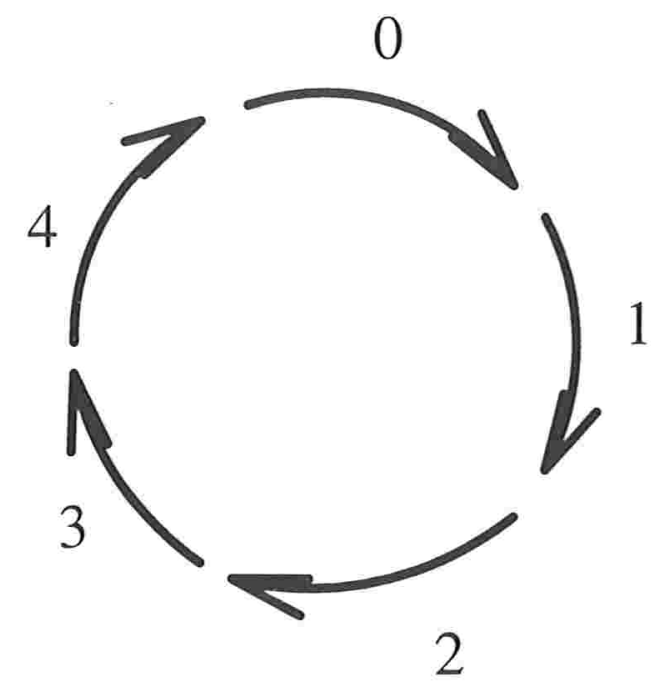

Brassica campestris (nabo)

Figura 3.8: Exemplos de cromossomos circulares de duas espécies de plantas.

sobre $\{0,1,2, \ldots, n-1\}$, onde $\vec{\pi}_{0}$ é o bloco inicial de $A$ e cada $\vec{\pi}_{i+1}$, para $0 \leq i \leq n-2$, é o bloco que aparece imediatamente após $\vec{\pi}_{i}$, quando percorremos $A$ em sentido horário. Para $a$ rótulo de $\vec{\pi}_{i}, \vec{\pi}_{i}=\vec{a}$, se a orientação do bloco rotulado por $a$ aparece em sentido horário em relação ao cromossomo circular $A$. Caso contrário, $\vec{\pi}_{i}=-\vec{a}=\overleftarrow{a}$

Observamos que, para escolhas diferentes de blocos iniciais, temos representações diferentes (permutações orientadas) de um mesmo cromossomo. Como exemplo, o cromossomo de $B$. oleracea da Figura 3.8 pode ser representado por qualquer uma das permutações orientadas

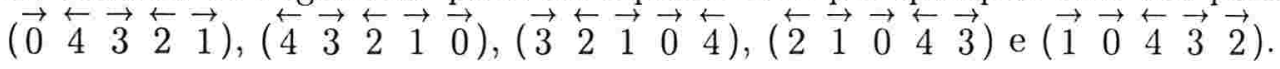

Além disso, observe que, se $A$ é um cromossomo circular e $\vec{\pi}$ uma permutação orientada que representa $A$, então, o fato de $A$ estar disposto no espaço, faz com que a permutação orientada obtida de $\vec{\pi}$ por reflexão também represente $A$. Em outras palavras, podemos representar $A$

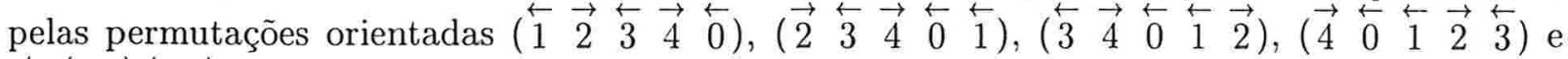
$(\stackrel{\leftarrow}{0} \stackrel{\leftarrow}{1} \overrightarrow{2} \stackrel{\leftarrow}{3} \overrightarrow{4})$

Deste modo, uma permutação orientada representando um cromossomo circular é apenas um representante de uma classe de equivalência no conjunto de todas as permutações orientadas. Se as permutações orientadas $\vec{\pi}$ e $\vec{\pi}^{\prime}$ representam o mesmo cromossomo, dizemos que $\vec{\pi}$ e $\vec{\pi}^{\prime}$ são equivalentes. Este fato é denotado por $\vec{\pi} \equiv \vec{\pi}^{\prime}$. Caso contrário, escrevemos $\vec{\pi} \not \equiv \vec{\pi}^{\prime}$. Se $\vec{\pi}$ é uma permutação orientada, denotamos

$$
[\vec{\pi}]=\left\{\vec{\sigma} \in \vec{S}_{n} \mid \vec{\pi} \equiv \vec{\sigma}\right\}
$$


a classe de equivalência representada por $\vec{\pi}$. À classe de equivalência $[\vec{\pi}]$ chamamos de permutação orientada circular $[\vec{\pi}]$.

Definimos uma rotaçâo como sendo uma operação básica $r$ que, aplicada a uma permutação orientada $\vec{\pi}$, resulta na permutação orientada

$$
r \bullet \vec{\pi}=\left(\begin{array}{lllll}
\vec{\pi}_{1} & \vec{\pi}_{2} & \cdots & \vec{\pi}_{n-1} & \vec{\pi}_{0}
\end{array}\right) .
$$

Definimos $r^{i}$, para todo $i \in \mathbb{Z}$, de maneira usual, isto é, $r^{i}$ é a composição de $r i$ vezes, para $i>0, r^{-i}$ é o inverso de $r^{i}$ e $r^{0}$ o elemento neutro. Valem as seguintes relações para a operação de rotação:

$$
\begin{gathered}
r^{i}=r^{j} \text { se } i \equiv j(\bmod n), \text { para todo } i, j \in \mathbb{Z} . \\
r^{i} r^{j}=r^{i+j}, \text { para todo } i, j \in \mathbb{Z} .
\end{gathered}
$$

Definimos uma reflexão como sendo uma operação básica $s$ que, aplicada a uma permutação orientada $\vec{\pi}$, resulta na permutação orientada

$$
s \bullet \vec{\pi}=\left(\begin{array}{lllll}
-\vec{\pi}_{n-1} & -\vec{\pi}_{n-2} & \cdots & -\vec{\pi}_{1} & -\vec{\pi}_{0}
\end{array}\right) .
$$

Definimos $s^{i}$, para todo $i \in \mathbb{Z}$, de maneira usual, isto é, $s^{i}$ é a composição de $s i$ vezes, para $i>0, s^{-i}$ é o inverso de $s^{i}$ e $s^{0}$ o elemento neutro. Valem as seguintes relações para a operação de reflexão

$$
\begin{gathered}
s^{i}=s^{j}, \text { se } i \equiv j(\bmod 2), \text { para todo } i, j \in \mathbb{Z} . \\
s^{i} s^{j}=s^{i+j} \text { para todo } i, j \in \mathbb{Z} .
\end{gathered}
$$

Note que, para duas permutações orientadas $\vec{\pi}$ e $\vec{\sigma}, \vec{\pi} \equiv \vec{\sigma}$ se, e somente se, existem $i, j \in \mathbb{Z}$ tais que $\vec{\sigma}=r^{i} s^{j} \bullet \vec{\pi}$.

Seja $\vec{\pi}=\left(\begin{array}{llll}\vec{\pi}_{0} & \vec{\pi}_{1} & \ldots & \vec{\pi}_{n-1}\end{array}\right)$ uma permutação orientada. O representante canônico de [ $\left.\vec{\pi}\right]$ é a permutação orientada $\operatorname{can}(\vec{\pi})$ tal que $\operatorname{can}(\vec{\pi})_{0}=\overrightarrow{0}$ e $[\vec{\pi}]=[\operatorname{can}(\vec{\pi})]$. Note que cada classe de equivalência possui um único representante canônico. Uma reversảo circular $\vec{\varrho}=[i . . j]$, para $0<i \leq j \leq n-1$, é uma operação que, aplicada a $[\vec{\pi}]$, transforma $[\vec{\pi}]$ na permutação orientada circular

$$
[\vec{\pi}] \cdot \vec{\varrho}=[\operatorname{can}(\vec{\pi}) \cdot \overrightarrow{(i . . j)}],
$$

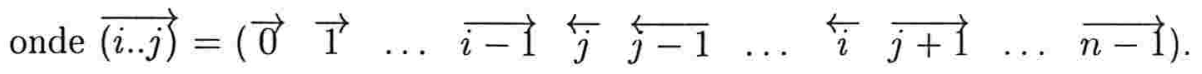

De forma análoga à formalização dos problemas MIN-SBR e MIN-SBRे (Capítulo 1), dados dois cromossomos circulares, representados pelas permutações orientadas $\vec{\alpha}$ e $\vec{\beta}$, que eles podem ser representados pelas permutações orientadas $\vec{\beta}^{-1} \cdot \vec{\alpha}$ e $\vec{\beta}^{-1} \cdot \vec{\beta}=\left(\begin{array}{llll}\overrightarrow{0} & \overrightarrow{1} & \ldots & \overrightarrow{n-1}\end{array}\right)$, respectivamente, e formalizar os seguintes conceitos.

Ordenar uma permutação orientada circular $[\vec{\pi}]$ é encontrar uma seqüência de reversões circulares orientadas $\vec{\varrho}_{1}, \vec{\varrho}_{2}, \ldots, \vec{\varrho}_{t}$, tal que

$$
[\vec{\pi}] \cdot \vec{\varrho}_{1} \cdot \vec{\varrho}_{2} \ldots \vec{\varrho}_{t}=\left[\begin{array}{llll}
\overrightarrow{0} & \overrightarrow{1} & \ldots & \overrightarrow{n-1}
\end{array}\right] .
$$


A distância por reversões circulares orientadas de uma permutação orientada circular $[\vec{\pi}]$ é o número mínimo de reversões circulares orientadas que ordenam $[\vec{\pi}]$. Denotamos por $d^{c}([\vec{\pi}])$ o valor da distância por reversões circulares.

\section{Problema 3 MIN- $\overrightarrow{S B R}-C I R C U L A R$}

Instância: Uma permutação orientada circular representada pela permutação orientada $\vec{\pi}$.

Objetivo: Encontrar uma seqüência de $d^{c}([\vec{\pi}])$ reversões circulares orientadas que ordenam $[\vec{\pi}]$.

Meidanis, Walter e Dias [MWD97] mostraram que este problema é essencialmente equivalente ao problema análogo em cromossomos lineares e mostraram os seguintes resultados.

Seja $\vec{\pi}$ uma permutação orientada sobre $\{0,1, \ldots, n-1\}$. Definimos

$$
\varphi([\vec{\pi}])=\left(\operatorname{can}(\vec{\pi})_{1} \quad \operatorname{can}(\vec{\pi})_{2} \quad \ldots \quad \operatorname{can}(\vec{\pi})_{n-1}\right) .
$$

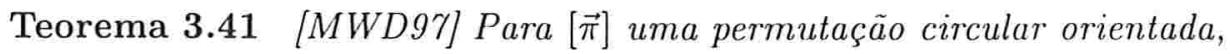

$$
d^{c}([\vec{\pi}])=\vec{d}(\varphi([\vec{\pi}])) .
$$

Note que, sendo $[\vec{\pi}]$ uma permutação circular orientada, podemos encontrar uma seqüência mínima de reversões circulares, determinando uma seqüência mínima de reversões orientadas que ordena a permutação

$$
\left(\operatorname{can}(\vec{\pi})_{1} \quad \operatorname{can}(\vec{\pi})_{2} \quad \ldots \quad \operatorname{can}(\vec{\pi})_{n-1}\right),
$$

usando o Algoritmo SBR-Orienta (Seção 3.4.4).

Definimos

$$
\vec{S}_{n}^{c}=\{\text { permutações orientadas circulares sobre }\{0,1, \ldots, n-1\}\} .
$$

Definimos o diâmetro de reversões em permutações orientadas circulares com $n$ elementos por $\vec{D}_{n}^{c}$, isto é

$$
\vec{D}_{n}^{c}=\max _{[\vec{\pi}] \in \vec{S}_{n}^{c}} d([\vec{\pi}]) .
$$

Deduzimos dos Teoremas 3.40 e 3.41 o seguinte resultado.

Teorema 3.42 [MWD97] Para todo n,

$$
\vec{D}_{n}^{c}= \begin{cases}n-1 & \text { se } n=1 \text { ou } n=3 \\ n & \text { caso contrário. }\end{cases}
$$




\section{Capítulo 4}

\section{Permutações Não-Orientadas}

Neste Capítulo tratamos do Problema MIN-SBR.

Os algoritmos exatos conhecidos para MIN-SBR são todos exponenciais. Uma técnica utilizada para obter um algoritmo com boa performance é o de branch and bound [KS95] usando limitantes superiores do valor da distância.

Hannenhalli e Pevzner [HP96] descreveram um outro algoritmo exato cujo tempo gasto é $O\left(2^{k} n^{3}+n^{4}\right)$, onde $k$ representa o número de vértices do grafo de pontos de quebra que possuem grau 4. (Na verdade, esse algoritmo usa como rotina um algoritmo para encontrar uma seqüência mínima de reversões orientadas que ordena uma permutação orientada definida a partir de uma permutação não-orientada. Substituindo essa rotina pelo Algoritmo SBR-Orienta (Capítulo 3), o algoritmo de Hannenhalli e Pevzner gasta tempo $O\left(2^{k} n+n^{2}\right)$.) Note que se $k=O(\log n)$, então esse algoritmo gasta tempo polinomial de execução.

$\mathrm{Na}$ Seção 4.1 detalhamos um algoritmo polinomial de aproximação que, para qualquer entrada $\pi$, devolve uma seqüência de $t$ reversões que ordena $\pi$, tal que $t / d(\pi) \leq 7 / 4$.

Na Seção 4.2 mostramos o valor, em função de $n$, da distância máxima de uma permutação sobre $n$.

Na Seção 4.3 fazemos uma breve discussão a respeito do valor da distância esperada.

\subsection{Algoritmos Aproximados}

Como mostramos no Capítulo 5, o Problema MIN-SBR é NP-difícil. Com isso, o desenvolvimento de algoritmos aproximados se torna interessante. Estamos interessados em algoritmos polinomiais que, para qualquer entrada $\pi$, obtenha uma seqüência de $t$ reversões que ordena $\pi$, onde $t$ é comprovadamente não muito maior do que $d(\pi)$.

Seja $\mathcal{A}$ um algoritmo que obtém, para cada entrada $\pi$, uma seqüência de reversões que ordena $\pi$. Denotamos por $T(\mathcal{A}, \pi)$ o comprimento da seqüência de reversões, que ordena $\pi$, obtida pelo Algoritmo $\mathcal{A}$. Dizemos que o Algoritmo $\mathcal{A}$ tem fator de aproximação $\mathcal{F}(\mathcal{A})$ se, para toda permutação $\pi, \mathcal{F}(\mathcal{A}) \geq T(\mathcal{A}, \pi) / d(\pi)$. 
Na Seção 4.1.1, mostramos um algoritmo polinomial descrito por Kececioglu e Sankoff [KS95], que denotamos por $K S$, que tem fator de aproximação 2. É interessante observar que esse foi o primeiro algoritmo de aproximação descrito para o Problema MIN-SBR.

Nas seções subseqüentes, mostramos um outro algoritmo polinomial, desenvolvido por Bafna e Pevzner [BP93], que denotamos por AproxMIN-SBR, que tem um fator de aproximação de $7 / 4$.

\subsubsection{Algoritmo $K S$}

Para $\pi$ uma permutação estendida e $0 \leq i \leq j \leq n+1$, definimos a função

$$
\pi_{i, \ldots, j}=\left(\begin{array}{llll}
\pi_{i} & \pi_{i+1} & \ldots & \pi_{j}
\end{array}\right)
$$

como sendo a função $\pi$ restrita ao conjunto $\{i, i+1, \ldots, j\}$.

Dizemos que $\pi_{i, \ldots, j}$ é um bloco(block) de $\pi$ se $\pi_{k} \sim \pi_{k+1}$, para todo $k, i \leq k \leq j-1$.

Dizemos que um bloco $s$ de uma permutação $\pi$ é uma corrente(strip) de $\pi$, se $s$ é um bloco maximal de $\pi$.

Para $s=\pi_{i, \ldots, j}$ um bloco (corrente) de uma permutação, dizemos que o bloco (corrente) $s$ é um $k$-bloco ( $k$-corrente), se $k=j-i+1$. Dizemos que $s$ é crescente, se ou $\pi_{i}<\pi_{j}$ ou $i=j=0$ ou $i=j=n+1$. Caso contrário, dizemos que $s$ é decrescente. Informalmente, entendemos que um $k$-bloco ( $k$-corrente), $k \geq 2$, é ou crescente ou decrescente de maneira óbvia e que um 1-bloco é sempre decrescente, exceto se este é formado ou por $\pi_{0}$ ou por $\pi_{n+1}$.

Dizemos que uma reversão $\rho$ adiciona (remove) pontos de quebra de uma permutação $\pi$, se $b(\pi . \rho)>b(\pi)(b(\pi . \rho)<b(\pi))$. Note que uma reversão pode adicionar ou remover no máximo dois pontos de quebra de uma permutação. Dizemos que a reversão $\rho$ é uma $j$-reversão em $\pi$, se $b(\pi)-b(\pi \cdot \rho)=j$.

Sejam $\pi_{i, \ldots, j}$ e $\pi_{k, \ldots, l}$ correntes de $\pi$ e $i<k$ (note, sendo as correntes blocos maximais em $\pi$, para todo $x, i \leq x \leq j$, e todo $y, k \leq y \leq l$, que $x<y$ ). Dizemos, neste caso, que $\pi_{i, \ldots, j}$ está à esquerda de $\pi_{k, \ldots, l}$ e, simetricamente, que $\pi_{k, \ldots, l}$ está à direita de $\pi_{i, \ldots, j}$.

Lema 4.1 [KS95] Seja $\pi$ uma permutação com uma corrente decrescente. Então, existe uma $k$-reversão em $\pi$, onde ou $k=1$ ou $k=2$. Além disso, se, para toda reversão $\rho$ que remove pelo menos um ponto de quebra de $\pi$, a permutação $\pi . \rho$ não possui qualquer corrente decrescente, então existe uma 2-reversão em $\pi$.

Prova. Considere $\pi_{j}$, elemento da corrente $s$, que é o menor elemento entre todas as correntes decrescentes de $\pi$. Segue que $\pi_{j}-1$ deve pertencer a uma corrente crescente que ou está à esquerda de $s$ ou à direita de $s$ como mostrado na Figura 4.1. Em ambos os casos, note que as reversões indicadas removem pelo menos um ponto de quebra em $\pi$.

Considere agora que, para toda reversão $\rho$ que remove pelo menos um ponto de quebra de $\pi$, $\pi . \rho$ não possui qualquer corrente decrescente. O Caso $(b)$ da Figura 4.1 não pode ocorrer, desde que $\rho$ é uma reversão que remove um ponto de quebra e $\pi . \rho$ não possui, por hipótese, qualquer corrente decrescente.

Sendo $\pi_{k}=\pi_{j}-1$ e toda corrente de $\pi . \rho$ crescente, note também que toda corrente em $\pi_{0, \ldots, k}$ é crescente e toda corrente em $\pi_{j+1, \ldots, n+1}$ é crescente e toda corrente em $\pi_{k+1, \ldots, j}$ é decrescente. 
Caso $(a)$
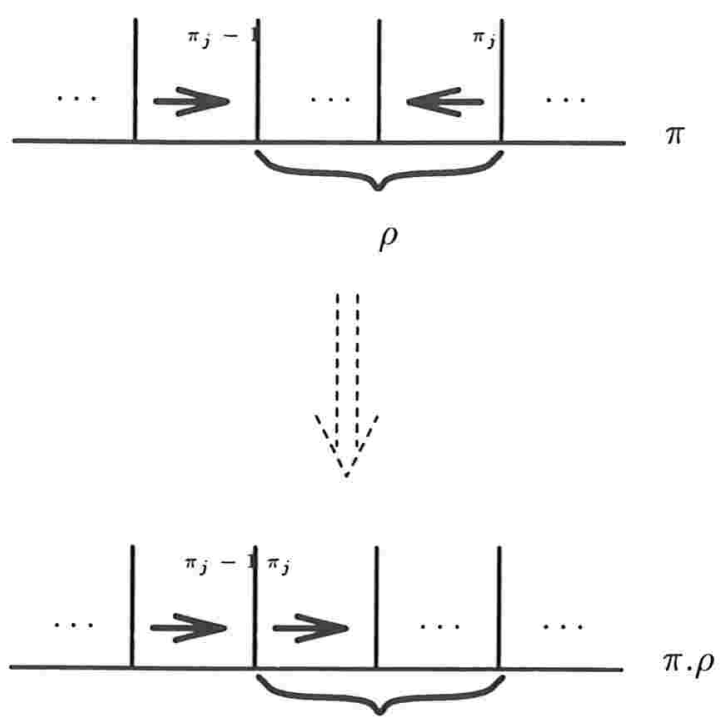

Caso $(b)$
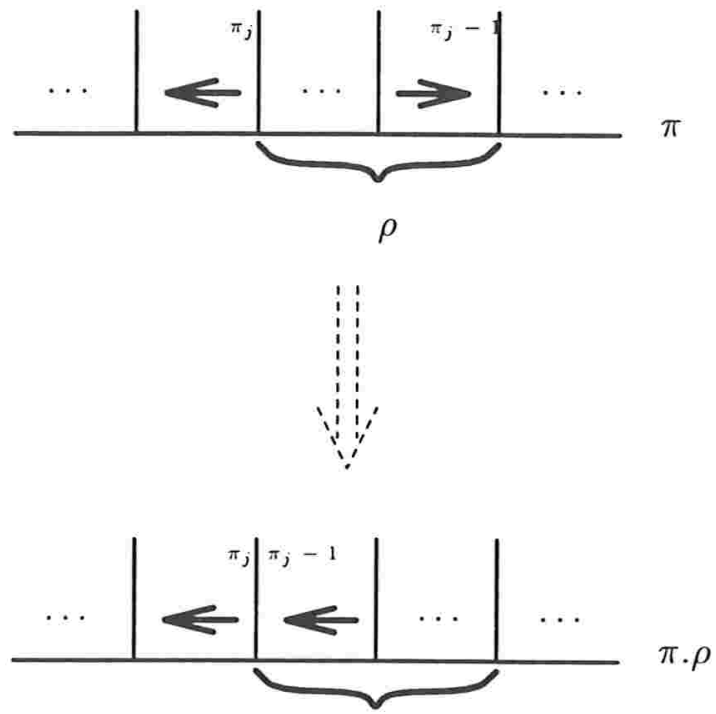

Figura 4.1: Uma permutação $\pi$ com uma corrente decrescente tem uma reversão $\rho$ que remove pelo menos um ponto de quebra.

Por raciocínio análogo, se $\pi_{i}$ é o maior elemento entre todas as correntes decrescentes de $\pi$, sendo $\pi_{l}=\pi_{i}+1$, temos que toda corrente em $\pi_{0, \ldots, i-1}$ é crescente e toda corrente em $\pi_{l, \ldots, n+1}$ é crescente e toda corrente em $\pi_{i, \ldots, l-1}$ é decrescente.

Segue que a única possibilidade é $i=k+1$ e $j=l-1$. Deduzimos, então, que se, para toda reversão $\rho$ que remove pelo menos um ponto de quebra de $\pi$, a permutação $\pi . \rho$ não possui qualquer corrente decrescente, então a reversão $(i . . j)$, onde $\pi_{i}$ é o maior elemento entre todas as correntes decrescentes de $\pi$ e $\pi_{j}$ é o menor elemento entre todas as correntes decrescentes de $\pi$, remove 2 pontos de quebra de $\pi$.

O Algoritmo $K S$ recebe uma permutação $\pi$ sobre $n$ e, desde que $\pi \neq \iota$ (permutação identidade) (neste caso não há nada a fazer), inicializa uma permutação auxiliar $\pi^{\prime}=\pi$. Em cada iteração $k$, entre todas as $j$-reversões em $\pi^{\prime}$, onde $j$ é máximo, o algoritmo escolhe, preferencialmente, uma reversão $\rho_{k}$ tal que pelo menos uma corrente de $\pi^{\prime} . \rho_{k}$ é decrescente. Determinada a reversão $\rho_{k}$, se $\pi^{\prime} . \rho_{k} \neq \iota$, então o algoritmo inicia a iteração $k+1 \operatorname{com} \pi^{\prime} . \rho_{k}$ no lugar de $\pi^{\prime}$, senão $K S$ devolve $\rho_{1}, \rho_{2}, \ldots, \rho_{k}$ e pára.

Lema 4.2 [KS95] O Algoritmo KS ordena uma permutação $\pi$ com no máximo b( $\pi$ ) reversões.

Prova. Particione a seqüência de reversões em etapas de maneira que cada etapa, exceto, talvez, a primeira, comece com uma 0-reversão. O Lema 4.1 implica que cada etapa termina com uma 2-reversão e, portanto, toda 0-reversão que inicia cada etapa, pode ser amortizada com uma 2-reversão no final dessa mesma etapa. Na média precisamos, portanto, de no máximo 


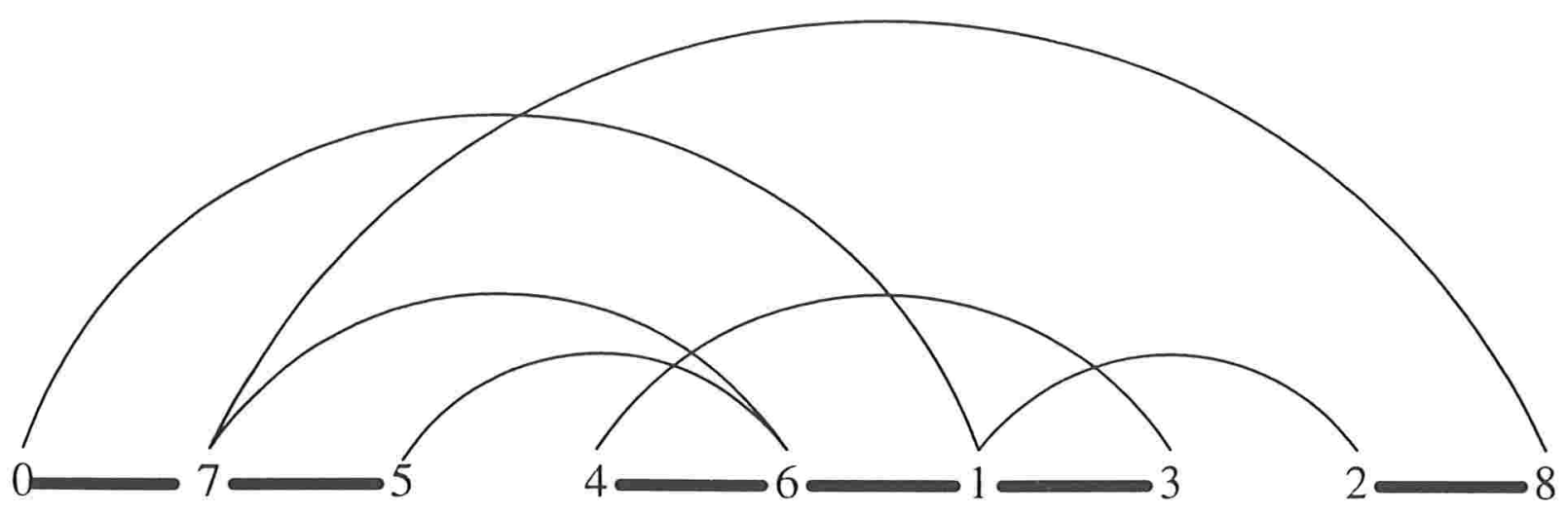

Figura 4.2: Observe a permutação $\pi=\left(\begin{array}{lllllll}7 & 5 & 4 & 6 & 1 & 3 & 2\end{array}\right)$, onde $G(\pi)$ possui 6 arestas vermelhas, o que implica que $c(\pi) \leq 3$. Mas $c(\pi)=3$ implica que existe uma decomposição máxima em circuitos de $G(\pi)$ onde todo circuito tem tamanho 2. Verificando que não existe circuito de tamanho 2 que passa pelos vértices 2 e 8 temos que $c(\pi) \leq 2$. Obtemos uma decomposição máxima nos circuitos $\left(\begin{array}{lllllll}0 & 1 & 3 & 4 & 6 & 7\end{array}\right)$ e $\left(\begin{array}{llllll}7 & 8 & 2 & 1 & 6 & 5\end{array}\right)$, e outra decomposição $\left(\begin{array}{llll}0 & 1 & 6 & 7\end{array}\right)$ e $\left(\begin{array}{llllllll}7 & 8 & 2 & 1 & 3 & 4 & 6 & 5\end{array}\right)$, onde o número de circuitos de tamanho 2 na primeira é 0 e na segunda é 1 .

uma reversão para remover um ponto de quebra. Portanto, a permutação $\pi$ é ordenada em no máximo $b(\pi)$ reversões.

O Lema 4.2 implica que, para toda permutação $\pi, T(K S, \pi) \leq b(\pi)$. Por outro lado, para toda permutação $\pi, d(\pi) \geq b(\pi) / 2$ (Seção 2.2 ) o que implica que $T(K S, \pi) \leq 2 d(\pi)$. Segue que $T(K S, \pi) / d(\pi) \leq 2$. Portanto,

Teorema 4.3 [KS95] O Algoritmo KS tem fator de aproximaçâo 2.

Kececioglu e Sankoff [KS95] mostraram que a complexidade de tempo do Algoritmo KS é $O\left(n^{2}\right)$.

\subsubsection{Limitante Inferior}

$\mathrm{Na}$ Seção 2.2 mostramos um limitante inferior da distância por reversões que é $b(\pi) / 2$. Nesta seção mostramos um novo limitante inferior para $d(\pi)$, determinado por Bafna e Pevzner [BP93], que facilita a análise do fator de aproximação do Algoritmo AproxMIN-SBR que descrevemos subseqüentemente.

O tamanho de um circuito $C$ de $G(\pi)$ é o número $l(C)$ de arestas vermelhas em $C$. Para uma permutação $\pi$ e uma decomposição máxima em circuitos $D$ de $G(\pi)$, denotamos por $c_{i}(\pi, D)$ o número de circuitos de tamanho $i$ em $D$. É interessante observar que o número de circuitos de tamanho $i$ depende não só da permutação $\pi$ como também da decomposição máxima em circuitos obtida (veja Figura 4.2). 
Teorema 4.4 Para qualquer permutação $\pi$ e qualquer decomposição máxima em circuitos $D$ de $G(\pi)$,

$$
d(\pi) \geq \frac{2 b(\pi)-c_{2}(\pi, D)}{3} .
$$

Prova. O número de arestas em $G(\pi)$ é o número de arestas vermelhas e azuis em $G(\pi)$. Como o número de arestas vermelhas e azuis de $G(\pi)$ é o mesmo, segue que o número de arestas de $G(\pi)$ é $2 b(\pi)$. Por outro lado, o valor $\sum_{i=2}^{n+1} 2 i c_{i}(\pi, D)$ também é o número de arestas de $G(\pi)$. Segue que, sendo $\sum_{i=3}^{n+1} c_{i}(\pi, D)=c(\pi)-c_{2}(\pi, D)$,

$$
\begin{aligned}
2 b(\pi) & =\sum_{i=2}^{n+1} 2 i c_{i}(\pi, D) \\
& =4 c_{2}(\pi, D)+\sum_{i=3}^{n+1} 2 i c_{i}(\pi, D) \\
& \geq 4 c_{2}(\pi, D)+6 \sum_{i=3}^{n+1} c_{i}(\pi, D) \\
& =4 c_{2}(\pi, D)+6\left(c(\pi)-c_{2}(\pi, D)\right) \\
& =6 c(\pi)-2 c_{2}(\pi, D) .
\end{aligned}
$$

Como, pelo Corolário $2.2, d(\pi) \geq b(\pi)-c(\pi)$, segue que

$$
\begin{aligned}
d(\pi) & \geq b(\pi)-c(\pi) \\
& \geq b(\pi)-\frac{2 b(\pi)+2 c_{2}(\pi, D)}{6} \\
& =\frac{2 b(\pi)-c_{2}(\pi, D)}{3} .
\end{aligned}
$$

\subsubsection{Grafo 2-circuito $J(\pi)$}

Dizemos que o circuito $C$ em $G(\pi)$ é um $i$-circuito se $l(C)=i$.

Uma estrutura que nos auxilia na análise do fator de aproximação de AproxMIN-SBR é o o grafo 2-circuito $J(\pi)$ definido como o grafo no qual cada vértice corresponde a um 2-circuito em $G(\pi)$ e os vértices $v$ e $w$ são adjacentes em $J(\pi)$, se os circuitos $v$ e $w$ possuem uma aresta em comum em $G(\pi)$.

Um conjunto independente máximo $\mu(\pi)$ é um conjunto de vértices de $J(\pi)$ de cardinalidade máxima cujos vértices representam circuitos de $G(\pi)$ 2-a-2 disjuntos nas arestas.

Observando que, para uma reversão $\rho=(i . . j)$, se um circuito $C$ em $G(\pi)$ não contém nem $\pi_{i}$ e nem $\pi_{j}$, então $C$ é um circuito em $G(\pi . \rho)$ e, como $\pi_{i}$ (assim como $\pi_{j}$ ) pode ser vértice de no máximo 2 circuitos disjuntos nas arestas, temos que no máximo 4 2-circuitos em $\mu(\pi)$ não são 2-circuitos em $G(\pi . \rho)$. Segue a afirmação abaixo. 
Fato 4.5 Para toda permutação $\pi$ e reversão $\rho$,

$$
|\mu(\pi)|-|\mu(\pi . \rho)| \leq 4 .
$$

\subsubsection{Explorando 2-reversão}

Dada uma permutação $\pi$, a primeira fase do Algoritmo AproxMIN-SBR é o Procedimento Transforma que determina uma seqüência de 2-reversões na permutação $\pi$ e na permutação $\pi^{-1}$, eliminando 2 pontos de quebra por reversão.

Essa tarefa é executada da seguinte forma. Inicializamos uma permutação auxiliar $\pi^{\prime} \leftarrow \pi$ e dois contadores, para os tamanhos das seqüências de 2-reversões a serem aplicadas a $\pi$ e a $\pi^{-1}, x \leftarrow 0$ e $y \leftarrow 0$, respectivamente. Em cada iteração fazemos o seguinte. Se existe uma 2reversão $\rho$ em $\pi^{\prime}$, então incrementamos $x$, atribuímos $\rho_{x} \leftarrow \rho$ e iniciamos uma nova iteração com $\pi^{\prime} . \rho_{x}$ no lugar de $\pi^{\prime}$. Se não existe uma 2-reversão em $\pi^{\prime}$ mas existe uma 2-reversão $\rho$ em $\pi^{\prime-1}$, então incrementamos $y$, atribuímos $\varrho_{y} \leftarrow \rho$ e iniciamos uma nova iteração com $\left(\pi^{\prime-1} \cdot \varrho_{y}\right)^{-1}$ no lugar de $\pi^{\prime}$. Se nem existe uma 2-reversão em $\pi^{\prime}$ e nem existe uma 2-reversão em $\pi^{\prime-1}$, então o algoritmo devolve as seqüências de reversões $\rho_{1}, \rho_{2}, \ldots, \rho_{x}$ e $\varrho_{1}, \varrho_{2}, \ldots, \varrho_{y}$ e a permutação $\lambda=\varrho_{1} \cdot \varrho_{2} \ldots \varrho_{y} \cdot \pi \cdot \rho_{1} \cdot \rho_{2} \ldots \ldots \rho_{x}$ e pára.

Note que nem em $\lambda$ e nem em $\lambda^{-1}$ existe uma 2-reversão. Além disso, se uma seqüência de reversões $\varphi_{1}, \varphi_{2}, \ldots, \varphi_{z}$ ordena $\lambda$, então $\pi \cdot \rho_{1} \cdot \rho_{2} \ldots . \rho_{x} \cdot \varphi_{1} \cdot \varphi_{2} \ldots . \varphi_{z} \cdot \varrho_{1} \cdot \varrho_{2} \ldots . \varrho_{y}=\iota$.

Do fato de que cada reversão elimina 2 pontos de quebra de uma permutação, segue a afirmação abaixo.

Fato 4.6 O número de pontos de quebra da permutação $\lambda$ é

$$
b(\lambda)=b(\pi)-2(x+y) .
$$

Segue das três observações abaixo que o tempo gasto por cada iteração do Procedimento Transforma é $O(n)$.

Para determinar se existe uma 2-reversão em uma permutação $\pi^{\prime}$, basta varrer a permutação $\pi^{\prime}$ de 0 até $n+1$ e verificar em tempo constante, para cada ponto de quebra $\left(\pi_{i}^{\prime}, \pi_{i+1}^{\prime}\right)$, se $\left(\pi_{j}^{\prime}, \pi_{k}^{\prime}\right)$, onde ou $j=\pi_{\pi_{i}^{\prime}-1}^{\prime-1}$ ou $j=\pi_{\pi_{i}^{\prime}+1}^{\prime-1}$, e ou $k=\pi_{\pi_{i+1}^{\prime}-1}^{\prime-1}$ ou $k=\pi_{\pi_{i+1}^{\prime}+1}^{\prime-1}$, e $j=k-1$, é um ponto de quebra em $\pi^{\prime}$. Isto implica que o tempo total gasto para determinar se existe uma 2-reversão em $\pi^{\prime}$ é $O(n)$.

Por raciocínio simétrico, o tempo total gasto para determinar se existe uma 2-reversão em $\pi^{\prime-1}$ também é $O(n)$.

Determinar $\pi^{\prime} \cdot \rho_{x}$ e $\left(\pi^{\prime} \cdot \rho_{x}\right)^{-1}$, assim como determinar as permutações $\left(\pi^{\prime-1} \cdot \varrho_{y}\right)^{-1}$ e $\pi^{\prime-1} \cdot \varrho_{y}$ também gasta tempo $O(n)$.

Como $\pi$ pode ter no máximo $n+1$ pontos de quebra e, em cada iteração do Procedimento Transforma, determinamos uma permutação com 2 pontos de quebra a menos, segue que o número de iterações do procedimento é limitado por $n / 2$. Concluímos que o Procedimento Transforma gasta tempo $O\left(n^{2}\right)$. 
É interessante notar que, embora uma 2-reversão elimine mais pontos de quebra do que uma 1-reversão, isso não significa que se uma permutação $\pi$ possui uma única 2-reversão $\rho$, então

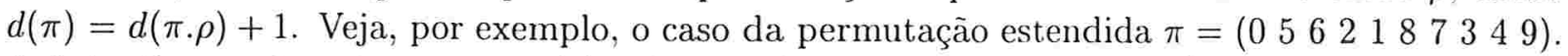

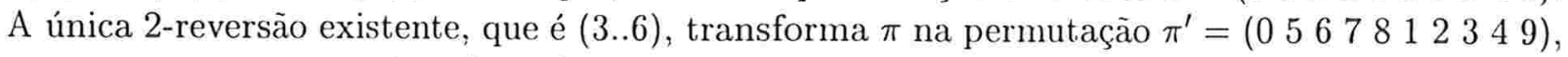
que, por sua vez, usando a força bruta, não pode ser ordenada usando menos que 3 reversões. Isto é, se a primeira reversão transformar $\pi$ em $\pi^{\prime}$, ordenamos $\pi$ com pelo menos 4 reversões. Porém, a seqüência de 3 reversões (1..4), (5..8) e (3..6) ordena a permutação $\pi$.

Seria razoável, então, perguntar se sempre que existe uma 2-reversão a ser aplicada ou a $\pi$ ou a $\pi^{-1}$, então existe uma 2-reversão $\rho$ tal que $d(\pi)=d\left(\pi^{\prime}\right)+1$, onde ou $\pi^{\prime}=\pi . \rho$ ou $\pi^{\prime}=\left(\pi^{-1} \cdot \rho\right)^{-1}$, respectivamente. Novamente a reposta é não. Veja a permutação estendida $\pi=\left(\begin{array}{l}06571211813129104314\end{array}\right)$. A única 2-reversão em $\pi$ é $\rho=(4 . .6)$, que transforma $\pi$

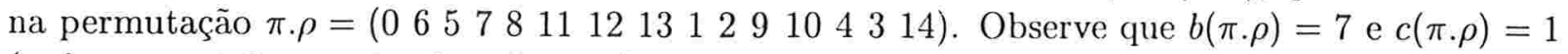
(a decomposição em circuitos é única), implicando pelo Corolário 2.2 que $d(\pi . \rho) \geq 7-1=6$.

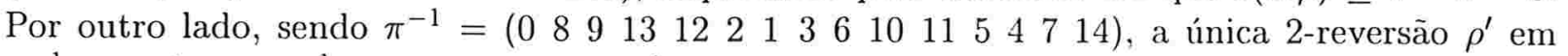

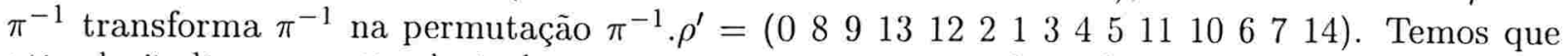
$b\left(\left(\pi^{-1} \cdot \rho^{\prime}\right)^{-1}\right)=7$ e $c\left(\left(\pi^{-1} \cdot \rho^{\prime}\right)^{-1}\right)=1$, implicando que $d\left(\left(\pi^{-1} \cdot \rho^{\prime}\right)^{-1}\right) \geq 7-1=6$. Concluímos que a tomada de decisão de escolher uma 2-reversão em $\pi$ ou $\pi^{-1}$ implica que ordenamos a permutação $\pi$ usando não menos do que 7 reversões. Surpreendentemente, veja a seqüência de reversões abaixo onde ordenamos a mesma permutação $\pi$ usando apenas 6 reversões.

$$
\begin{aligned}
& \pi=\left(\begin{array}{llll}
0 & 657121181312 \underline{91043} 14)
\end{array}\right.
\end{aligned}
$$

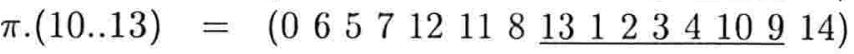

$$
\begin{aligned}
& \pi \cdot(10 . .13) \cdot(7 . .13)=(0 \underline{657121189104321} 1314) \\
& \pi \cdot(10 . .13) \cdot(7 . .13) \cdot(1 . .12)=(012341098 \underline{11127} 561314)
\end{aligned}
$$

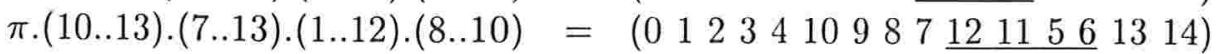

$$
\begin{aligned}
& \pi .(10 . .13) \cdot(7 . .13) \cdot(1 . .12) \cdot(8 . .10) \cdot(9 . .12)=(01234 \underline{1098765} 11121314) \\
& \pi \cdot(10 . .13) \cdot(7 . .13) \cdot(1 . .12) \cdot(8 . .10) \cdot(9 . .12) \cdot(5 . .10)=(01234567891011121314) \text {. }
\end{aligned}
$$

O procedimento Transforma além de eliminar muitos pontos de quebra por reversão gera a permutação $\lambda$ que possui uma importante propriedade que mostramos a seguir.

\section{Lema 4.7 [BP93] O grafo $J(\lambda)$ é bipartido.}

Prova. Considere um vértice em $J(\lambda)$ (um 2-circuito em $G(\lambda)$ ) formado pelos vértices $\lambda_{i}, \lambda_{i+1}, \lambda_{j}$ e $\lambda_{j+1}$ de $G(\lambda)$, onde $i+1<j$. Como nenhuma 2-reversão é possível em $\lambda$, temos que $\lambda_{i} \sim \lambda_{j+1}$ e $\lambda_{j} \sim \lambda_{i+1}$. Agora, observe que $i, i+1, j, j+1$ formam um 2-circuito em $G\left(\lambda^{-1}\right)$ e, como nenhuma 2-reversão também é possível em $\lambda^{-1}, \lambda_{i}-\lambda_{j+1}=\lambda_{j}-\lambda_{i+1}$.

Para interpretar este fato graficamente, dirija as arestas vermelhas do grafo $G(\lambda)$ de $\lambda_{k}$ para $\lambda_{k+1}$ e as arestas azuis de $l$ para $l+1$. Dizemos que as arestas de um circuito são coordenadas se elas são dirigidas da mesma maneira ao longo do circuito. Note que, desde que não existe uma 2-reversão a ser aplicada a $\lambda$, as arestas vermelhas em todo 2-circuito de $G(\lambda)$ são coordenadas. Também, desde que não existe uma 2-reversão a ser aplicada a $\lambda^{-1}$, as arestas azuis em todo 2-circuito de $G(\lambda)$ são coordenadas. Então, somente dois tipos de 2-circuitos são possíveis, isto é, podemos ter circuitos onde todas as arestas são coordenadas e circuitos onde as arestas vermelhas são coordenadas e as arestas azuis são coordenadas mas as arestas vermelhas 
em relação as arestas azuis são dirigidas de maneira oposta. Denotamos por $c_{+}$e por $c_{-}$os dois tipos de circuitos descritos acima, respectivamente. Observe agora que todos os 2-circuitos que compartilham arestas com um circuito do tipo $c_{+}$deve ser do tipo $c_{-}$e vice-versa, implicando que $J(\lambda)$ é bipartido.

\subsubsection{Encontrando o Candidato Apropriado de uma Permutação}

Dizemos que uma permutação orientada $\vec{\sigma}=\left(\vec{\sigma}_{1} \vec{\sigma}_{2} \ldots \vec{\sigma}_{n}\right)$ é um candidato orientado(spin) da permutação não-orientada $\lambda=\left(\begin{array}{llll}\lambda_{1} & \lambda_{2} & \ldots & \lambda_{n}\end{array}\right)$, se $\left|\vec{\sigma}_{i}\right|=\lambda_{i}$, para todo $1 \leq i \leq n$.

Note que, sendo $\sigma$ retrato de $\vec{\sigma}$ e sendo $\vec{\sigma}$ candidato orientado de $\lambda$, se uma sequência de reversões pares $\left(2 i_{1}-1 . .2 j_{1}\right),\left(2 i_{2}-1 . .2 j_{2}\right), \ldots,\left(2 i_{z}-1 . .2 j_{z}\right)$ ordena $\sigma$, então a seqüência $\left(i_{1} . . j_{1}\right),\left(i_{2} . . j_{2}\right), \ldots,\left(i_{z} . . j_{z}\right)$ ordena a permutação $\lambda$, implicando que $d(\sigma) \geq d(\lambda)$.

Um candidato apropriado $\vec{\sigma}$ de uma permutação $\lambda$ é um candidato orientado de $\lambda$ tal que, sendo $\sigma$ retrato de $\vec{\sigma}, b(\sigma)=b(\lambda)$ e $c_{2}(\sigma) \geq|\mu(\lambda)|$, onde $c_{2}(\sigma)=c_{2}(\sigma, D)$ e $D$ é a (única) decomposição máxima em circuitos de $G(\vec{\sigma})$.

A segunda fase do Algoritmo AproxMIN-SBR consiste em determinar um candidato apropriado $\vec{\sigma}$ de $\lambda$. A seguir, mostramos como executar esta tarefa.

\section{Determinando Conjunto Independente de Vértices}

Primeiramente, computamos o conjunto $\mu(\lambda)$. (Determinar um conjunto independente máximo em um grafo qualquer é um problema difícil, entretanto, para grafos bipartidos (como, pelo Lema 4.7, é o caso de $J(\lambda)$ ), existe um algoritmo exato, que é executado em tempo $O\left(n^{3 / 2}\right)$, cuja descrição podemos encontrar em [CLR90]).

\section{Determinando Candidato Apropriado}

A permutação $\vec{\sigma}$ é, então, determinada em três etapas como segue.

Na primeira etapa, para todo elemento $\lambda_{i}, 1 \leq i \leq n$, que é elemento de uma $k$-corrente crescente, $k \geq 2$, atribuímos $\vec{\sigma}_{i} \leftarrow \lambda_{i}$ e, para todo elemento $\lambda_{i}$ que é elemento de uma $k$-corrente decrescente, $k \geq 2$, atribuímos $\vec{\sigma}_{i} \leftarrow-\lambda_{i}$.

Na segunda etapa, para toda aresta vermelha $\left(\lambda_{i}, \lambda_{i+1}\right)$ de um circuito $C$ de $G(\lambda)$ que corresponde a um elemento de $\mu(\lambda)$, atribuímos valores a $\vec{\sigma}_{i}$ e $\vec{\sigma}_{i+1}$, conforme os casos a seguir. Se $\left(\lambda_{i}, \lambda_{j}\right)$ é uma aresta azul de $C$ e $\lambda_{i}<\lambda_{j}$, então atribuímos $\vec{\sigma}_{i} \leftarrow \lambda_{i}$, senão atribuímos $\vec{\sigma}_{i} \leftarrow-\lambda_{i}$. De forma simétrica, se $\left(\lambda_{i+1}, \lambda_{j}\right)$ é uma aresta azul de $C$ e $\lambda_{i+1}>\lambda_{j}$, então atribuímos $\vec{\sigma}_{i+1} \leftarrow \lambda_{i+1}$, senão atribuímos $\vec{\sigma}_{i+1} \leftarrow-\lambda_{i+1}$.

$\mathrm{Na}$ terceira etapa, para todo $i$ tal que $\vec{\sigma}_{i}$ não foi determinado pelas duas etapas anteriores, atribuímos $\vec{\sigma}_{i} \leftarrow \lambda_{i}$.

Considere $\sigma$ retrato de $\vec{\sigma}$. 
Note que, após a primeira etapa, para quaisquer valores dos elementos de $\vec{\sigma}$ que correspondem a 1-corrente em $\lambda$, temos que $b(\sigma)=b(\lambda)$.

Por outro lado, após a segunda etapa, para cada elemento de $\mu(\lambda)$, obtemos um 2-circuito diferente em $G(\sigma)$. Ou seja, $c_{2}(\sigma) \geq|\mu(\lambda)|$. Observe, também, que essa segunda etapa não pode atribuir valores diferentes a um elemento definido na primeira etapa. Para verificar esse fato vejamos o seguinte.

Se $\left(\lambda_{i}, \lambda_{i+1}\right)$ e $\left(\lambda_{i}, \lambda_{j}\right)$ são arestas vermelha e azul, respectivamente, de um 2-circuito $C$ em $G(\lambda)$ e $\lambda_{j}=\lambda_{i}+1$, então $\lambda_{i}$ não pode ser elemento de uma $k$-corrente decrescente, $k \geq 2$, desde que $\lambda_{i+1} \nsim \lambda_{i}$ e $j \nsim i$. Os demais casos são analisados de maneira análoga.

Portanto, o procedimento descrito nesta seção, determina um candidato apropriado de $\lambda$.

Desde que cada uma destas três etapas pode ser executada em tempo proporcional a $n$, a complexidade de tempo para determinar um candidato apropriado de $\lambda$ a partir das permutações $\lambda, \lambda^{-1}$ e do conjunto $\mu(\lambda)$, é $O(n)$.

\subsubsection{Ordenando o Retrato de um Candidato Apropriado}

Após determinarmos um candidato apropriado $\vec{\sigma}$ de $\lambda$, o retrato $\sigma$ de $\vec{\sigma}$ é dado como entrada para o Algoritmo SBR-Orienta (veja Seção 3.4), que devolve uma seqüência mínima de reversões pares $\left(2 i_{1}-1 . .2 j_{1}\right),\left(2 i_{2}-1 . .2 j_{2}\right), \ldots,\left(2 i_{z}-1 . .2 j_{z}\right)$ que ordena $\sigma$. Claramente, a seqüência de reversões $\left(i_{1} . . j_{1}\right),\left(i_{2} . . j_{2}\right), \ldots,\left(i_{t} . . j_{z}\right)$ ordena a permutação $\lambda$.

A complexidade de tempo para ordenar o retrato $\sigma$ do candidato apropriado de $\lambda$ é $O(n d)$ (Teorema 3.39), onde $d=d(\sigma)$.

\subsubsection{Algoritmo AproxMIN-SBR}

Dos procedimentos vistos nas seções anteriores, sintetizamos a seguir o funcionamento do Algoritmo AproxMIN-SBR.

Algoritmo AproxMIN-SBR;

Entrada: A permutação $\pi$.

Saída: Uma seqüência de reversões que ordena $\pi$.

determine as reversões $\rho_{1}, \rho_{2}, \ldots, \rho_{x}$ e $\varrho_{1}, \varrho_{2}, \ldots, \varrho_{y}$ e a permutação $\lambda$ usando o Procedimento Transforma para a entrada $\pi$;

determine o retrato $\sigma$ de um candidato apropriado de $\lambda$ (veja Seção 4.1.5);

determine uma seqüência de reversōes pares $\left(2 i_{1}-1 . .2 j_{1}\right),\left(2 i_{2}-1 . .2 j_{2}\right), \ldots,\left(2 i_{z}-1 . .2 j_{z}\right)$ que ordena $\sigma$ usando o Algoritmo SBR-Orienta para a entrada $\sigma$;

devolva a seqüência de reversões $\rho_{1}, \rho_{2}, \ldots, \rho_{x}, \varphi_{1}, \varphi_{2}, \ldots, \varphi_{z}, \varrho_{1}, \varrho_{2}, \ldots, \varrho_{y}$. onde $\varphi_{k}=\left(i_{k} . j_{k}\right)$.

\subsubsection{Fator de Aproximação de AproxMIN-SBR}

A fim de demonstrar o fator de aproximação $7 / 4$ do algoritmo descrito, precisaremos de dois resultados. 
Lema 4.8 Para $\sigma$ retrato de uma permutação orientada,

$$
d(\sigma) \leq b(\sigma)-\frac{c_{2}(\sigma)}{2} .
$$

Prova. Desde que $d(\sigma)=b(\sigma)-c(\sigma)+h(\sigma)+f(\sigma)$ (Teorema 3.18), segue que, para provar o lema, basta mostrar que, para todo retrato $\sigma$ de uma permutação orientada,

$$
c(\sigma) \geq \frac{c_{2}(\sigma)}{2}+h(\sigma)+f(\sigma) .
$$

Para $M$ uma componente em $H(\sigma)$, denotamos por $C(M)$ o conjunto de circuitos em $G(\sigma)$ cujas arestas azuis são todas vértices de $M$.

Sejam $M$ uma componente em $H(\sigma)$ e, $x$ aresta de um circuito $C$ em $G(\sigma)$ e vértice de $M$. Segue do Lema 3.6 que $C \in C(M)$. Observando que, se $M$ é uma componente má e $C$ é um 2-circuito e $y \neq x$ é a outra aresta azul de $C$, então $x \bowtie y$ em $\sigma$, segue do Lema 3.4 que existe um vértice $z$ de $G(\sigma)$, tal que $z \bowtie x$. Segue que $|C(M)| \geq 2$.

Seja $\mathcal{P}$ o sub-conjunto de obstáculos em $H(\sigma)$, tal que $M \in \mathcal{P}$, se um dos vértices de $M$ é aresta de um 2-circuito em $G(\sigma)$.

Seja $c^{2}(\sigma)$ o número de circuitos em $G(\sigma)$ cujas arestas azuis são vértices de uma componente $M \in \mathcal{P}$. Seja $c_{2}^{2}(\sigma)$ o número de 2 -circuitos em $G(\sigma)$ cujas arestas azuis são vértices de uma componente $M \in \mathcal{P}$. Seja $h^{2}(\sigma)=|\mathcal{P}|$.

Como, para toda componente $M \in \mathcal{P},|C(M)| \geq 2$, temos que $c^{2}(\sigma) \geq 2 h^{2}(\sigma)$. Como $c^{2}(\sigma) \geq c_{2}^{2}(\sigma)$, segue que $2 c^{2}(\sigma) \geq c_{2}^{2}(\sigma)+2 h^{2}(\sigma)$. Portanto,

$$
c^{2}(\sigma) \geq \frac{c_{2}^{2}(\sigma)}{2}+h^{2}(\sigma) .
$$

Considere $c^{0}(\sigma)=c(\sigma)-c^{2}(\sigma)$ e $c_{2}^{0}(\sigma)=c_{2}(\sigma)-c_{2}^{2}(\sigma)$ e $h^{0}(\sigma)=h(\sigma)-h^{2}(\sigma)$ e $\overline{\mathcal{P}} \mathrm{o}$ sub-conjunto das componentes de $H(\sigma)$, tal que $M \in \overline{\mathcal{P}}$ se $M \notin \mathcal{P}$.

Segue do Lema 3.6 que $c^{0}(\sigma)$ é o número de circuitos em $G(\sigma)$ cujas arestas azuis são vértices de uma componente $M \in \overline{\mathcal{P}}$.

Note que, para cada circuito $p$ em $C(M), M \in \overline{\mathcal{P}}$, não pode ocorrer ao mesmo tempo de $p$ ser um 2-circuito e $M$ um obstáculo. Segue que,

$$
c^{0}(\sigma) \geq c_{2}^{0}(\sigma)+h^{0}(\sigma)=\frac{c_{2}^{0}(\sigma)}{2}+h^{0}(\sigma)+\frac{c_{2}^{0}(\sigma)}{2} .
$$

Se $f(\sigma)=0$, então, como $\frac{c_{2}^{0}(\sigma)}{2} \geq 0$,

$$
c^{0}(\sigma) \geq \frac{c_{2}^{0}(\sigma)}{2}+h^{0}(\sigma)+f(\sigma)
$$

Se $f(\sigma)=1$, então existe um não-obstáculo $K$ em $H(\sigma)$ e pelo menos uma das duas condições a seguir ocorre. Se todos os circuitos em $C(K)$ são 2-circuitos, então, como $K$ é uma componente má, existem pelo menos dois 2-circuitos em $C(K)$ e, portanto, $\frac{c_{2}^{0}(\sigma)}{2} \geq 1$. Se existe um circuito $q$ em $C(K)$ que não é um 2-circuito, como, para cada circuito $p$ em $C(M), M \in \overline{\mathcal{P}}$, não pode ocorrer 
ao mesmo tempo de $p$ ser um 2-circuito e $M$ um obstáculo, segue que $c^{0}(\sigma) \geq \frac{c_{2}^{0}(\sigma)}{2}+h^{0}(\sigma)+1$. Portanto, para $f(\sigma)=1$, temos também que

$$
c^{0}(\sigma) \geq \frac{c_{2}^{0}(\sigma)}{2}+h^{0}(\sigma)+f(\sigma) .
$$

Segue que,

$$
c(\sigma)=c^{0}(\sigma)+c^{2}(\sigma) \geq \frac{c_{2}^{0}(\sigma)}{2}+\frac{c_{2}^{2}(\sigma)}{2}+h^{0}(\sigma)+h^{2}(\sigma)+f(\sigma)=\frac{c_{2}(\sigma)}{2}+h(\sigma)+f(\sigma) .
$$

Lema 4.9 [BP93] Dada uma entrada $\pi$, o Algoritmo AproxMIN-SBR encontra uma seqüência de no máximo $b(\pi)-c_{2}(\pi, D) / 4$ reversões, para qualquer decomposição máxima em circuitos $D$.

Prova. Como $c_{2}(\sigma) \geq|\mu(\lambda)|$ e $b(\sigma)=b(\lambda)$ (pois $\sigma$ é o retrato de um candidato apropriado de $\lambda)$, e $|\mu(\pi)| \geq c_{2}(\pi, D)$, segue dos Fatos 4.5 e 4.6 e do Lema 4.8 que

$$
\begin{aligned}
x+y+z & \leq x+y+b(\sigma)-\frac{c_{2}(\sigma)}{2} \\
& \leq x+y+b(\sigma)-\frac{|\mu(\lambda)|}{2} \\
& =b(\pi)-(x+y)-\frac{|\mu(\lambda)|}{2} \\
& \leq b(\pi)-\frac{|\mu(\pi)|-|\mu(\lambda)|}{4}-\frac{|\mu(\lambda)|}{2} \\
& \leq b(\pi)-\frac{|\mu(\pi)|}{4}-\frac{|\mu(\lambda)|}{4} \\
& \leq b(\pi)-\frac{|\mu(\pi)|}{4} \\
& \leq b(\pi)-\frac{c_{2}(\pi, D)}{4} .
\end{aligned}
$$

Teorema 4.10 O Algoritmo AproxMIN-SBR garante um fator de aproximação de 7/4.

Prova. Seja $D$ uma decomposição máxima em circuitos de $G(\pi)$. Note que $b(\pi) \geq 2 c_{2}(\pi, D)$. Do Teorema 4.4 e do Lema 4.9 segue que

$$
\begin{aligned}
\frac{T(\text { AproxMIN-SBR }, \pi)}{d(\pi)} & \leq \frac{b(\pi)-c_{2}(\pi, D) / 4}{2(\pi) / 3-c_{2}(\pi, D) / 3} \\
& =\frac{3}{4} \frac{4 b(\pi)-c_{2}(\pi, D)}{2 b(\pi)-c_{2}(\pi, D)}
\end{aligned}
$$




$$
\begin{aligned}
& =\frac{3}{4}\left(\frac{4 b(\pi)-2 c_{2}(\pi, D)}{2 b(\pi)-c_{2}(\pi, D)}+\frac{c_{2}(\pi, D)}{2 b(\pi)-c_{2}(\pi, D)}\right) \\
& =\frac{3}{2}+\frac{3}{4} \frac{c_{2}(\pi, D)}{2 b(\pi)-c_{2}(\pi, D)} \\
& \leq \frac{3}{2}+\frac{3}{4} \frac{c_{2}(\pi, D)}{4 c_{2}(\pi, D)-c_{2}(\pi, D)} \\
& =\frac{7}{4} .
\end{aligned}
$$

\subsubsection{Complexidade de Tempo de AproxMIN-SBR}

Verificando que cada fase de AproxMIN-SBR pode ser implementada em tempo $O\left(n^{2}\right)$, temos que essa é a complexidade de tempo total do algoritmo.

\subsection{Diâmetro de Reversão do Grupo Simétrico}

Seja $S_{n}$ o grupo simétrico com $n$ elementos, isto é,

$$
S_{n}=\{\text { permutações sobre }\{1,2, \ldots, n\}\} \text {. }
$$

Definimos

$$
d(n)=\max _{\pi \in S_{n}} d(\pi),
$$

como sendo o diâmetro de reversões do grupo simétrico $S_{n}$.

Watterson, Ewens, Hall e Morgan [WEHM82] sugeriram um algoritmo que ordena uma permutação $\pi$ sobre $n$ com no máximo $n-1$ reversões, fazendo, em cada iteração $i=1, \ldots, n-1$, a reversão $\left(i . . \pi_{i}^{-1}\right)$, se $\pi_{i} \neq i$. Em outras palavras, ele procura em cada iteração $i$ o elemento $\pi_{j}=i$ e, então, se $i \neq j$, aplica a reversão $(i . . j)$. Imediatamente obtemos o seguinte limitante superior.

Lema 4.11 Para todo $n$,

$$
d(n) \leq n-1
$$

Curiosamente, embora uma permutação $\pi$ seja ordenada de maneira eficiente usando o algoritmo acima, o tamanho da seqüência de reversões que ele devolve pode ser muitíssimo maior que $d(\pi)$. Observe, por exemplo, como esse algoritmo se comporta para a entrada $\left(\begin{array}{llllll}n & 1 & 2 & 3 & \ldots & n-1\end{array}\right)$. Em cada iteração $i$, o algoritmo determina a reversão $(i . . i+1)$, ordenando a permutação usando $n-1$ reversões. Entretanto, note que bastam apenas duas reversões para ordenar a permutação $\pi$ (aplique a reversão (1..n) seguida pela $(1 . . n-1)$ ). 


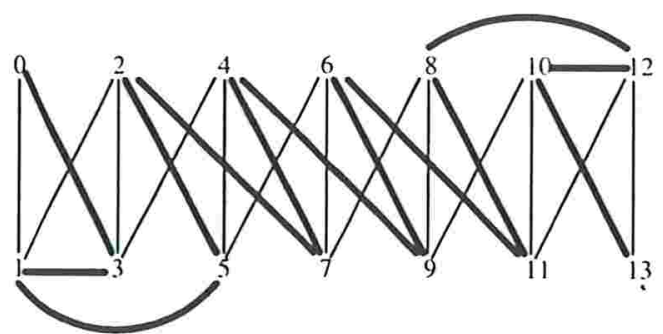

$G\left(\gamma^{12}\right)$

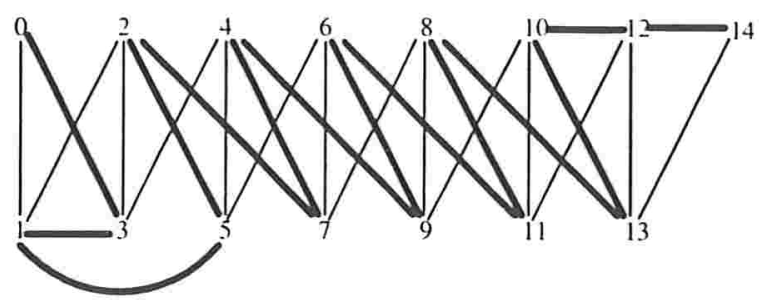

$G\left(\gamma^{13}\right)$

Figura 4.3: Grafo de pontos de quebra de $G\left(\gamma^{12}\right)$ e $G\left(\gamma^{13}\right)$.

Surge, então, uma questão intrigante a respeito do problema. Existiria alguma permutação $\pi$ tal que $d(\pi)=n-1$ ? Gollan conjecturou, conforme mencionado em [KS95], que a distância por reversões de uma particular permutação de $n$ elementos, que chamamos de permutação de Gollan, e que denotamos por $\gamma^{(n)}$, fosse $n-1$. Tal permutação particular é assim definida para $n \geq 1$,

$$
\gamma_{i}^{(n)}=\left\{\begin{array}{lll}
i+2 & \text { para } i \text { ímpar e } & 1 \leq i \leq n-2, \\
i-2 & \text { para } i \text { par e } & 4 \leq i \leq n, \\
i+1 & \text { para } i \text { ímpar e } & 1 \leq i=n-1, \\
i-1 & \text { para } i \text { ímpar e } & 3 \leq i=n, \\
i-1 & \text { para } & 2=i \leq n, \\
i & \text { para } & 1=i=n .
\end{array}\right.
$$

Gollan verificou a veracidade, para $n \leq 11$, computando a distância de $\gamma^{(n)}$. Bafna e Pevzner [BP93] usaram propriedades descobertas no grafo de pontos de quebra para provar a conjectura de Gollan para todo $n$. A seguir descrevemos a prova da conjectura.

Lema 4.12 [BP93] Para todo $n>0$,

$$
d\left(\gamma^{(n)}\right)=d\left(\gamma^{(n)^{-1}}\right)=n-1
$$

\section{(Conjectura de Gollan.)}

Prova. Primeiramente mostramos que todo circuito alternante em $G\left(\gamma^{(n)}\right)$ contém os vértices 1 ou 3. Para mostrar esse fato, considere $i, j, k$ três rótulos consecutivos em um circuito alternante $C$ em $G\left(\gamma^{(n)}\right)$, tais que $i$ é um rótulo ímpar de $C$ e $(i, j) \in R$ (veja Figura 4.3).

Desde que, para $i>5$, temos que ou $j=i-5$ ou $j=i-3$ e ou $k=j+1$ ou $k=j-1$, o que implica que $k$ é ímpar e $k<i$, segue que se $i$ é o menor rótulo em um circuito alternante em $G\left(\gamma^{(n)}\right)$, então $i \leq 5$.

Desde que, para $i=5$, temos que ou $j=1$ ou $j=2$ e, se $j=2$, então ou $k=j-1$ ou $k=j+1$ o que implica, novamente, que $k$ é ímpar e $k<i$, segue que se $i$ é o menor rótulo em um circuito alternante em $G\left(\gamma^{(n)}\right)$, então $i \neq 5$.

Como, para $i$ o menor rótulo ímpar de um circuito alternante em $G\left(\gamma^{(n)}\right), i \leq 5$ e $i \neq 5$, segue que ou $i=1$ ou $i=3$. 


$$
\gamma_{i}^{(n)^{-1}}=\left\{\begin{array}{lll}
i-2 & \text { para } i \text { impar e } & 3 \leq i \leq n, \\
i+2 & \text { para } i \text { par e } & 2 \leq i \leq n-2, \\
i-1 & \text { para } i \text { par e } & 2 \leq i=n, \\
i+1 & \text { para } i \text { par e } & 2 \leq i=n-1, \\
i+1 & \text { para } & 1=i \leq n, \\
i & \text { para } & 1=i=n .
\end{array}\right.
$$

Figura 4.4: Permutação $\gamma^{(n)^{-1}}$.

A seguir, verificamos que, para todo $n, c\left(\gamma^{(n)}\right) \leq 2$. Para isto, particione o conjunto de vértices de $G\left(\gamma^{(n)}\right)$ em $V^{\prime}=\{0,1,3\}$ e $V^{\prime \prime}$. Observe que o corte $\left(V^{\prime}, V^{\prime \prime}\right)$ possue 4 arestas: $\{(1,2) ;(1,5) ;(3,2) ;(3,4)\}$. Como todo circuito alternante passa por $V^{\prime}$ e não existe um circuito alternante que tem como vértices somente elementos de $V^{\prime}$, segue que o número máximo de circuitos disjuntos nas arestas em uma decomposição máxima de $G\left(\gamma^{(n)}\right)$ é no máximo $4 / 2=2$.

Como $b\left(\gamma^{(n)}\right)=n+1$ e $c\left(\gamma^{(n)}\right) \leq 2$, segue do Lema 4.11 e do Teorema 2.1 que

$$
n-1 \geq d(n) \geq d\left(\gamma^{(n)}\right) \geq b\left(\gamma^{(n)}\right)-c\left(\gamma^{(n)}\right) \geq(n+1)-2=n-1,
$$

o que implica que $d\left(\gamma^{(n)}\right)=n-1$.

Concluímos também, por prova simétrica, que $d\left(\gamma^{(n)^{-1}}\right)=n-1$.

Dos Lemas 4.11 e 4.12 segue o seguinte resultado.

Teorema 4.13 Para todo $n>0$,

$$
d(n)=n-1
$$

Bafna e Pevzner [BP93] mostraram um resultado mais forte e mais surpreendente. Eles provaram que $\gamma^{(n)}$ e $\gamma^{(n)^{-1}}$ são as únicas permutações que requerem pelo menos $n-1$ reversões para serem ordenadas. Entretanto, a base de indução da prova que os autores acima apresentam está errada. Mostramos a seguir a prova desse resultado com a devida correção.

Antes disso, vejamos os seguintes conceitos.

Seja $\pi$ uma permutação sobre $n-1$. Denotamos por $\pi n$ a permutação $\left(\begin{array}{lllll}\pi_{1} & \pi_{2} & \ldots & \pi_{n-1} & n\end{array}\right)$, ou seja,

$$
(\pi n)_{i}= \begin{cases}\pi_{i} & \text { se } 1 \leq i \leq n-1, \\ n & \text { se } i=n .\end{cases}
$$

Denotamos por $1 \hat{\pi}$ a permutação $\left(\begin{array}{lllll}1 & \pi_{1}+1 & \pi_{2}+1 & \ldots & \pi_{n-1}+1\end{array}\right)$, ou seja,

$$
(1 \hat{\pi})_{i}= \begin{cases}1 & \text { se } i=1, \\ \pi_{i-1}+1 & \text { se } 2 \leq i \leq n .\end{cases}
$$

Fato 4.14 Para $\pi$ uma permutação sobre $n-1$,

$$
d(\pi)=d(\pi n)=d(1 \hat{\pi}) .
$$


Teorema 4.15 [BP93] Para todo $n, \gamma^{(n)}$ e $\gamma^{(n)^{-1}}$ são as únicas permutações que requerem $n-1$ reversões para serem ordenadas.

(Conjectura forte de Gollan.)

Prova. Seja $\mathcal{P}_{n}=\left\{\pi \mid \pi \in S_{n}\right.$ e $\left.d(\pi)=n-1\right\}$.

Segue do Lema 4.12 que $\mathcal{P}_{n} \supseteq\left\{\gamma^{(n)}, \gamma^{(n)^{-1}}\right\}$. Segue, por sua vez, que para provar o teorema, basta mostrar que $\mathcal{P}_{n} \subseteq\left\{\gamma^{(n)}, \gamma^{(n)^{-1}}\right\}$.

Para $n \leq 5, \mathcal{P}_{n} \subseteq\left\{\gamma^{(n)}, \gamma^{(n)^{-1}}\right\}$ pode ser verificado por força bruta. Suponha. então, que a afirmação vale para $n-1, n \geq 6$, e, então, mostramos que o teorema também vale para $n$. Considere $\pi \in \mathcal{P}_{n}$.

Seja $\rho_{\pi}$ a única reversão em $\pi$, tal que $\left(\pi \cdot \rho_{\pi}\right)_{n}=n$, isto é, $\pi \cdot \rho_{\pi}=\pi^{\prime} n$, onde $\pi^{\prime}$ é uma permutação sobre $n-1$. Como $d(\pi) \leq 1+d\left(\pi^{\prime} n\right)$, segue do Lema 4.11 e do Fato 4.14 que

$$
n-2 \geq d\left(\pi^{\prime}\right)=d\left(\pi^{\prime} n\right) \geq d(\pi)-1=n-1-1=n-2,
$$

o que implica que $d\left(\pi^{\prime}\right)=n-2$. Segue, por hipótese de indução, que ou $\pi^{\prime} n=\gamma^{(n-1)} n$ ou $\pi^{\prime} n=\gamma^{(n-1)^{-1}} n$.

Por raciocínio análogo, definindo $\rho_{\pi}^{\prime}$ como a única reversão em $\pi$, tal que $\pi \cdot \rho_{\pi}^{\prime}=1 \hat{\pi}^{\prime}$, segue que ou $1 \hat{\pi}^{\prime}=1 \hat{\gamma}^{(n-1)}$ ou $1 \hat{\pi}^{\prime}=1 \hat{\gamma}^{(n-1)^{-\frac{\pi}{1}}}$.

$\operatorname{Sejam} \mathcal{A}=\left\{\pi \mid \pi \cdot \rho_{\pi}=\gamma^{(n-1)} n\right\}$ e $\mathcal{B}=\left\{\pi \mid \pi \cdot \rho_{\pi}=\gamma^{(n-1)^{-1}} n\right\}$ e $\mathcal{C}=\left\{\pi \mid \pi \cdot \rho_{\pi}^{\prime}=1 \hat{\gamma}^{(n-1)}\right\}$ e $\mathcal{D}=\left\{\pi \mid \pi \cdot \rho_{\pi}^{\prime}=1 \hat{\gamma}^{(n-1)^{-1}}\right\}$. Segue das considerações acima que

$$
\mathcal{P}_{n} \subseteq \mathcal{A} \cup \mathcal{B} \text { e } \mathcal{P}_{n} \subseteq \mathcal{C} \cup \mathcal{D}
$$

Como, para $n \geq 6, \mathcal{A} \cap \mathcal{C}=\emptyset$ (Lema 4.19) e $\mathcal{A} \cap \mathcal{D}=\left\{\gamma^{(n)}\right\}$ (Lema 4.20) e $\mathcal{B} \cap \mathcal{C}=\left\{\gamma^{(n)^{-1}}\right\}$ (Lema 4.22) e $\mathcal{B} \cap \mathcal{D}=\emptyset$ (Lema 4.21), concluímos que $\mathcal{P}_{n} \subseteq\left\{\gamma^{(n)}, \gamma^{(n)^{-1}}\right\}$.

O quê diferencia a prova do Teorema 4.15 daquela apresentada por Bafna e Pevzner [BP93] é a base de indução de $n=2$ na segunda. Entretanto, não é verdade que $\mathcal{A} \cap \mathcal{C}=\emptyset$ para $n \geq 3$ pois, para $n=5$,

$$
\left(\begin{array}{lllll}
5 & 2 & 4 & 1 & 3
\end{array}\right) \in \mathcal{A} \cap \mathcal{C} .
$$

Para demonstrar os Lemas 4.19 e 4.20 e 4.22 e 4.21 vejamos os seguintes conceitos.

Seja $\pi$ uma permutação sobre $n$. Dizemos que $i$ precede $j$ em $\pi$, se $\pi_{i}^{-1}<\pi_{j}^{-1}$. Em outras palavras, $\pi=\left(\begin{array}{llllll}\ldots & i & \ldots & j & \ldots\end{array}\right)$.

Fato 4.16 Seja $\pi$ uma permutação sobre $n, n \geq 6$, tal que 1 precede $n$ em $\pi$.

Se $\pi \in \mathcal{A}$, então

$$
\pi=\left(\begin{array}{lllll}
3 & 1 & \ldots & n & \ldots
\end{array}\right) .
$$

Se $\pi \in \mathcal{B}$, então

$$
\pi=\left(\begin{array}{llllll}
2 & 4 & 1 & \ldots & n & \ldots
\end{array}\right) .
$$

Fato 4.17 Seja $\pi$ uma permutação sobre $n, n \geq 6$, tal que $n$ precede $1 \mathrm{em} \pi$.

Se $\pi \in \mathcal{A}$, então

$$
\text { ou } \pi=\left(\begin{array}{llll}
n & \ldots & 1 & 3
\end{array}\right) \text { ou } \pi=\left(\begin{array}{llll}
3 & n & \ldots & 1
\end{array}\right) .
$$

Se $\pi \in \mathcal{B}$, então

$$
\text { ou } \pi=\left(\begin{array}{lllll}
n & \ldots & 1 & 4 & 2
\end{array}\right) \text { ou } \pi=\left(\begin{array}{lllll}
2 & n & \ldots & 1 & 4
\end{array}\right) \text { ou } \pi=\left(\begin{array}{lllll}
2 & 4 & n & \ldots & 1
\end{array}\right) .
$$




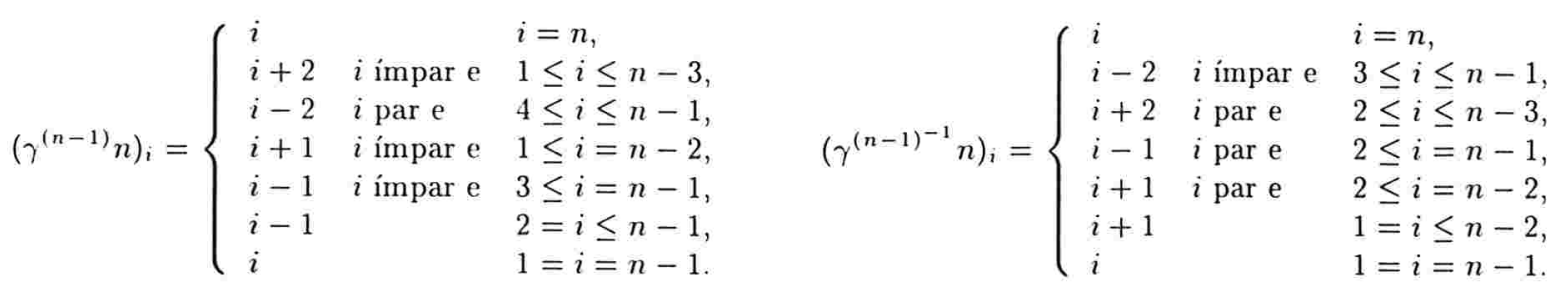

Figura 4.5: Permutações $\gamma^{(n-1)} n$ e $\gamma^{(n-1)^{-1}} n$.

Fato 4.18 Para $n \geq 6$,

$$
\gamma^{(n)} \in(\mathcal{A} \cap \mathcal{D}) \text { e } \gamma^{(n)^{-1}} \in(\mathcal{B} \cap \mathcal{C}) .
$$

Lema 4.19 Para $n \geq 6$,

$$
\mathcal{A} \cap \mathcal{C}=\emptyset \text {. }
$$

Prova. Seja $\pi \in \mathcal{A}, n \geq 6$.

Para 1 precede $n$ em $\pi$, segue do Fato 4.16 que

$$
\left(\pi \cdot \rho_{\pi}^{\prime}\right)_{2}=3 \neq 4=\left(1 \hat{\gamma}^{(n-1)}\right)_{2},
$$

e, para $n$ precede 1 , segue do Fato 4.17 que

$$
\left(\pi \cdot \rho_{\pi}^{\prime}\right)_{n}=3<\left(1 \hat{\gamma}^{(n-1)}\right)_{n} .
$$

Logo, $\pi \in \mathcal{A} \Rightarrow \pi \notin \mathcal{C}$. Portanto, $\mathcal{A} \cap \mathcal{C}=\emptyset$.

Lema 4.20 Para $n \geq 6$,

$$
\mathcal{A} \cap \mathcal{D}=\left\{\gamma^{(n)}\right\} .
$$

Prova. Como, pelo Fato 4.18, $\gamma^{(n)} \in \mathcal{A} \cap \mathcal{D}$, segue que, para provar o lema, basta mostrar que, para $n \geq 6,(\mathcal{A} \cap \mathcal{D}) \backslash\left\{\gamma^{(n)}\right\}=\emptyset$.

Seja $\pi \in \mathcal{A}, \pi \neq \gamma^{(n)}, n \geq 6$.

Se 1 precede $n$ em $\pi$, sendo $\pi \neq \gamma^{(n)}$, então, para $n$ par, $\pi_{n-1} \neq n$ e, para $n$ ímpar, $\pi_{n-2} \neq n$. Segue que

$$
\left(\pi \cdot \rho_{\pi}^{\prime}\right)_{\pi_{n}^{-1}} \neq\left(1 \hat{\gamma}^{(n-1)^{-1}}\right)_{\pi_{n}^{-1}}
$$

Se $n$ precede 1 em $\pi$, então, segue do Fato 4.17,

$$
\left(\pi \cdot \rho_{\pi}^{\prime}\right)_{n}=3<\left(1 \hat{\gamma}^{(n-1)^{-1}}\right)_{n} .
$$




$$
\left(1 \hat{\gamma}^{(n-1)}\right)_{i}=\left\{\begin{array}{lll}
i & & i=1, \\
i-2 & i \text { impar e } & 5 \leq i \leq n, \\
i+2 & i \text { par e } & 2 \leq i \leq n-2, \\
i-1 & i \text { par e } & 4 \leq i=n, \\
i+1 & i \text { par e } & 2 \leq i=n-1, \\
i-1 & & 3=i \leq n, \\
i & 2=i=n .
\end{array} \quad\left(1 \hat{\gamma}^{(n-1)^{-1}}\right)_{i}=\left\{\begin{array}{lll}
i & & i=1, \\
i+2 & i \text { impar } \mathrm{e} & 3 \leq i \leq n-2, \\
i-2 & i \text { par e } & 4 \leq i \leq n, \\
i+1 & i \text { impar } \mathrm{e} & 3 \leq i=n-1, \\
i-1 & i \text { impar } \mathrm{e} & 3 \leq i=n, \\
i+1 & & 2=i \leq n-1, \\
i & & 2=i=n .
\end{array}\right.\right.
$$

Figura 4.6: Permutações $1 \hat{\gamma}^{(n-1)}$ e $1 \hat{\gamma}^{(n-1)^{-1}}$.

Concluímos, portanto, que, independentemente de ou 1 precede $n$ ou $n$ precede 1 em $\pi$, $(\mathcal{A} \cap \mathcal{D}) \backslash\left\{\gamma^{(n)}=\emptyset\right.$.

Por raciocínio simétrico às provas dos Lemas 4.19 e 4.20 , mostramos a veracidade dos seguintes lemas, respectivamente.

Lema 4.21 Para $n \geq 6$,

$$
\mathcal{B} \cap \mathcal{D}=\emptyset
$$

Lema 4.22 Para $n \geq 6$,

$$
\mathcal{B} \cap \mathcal{C}=\left\{\gamma^{(n)^{-1}}\right\}
$$

\subsection{Distância Esperada por Reversões}

Nesta seção mostramos um limitante inferior para o valor esperado da distância por reversões de uma permutação $\pi$, escolhida aleatória e uniformemente, em $S_{n}$. Denotamos por $E^{n}$ a distância esperada de reversão de uma permutação sobre $n$.

Esse limitante inferior foi determinado por Bafna e Pevzner [BP93], e entendemos que seu significado pode ser interpretado da seguinte forma. Se, para uma permutação $\pi$ sobre $n$, que representa dois cromossomos de duas espécies $A$ e $B$ (um representado por $\pi$ e outro pela permutação identidade), $d(\pi)<E^{n}$, então é muito provável que $d(\pi)$ represente, de fato, o número de eventos de reversão que, ao longo do tempo, transformaram um ancestral comum nas espécies $A$ e $B$.

Teorema 4.23 [BP93] Para todo n,

$$
E^{n} \geq\left(1-\frac{4,5}{\log n}\right) n
$$




\section{Capítulo 5}

\section{Complexidade de MIN-SBR}

\subsection{Introdução}

Caprara [Cap96] demonstrou que MIN-SBR é um problema $N P$-difícil. Nesta seção mostramos os pontos principais de uma prova baseada no trabalho acima citado.

O ponto de partida da prova é o seguinte problema. Dado um grafo $H$, determinar se o conjunto de arestas de $H$ pode ser particionado em cliques de tamanho $k$. Holyer [Hol81] mostrou que esse problema é $N P$-completo, para todo $k \geq 3$ fixo. Podemos definir, a partir desse problema, o seguinte problema de decisão.

\section{Problema 4 CLIQUE-3}

Instância: Um grafo $H$.

Pergunta: O conjunto de arestas de $H$ pode ser particionado em triângulos (cliques de tamanho 3$)$ ?

Segue, dessas observações, o resultado abaixo.

Teorema 5.1 CLIQUE-3 é NP-completo.

A idéia que usamos para provar que MIN-SBR é NP-difícil é a seguinte. Definimos nas próximas seções os problemas MAX-ECD e MAX-ACD; fazemos uma redução polinomial do Problema CLIQUE-3 ao Problema MAX-ECD; em seguida fazemos uma redução polinomial do Problema MAX-ECD ao Problema MAX-ACD. Finalmente fazemos uma redução polinomial do Problema MAX-ACD ao Problema MIN-SBR.

\subsection{Complexidade de MAX-ECD}

Seja $H$ um grafo euleriano. Uma decomposição em circuitos de um grafo euleriano $H$ é uma partição das arestas de $H$ em circuitos. Uma decomposição máxima em circuitos de um grafo euleriano $H$ é uma decomposição em $t$ circuitos, onde $t$ é máximo.

Denotamos por $\hat{c}(H)$ o número de circuitos obtidos em uma decomposição máxima em circuitos de um grafo euleriano $H$. Definimos o seguinte problema. 


\section{Problema $5 M A X-E C D$}

Instância: Um grafo euleriano $H$.

Objetivo: Determinar $\hat{c}(H)$.

Considere um algoritmo que resolve o Problema MAX-ECD, isto é, recebe um grafo euleriano $H$, que possui o conjunto $A$ de arestas, e devolve $\hat{c}(H)$. Note que a saída desse algoritmo é $|A| / 3$ se, e somente se, podemos particionar $A$ em triângulos. Ou seja, a saída é $|A| / 3$ se, e somente se, a resposta do Problema CLIQUE-3 para $H$ é "sim". Como CLIQUE-3 é $N P$-completo, temos o seguinte resultado.

Teorema 5.2 MAX-ECD é NP-difícil.

\subsection{Complexidade de MAX-ACD}

Dizemos que um grafo simples bicolorido $G=(W, R \cup B)$ é um grafo de pontos de quebra, se as seguintes condições são satisfeitas.

- cada componente no grafo $G(B)$ e cada componente do grafo $G(R)$ é um caminho simples;

- cada vértice $v \in W$ tem o mesmo grau que é 1 ou 2 em $G(B)$ e em $G(R)$;

- $R \cap B=\emptyset$.

Note que o fato de que cada vértice $v \in W$ tem o mesmo grau em $G(B)$ e em $G(R)$, garante, para qualquer grafo de pontos de quebra $G$, uma decomposição em circuitos alternantes de $G$.

Denotamos por $c(G)$ o número de circuitos obtidos em uma decomposição máxima em circuitos alternantes de $G$.

\section{Problema $6 M A X-A C D$}

Instância: Um grafo de pontos de quebra $G$.

Questão: Determinar $c(G)$.

Na Seção 5.3.1 descrevemos o Procedimento Trans_Euleriano, que recebe um grafo euleriano $H$ e constrói um grafo de pontos de quebra $G$ com as seguintes propriedades.

- $G$ pode ser construído em tempo (e tamanho) polinomial no número de arestas de $H$;

- $\hat{c}(H)=c(G)$.

Dado um grafo euleriano $H$, o Procedimento Trans_Euleriano constrói um grafo de pontos de quebra $G$. O grafo $G$ é, então, dado como entrada para um algoritmo que resolve o Problema MAX-ACD, determinando, assim, $c(G)=\hat{c}(H)$ e, portanto, resolvendo também o Problema MAX-ECD. Como Trans_Euleriano constrói o grafo $G$ em tempo polinomial no número de arestas do grafo $H$, temos o seguinte resultado.

Teorema 5.3 MAX-ACD é NP-difícil. 


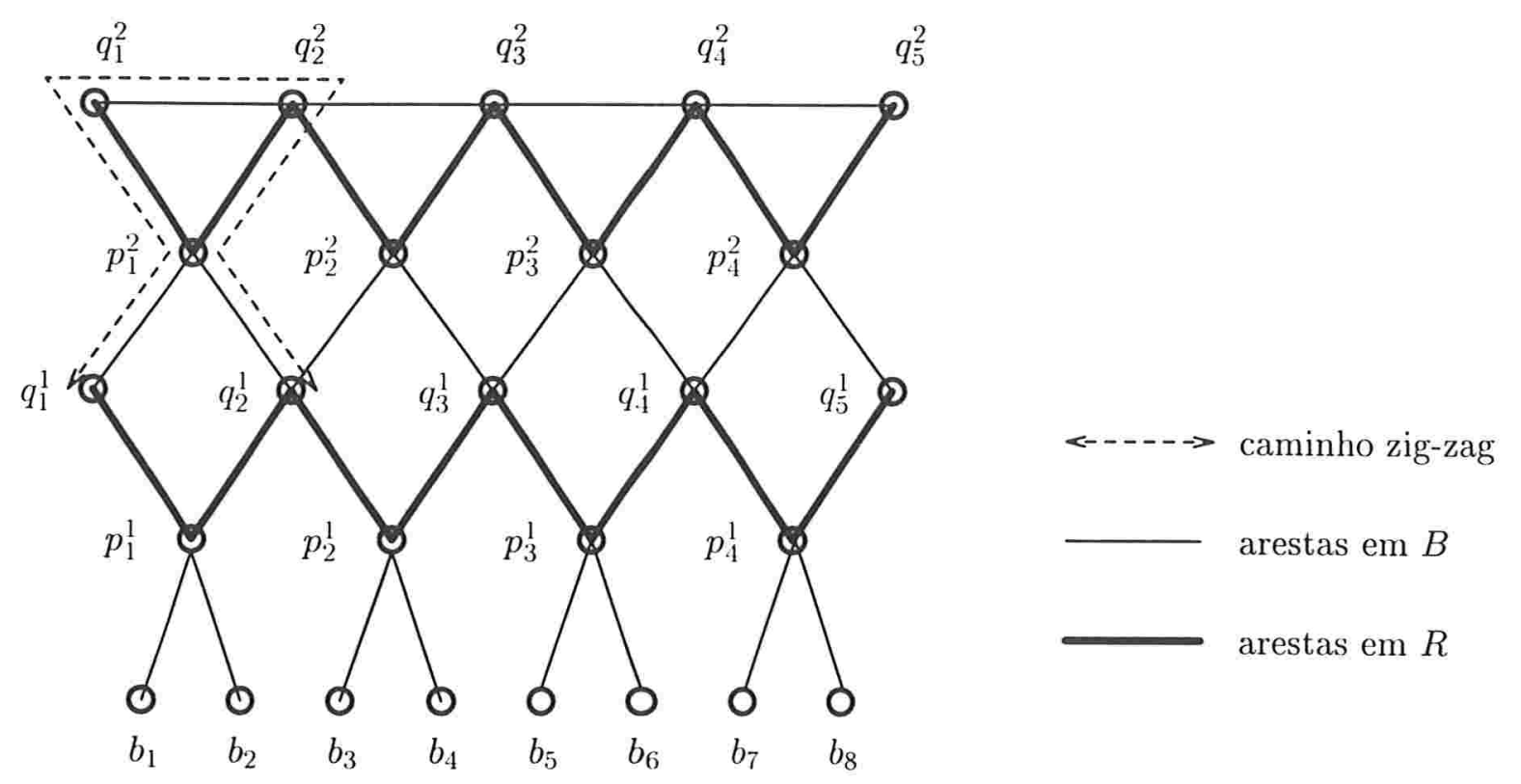

Figura 5.1: Grafo bicolorido $G(d, m)$ para $d=8$ e $m=2$.

\subsubsection{Transformando um Grafo Euleriano em um Grafo de Pontos de Quebra}

Nesta seção descrevemos o Procedimento Trans_Euleriano que recebe um grafo euleriano $H$ e constrói um grafo de pontos de quebra $G$ com as seguintes propriedades.

- $G$ pode ser construído em tempo polinomial no número de arestas de $H$;

- $\hat{c}(H)=c(G)$.

A idéia dessa construção é baseada na substituição de cada vértice $v$ de grau $d$ em $H$ por um grafo bicolorido $G(v)$, unicamente determinado por $d$. Em particular, $G(v)$ possui $d$ vértices de grau 1, cada um com uma aresta azul a ele incidente. Os demais são vértices de grau ou 2 ou 4, cada um com o mesmo número de arestas azuis e vermelhas a ele incidentes. Além disso, $G(v)$ não contém circuitos alternantes e, para qualquer partição de seus vértices de grau $1 \mathrm{em}$ pares, o conjunto de arestas de $G(v)$ pode ser decomposto em $d / 2$ caminhos alternantes disjuntos nas arestas, cada qual ligando os vértices de um par da partição definida.

O grafo $G$ é, então, obtido conectando os diversos grafos $G(v)$ 's construídos. Para cada aresta $p=(u, v)$ de $H$, um vértice de grau 1 no grafo $G(v)$ e um vértice de grau 1 em $G(u)$ são ligados por uma aresta vermelha, garantindo que cada vértice de $G$, no final da construção, tenha o mesmo número de arestas azuis e vermelhas a ele incidentes.

Mostramos a seguir a estrutura de cada grafo $G(v)$ e provamos as propriedades acima mencionadas.

Para cada par de inteiros $d$ e $m$, onde $d$ é par, seja $G(d, m)$ o grafo bicolorido definido a seguir. Mostramos na Figura 5.1 o exemplo para $d=8$ e $m=2$. Seja $s=d / 2$ e $r=\lceil d / 4\rceil$. $G(d, m)$ é subdividido em $m$ níveis, que são todos iguais a cada outro com exceção do último.

Cada nível $l=1, \ldots, m$ contém $2 s+1$ vértices, sendo $s+1$ deles os vértices!superiores do nível, denotados por $q_{1}^{l}, \ldots, q_{s+1}^{l}$, e $s$ outros os vértices inferiores do nível, denotados por $p_{1}^{l}, \ldots, p_{s}^{l}$. Os 
vértices $q_{1}^{l}, \ldots, q_{s+1}^{l}$ e $p_{1}^{l}, \ldots, p_{s}^{l}$ são ligados por $d$ arestas vermelhas $\left(q_{i}^{l}, p_{i}^{l}\right),\left(q_{i+1}^{l}, p_{i}^{l}\right), i=1, \ldots, s$. Além disso, para $l=1, \ldots, m-1$, os vértices superiores $q_{1}^{l}, \ldots, q_{s+1}^{l}$ e os vértices inferiores do nível $l+1$ são ligados por $d$ arestas azuis $\left(p_{i}^{l+1}, q_{i}^{l}\right),\left(p_{i}^{l+1}, q_{i+1}^{l}\right), i=1, \ldots, s$. Finalmente, os vértices superiores do último nível $m$ são ligados pelas arestas azuis $\left(q_{i}^{m}, q_{i+1}^{m}\right), i=1, \ldots, s$.

$G(d, m)$ também contém $d$ vértices bases, denotados por $b_{1}, \ldots, b_{d}$. Os vértices bases e os vértices inferiores do nível 1 são ligados por $d$ arestas azuis $\left(b_{2 i-1}, p_{i}^{1}\right), \quad\left(b_{2 i}, p_{i}^{1}\right), i=1, \ldots, s$.

Fato 5.4 Cada vértice que não é um vértice base em $G(d, m)$ tem o mesmo número de arestas vermelhas e azuis a ele incidentes. Além disso, $G(d, m)$ não contém circuitos alternantes, e todo caminho alternante ligando dois vértices bases é formado por $4 m+1$ arestas, sendo a $(2 m+1)$ ésima uma aresta azul ligando dois vértices superiores do nivel $m$.

Portanto, quaisquer s caminhos alternantes disjuntos nas arestas ligando vértices bases é uma partição do conjunto de arestas de $G(d, m)$.

De maneira a mostrar a propriedade chave de $G(d, m)$, primeiramente provamos um resultado intermediário. Para esse propósito, necessitamos de algumas definições.

O caminho zig-zag que liga os vértices $q_{h}^{l}$ e $q_{h+1}^{l}$ em $G(d, m), 1 \leq l \leq m, 1 \leq h \leq s$, é o caminho resultante da concatenação do caminho alternante definido pelas arestas $\left(q_{h}^{k-1}, p_{h}^{k}\right)$, $\left(p_{h}^{k}, q_{h}^{k}\right), k=l+1, \ldots, m-1$, com a aresta $\left(q_{h}^{m}, q_{h+1}^{m}\right)$ e com o caminho alternante definido pelas arestas $\left(q_{h+1}^{k}, p_{h}^{k}\right),\left(p_{h}^{k}, q_{h+1}^{k-1}\right), k=m, \ldots, l+1$. Veja, por exemplo, o caminho zig-zag $q_{1}^{1} p_{1}^{2} q_{1}^{2} q_{2}^{2} p_{1}^{2} q_{2}^{1}$ na Figura 5.1.

Considere $t$ caminhos alternantes disjuntos nas arestas $P_{1}, \ldots, P_{t}$, cada um ligando vértices superiores do nível $l$. Seja $q_{h}^{l}$ um vértice com pelo menos uma aresta que liga $q_{h}^{l}$ e um vértice do nível $l+1$, e que não é aresta de nenhum caminho $P_{1}, \ldots, P_{t}$. O caminho zig-zag adaptado em relação aos caminhos $P_{1}, \ldots, P_{t}$ com origem em $q_{h}^{l}$ é um caminho alternante que não possui aresta em comum com $P_{1}, \ldots, P_{t}$ e que liga o vértice $q_{h}^{l}$ e um vértice do nível $l$ e que definimos a seguir.

O caminho primeiramente alcança um vértice superior do nível $m$ tentando usar arestas do tipo $\left(q_{i}^{k}, p_{i}^{k+1}\right)$ e $\left(p_{i}^{k}, q_{i}^{k}\right)$. Se ou $\left(q_{i}^{k}, p_{i}^{k+1}\right)$ ou $\left(p_{i}^{k}, q_{i}^{k}\right)$ já é aresta de algum caminho $P_{1}, \ldots, P_{t}$, o caminho usa ou a aresta $\left(q_{i}^{k}, p_{i-1}^{k+1}\right)$ ou a aresta $\left(p_{i}^{k}, q_{i+1}^{k}\right)$, respectivamente. Uma vez alcançado algum vértice $q_{j}^{m}$ o caminho usa a aresta $\left(q_{j}^{m}, q_{j+1}^{m}\right)$, a menos que $\left(q_{j}^{m}, q_{j+1}^{m}\right)$ seja aresta de algum caminho $P_{1}, \ldots, P_{t}$, usando, neste caso, a aresta $\left(q_{j}^{m}, q_{j-1}^{m}\right)$. Então, o caminho segue até um vértice superior do nível $l$ tentando usar as arestas do tipo $\left(q_{i}^{k}, p_{i-1}^{k}\right)$ e $\left(p_{i}^{k}, q_{i+1}^{k-1}\right)$, e do tipo $\left(q_{i}^{k}, p_{i}^{k}\right)$ e $\left(p_{i}^{k}, q_{i}^{k-1}\right)$, respectivamente, se as primeiras forem arestas em $P_{1}, \ldots, P_{t}$.

Na Figura 5.1, podemos verificar o seguinte exemplo. Para os caminhos $P_{1}=q_{1}^{1} p_{1}^{2} q_{2}^{2} q_{3}^{2} p_{3}^{2} q_{4}^{1}$ e $P_{2}=q_{2}^{1} p_{2}^{2} q_{3}^{2} q_{4}^{2} p_{4}^{2} q_{5}^{1}$, o caminho zig-zag adaptado $P$ em relação aos caminhos $P_{1}$ e $P_{2}$ com origem em $q_{2}^{l}$ é um caminho alternante $P=q_{2}^{1} p_{1}^{2} q_{1}^{2} q_{2}^{2} p_{2}^{2} q_{3}^{1}$.

O caminho direito que liga os vértices $q_{h}^{l}$ e $q_{h+k}^{l+k}$ em $G(d, m), 1 \leq l \leq m-k, 1 \leq h \leq s+1-k$, é o caminho alternante definido pelas arestas $\left(q_{h+i}^{l+i}, p_{h+i}^{l+i+1}\right),\left(p_{h+i}^{l+i+1}, q_{h+i+1}^{l+i+1}\right), i=0, \ldots, k-1$ (veja, por exemplo, o caminho direito $q_{1}^{1} p_{1}^{2} q_{2}^{2}$ na Figura 5.1). De modo semelhante, definimos o caminho esquerdo que liga os vértices $q_{h}^{l}$ e $q_{h-k}^{l+k}$ em $G(d, m), 1 \leq l \leq m-k, k+1 \leq h \leq s+1$, com o 
caminho alternante definido pelas arestas $\left(q_{h-i}^{l+i}, p_{h-i-1}^{l+i+1}\right),\left(p_{h-i-1}^{l+i+1}, q_{h-i-1}^{l+i+1}\right), i=0, \ldots, k-1$ (veja, por exemplo, o caminho esquerdo $q_{5}^{1} p_{4}^{2} q_{4}^{2}$ na Figura 5.1).

Lema 5.5 [Cap96] Considere os $s+1$ vértices superiores do nível l em $G(d, m), q_{1}^{l}, \ldots, q_{s+1}^{l}$. Se $m \geq l+r$, para algum par $i$ e $j, 1 \leq i<j \leq s$, existem $s$ caminhos alternantes disjuntos nas arestas ligando pares de vértices $q_{h}^{l}, q_{h+1}^{l}, h \in\{1, \ldots, s\} \backslash\{i, j\}$, e ligando ambos ou os pares $q_{i}^{l}$ e $q_{j}^{l}$, e $q_{i+1}^{l}$ e $q_{j+1}^{l}$, ou os pares $q_{i}^{l}$ e $q_{j+1}^{l}$, e $q_{i+1}^{l}$ e $q_{j}^{l}$.

Prova. Se $j=i+1$, a prova é trivial, desde que todos os pares de nós podem ser ligados por caminhos zig-zag. (De fato, se $q_{i}^{l}$ deve ser ligado ao vértice $q_{j+1}^{l}=q_{i+2}^{l}$ e $q_{i+1}^{l}$ a $q_{j}^{l}=q_{i+1}^{l}$, isto é, a ele mesmo, os caminhos correspondentes podem ser imediatamente derivados dos caminhos zig-zag ligando $q_{i}^{l}$ e $q_{i+1}^{l}$, e $q_{i+1}^{l}$ e $q_{i+2}^{l}$.) Por outro lado, observe que podemos assumir, sem perda de generalidade, que $i=1$ e $j=s$. De fato, se $i \neq 1$ ou $j \neq s$, todos os pares $q_{h}^{l}, q_{h+1}^{l}$, $h=1, \ldots, i-1$ e $h=j+1, \ldots, s$, podem ser ligados por caminhos zig-zag. Portanto, para mostrar a validade da afirmação, basta mostrar o caso $s^{\prime}=j-i+1, i=1$, e $j=s^{\prime}$.

Assumimos, portanto, $i=1, j=s$ e $s>2$. Mostramos a seguir os caminhos ligando cada par desejado de vértices. Para o caminho ligando $q_{1}^{l}$ e ou $q_{s}^{l}$ ou $q_{s+1}^{l}$, digamos $P_{1}$, e o caminho ligando $q_{2}^{l}$ e ou $q_{s}^{l}$ ou $q_{s+1}^{l}$, digamos $P_{2}$, consideramos a seguir os casos para $s$ par e para $s$ ímpar.

Se $s$ é par, e, portanto, $r=s / 2(=d / 4), P_{1}$ é definido pela concatenação do caminho direito ligando $q_{1}^{l}$ e $q_{r+1}^{l+r}$, com o caminho zig-zag ligando $q_{r+1}^{l+r}$ e $q_{r+2}^{l+r}$, com o caminho esquerdo ligando $q_{r+2}^{l+r}$ e $q_{s+1}^{l+1}$, com a aresta $\left(q_{s+1}^{l+1}, p_{s}^{l+1}\right)$ e ou com a aresta $\left(p_{s}^{l+1}, q_{s}^{l}\right)$ ou com a aresta $\left(p_{s}^{l+1}, q_{s+1}^{l}\right)$, dependendo do caso. Simetricamente, $P_{2}$ é definido pela concatenação ou da aresta $\left(q_{s+1}^{l}, p_{s}^{l+1}\right)$ ou da aresta $\left(q_{s}^{l}, p_{s}^{l+1}\right)$ com a aresta $\left(p_{s}^{l+1}, q_{s}^{l+1}\right)$ e com o caminho esquerdo ligando $q_{s}^{l+1}$ e $q_{r+1}^{l+r}$ e com o caminho zig-zag ligando $q_{r+1}^{l+r}$ e $q_{r}^{l+r}$ e com o caminho direito ligando $q_{r}^{l+r}$ e $q_{1}^{l+1}$ e com o caminho $q_{1}^{l+1} p_{1}^{l+1} q_{2}^{l}$.

Se $s$ é ímpar, e, portanto, $r=(s+1) / 2(=(d+2) / 4), P_{1}$ é definido pela concatenação do caminho direito ligando $q_{1}^{l}$ e $q_{r+1}^{l+r}$ com o caminho zig-zag ligando $q_{r+1}^{l+r}$ e $q_{r+2}^{l+r}$ e com o caminho esquerdo ligando $q_{r+2}^{l+r}$ e $q_{s+1}^{l+2}$ e com o caminho $q_{s+1}^{l+2} p_{s}^{l+2} q_{s+1}^{l+1} p_{s}^{l+1}$ e ou com a aresta $\left(p_{s}^{l+1}, q_{s}^{l}\right)$ ou com a aresta $\left(p_{s}^{l+1}, q_{s+1}^{l}\right)$, dependendo do caso. Simetricamente, $P_{2}$ é definido pela concatenação ou da aresta $\left(q_{s+1}^{l}, p_{s}^{l+1}\right)$ ou da aresta $\left(q_{s}^{l}, p_{s}^{l+1}\right)$ com a aresta $\left(p_{s}^{l+1}, q_{s}^{l+1}\right)$ e com o caminho esquerdo ligando $q_{s}^{l+1}$ e $q_{r}^{l+r}$ e com o caminho zig-zag ligando $q_{r}^{l+r}$ e $q_{r-1}^{l+r}$ e com o caminho direito ligando $q_{r-1}^{l+r}$ e $q_{1}^{l+2}$ e com o caminho $q_{1}^{l+2} p_{1}^{l+2} q_{1}^{l+1} p_{1}^{l+1} q_{2}^{l}$.

Em ambos os casos, note que, para $h=2, \ldots, s-1$, o caminho zig-zag adaptado em relação aos caminhos $P_{1}$ e $P_{2}$ com origem em $q_{h}^{l}$ liga $q_{h}^{l}$ e $q_{h+1}^{l}$. Novamente, todos esses caminhos adaptados possuem nenhuma aresta em comum e, portanto, junto com $P_{1}$ e $P_{2}$, formam o conjunto de caminhos desejado.

A propriedade chave de $G(d, m)$ é mostrada a seguir.

Lema 5.6 [Cap96] Considere uma partição dos vértices bases em pares. Se $m \geq r(s-1)+1$, o conjunto de arestas de $G(d, m)$ pode ser decomposto em $s$ caminhos alternantes, cada um deles ligando os vértices de um par da partição definida.

Prova. Considere alguma partição $\tau$ dos vértices bases nos pares

$$
\left\{b_{t_{1}}, b_{t_{2}}\right\},\left\{b_{t_{3}}, b_{t_{4}}\right\}, \ldots,\left\{b_{t_{d-1}}, b_{t_{d}}\right\} .
$$




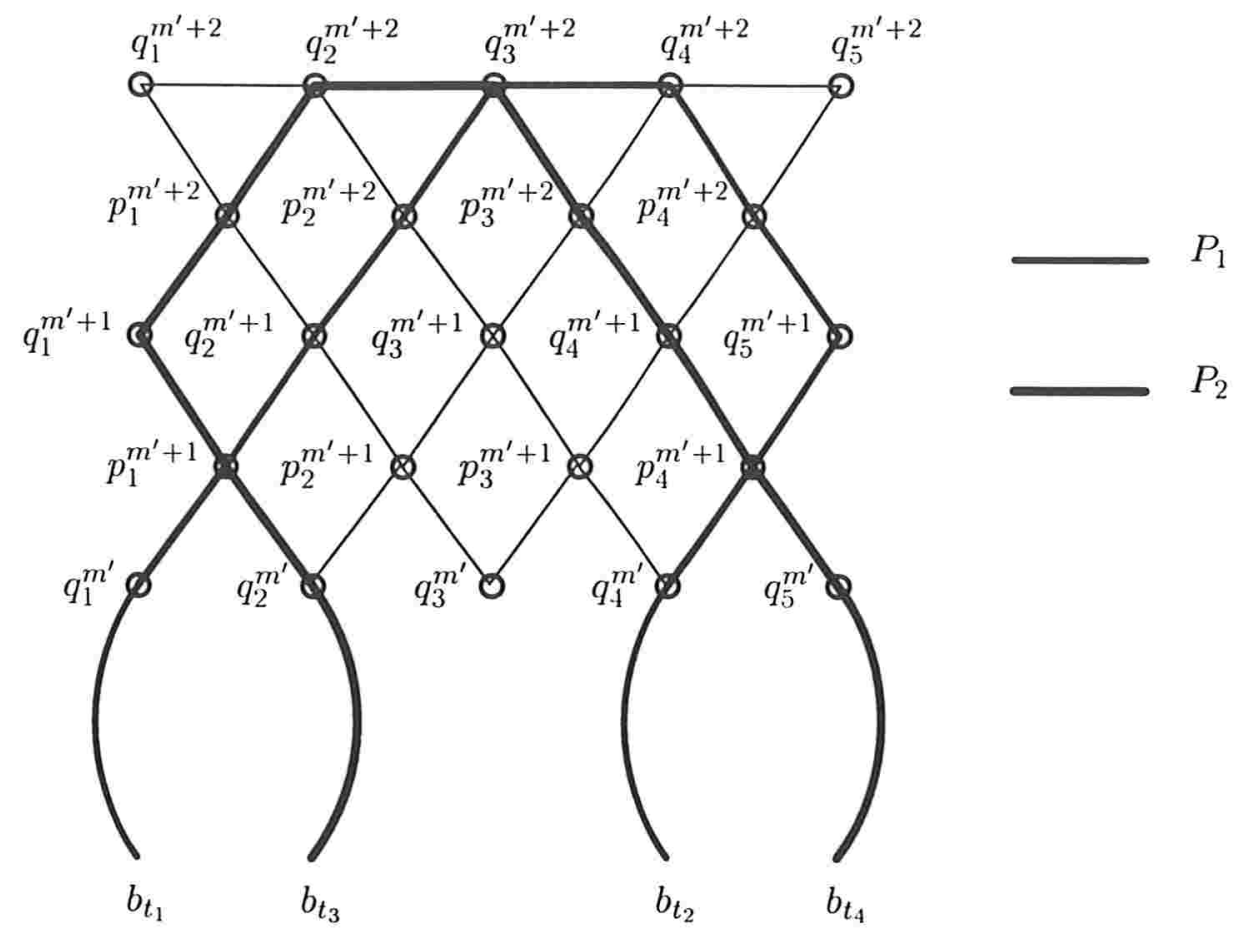

Figura 5.2: O passo indutivo na prova do Lema 5.6, para $d=8$ (e portanto $s=4, r=2$ ) e $a=1$ e $b=4$. As linhas escuras representam os caminhos $P_{1}$ que liga $b_{t_{1}}$ a $b_{t_{2}}$ e $P_{2}$ que liga $b_{t_{3}}$ a $b_{t_{4}}$.

Observe que $\tau$ pode ser obtida da partição $\sigma \leftarrow\left\{b_{1}, b_{2}\right\},\left\{b_{3}, b_{4}\right\}, \ldots,\left\{b_{d-1}, b_{d}\right\}$, pela troca, $k$ vezes, $k \leq s-1$, de elementos entre dois diferentes pares. Mostramos, por indução em $k$, que os caminhos alternantes, cada um deles ligando os vértices de um par da partição, existem para $m \geq r k+1$. Observe que usando caminhos zig-zag é trivial mostrar que se os caminhos existem para um determinando valor de $m$, então eles também existem para valores maiores do que $m$.

Para $k=0$ e $m=1$, claramente, os caminhos existem. Suponha, então, quo os caminhos existem para $k=z-1$ e $m=r(z-1)+1$. Mostramos a seguir que eles também existem para $k=z$ e $m=r z+1$.

Considere uma partição $\tau$ de vértices bases, obtidos de $\sigma$ por $k=z$ trocas. Por hipótese de indução, sendo $\tau$ obtido por uma troca de uma partição $\omega$, temos que existem caminhos alternantes disjuntos nas arestas em $G\left(d, m^{\prime}(=r(z-1)+1)\right)$, ligando todos os pares de nós correspondentes em $\omega$.

Sem perda de generalidade, sejam $\left\{b_{t_{1}}, b_{t_{2}}\right\}$ e $\left\{b_{t_{3}}, b_{t_{4}}\right\}$ os novos pares em $\tau$ após a (única) troca em $\omega$, e $\left\{b_{t_{1}}, b_{t_{3}}\right\}$ e $\left\{b_{t_{2}}, b_{t_{4}}\right\}$ os pares correspondentes em $\omega$. Sejam $q_{a}^{m^{\prime}}$ e $q_{a+1}^{m^{\prime}}$ os vértices superiores tais que os caminhos ligando $b_{t_{1}}$ e $b_{t_{3}}$ em $G\left(d, m^{\prime}\right)$ é definido pelos concatenação do caminho alternante ligando $b_{t_{1}}$ e $q_{a}^{m^{\prime}}$ com a aresta $\left(q_{a}^{m^{\prime}}, q_{a+1}^{m^{\prime}}\right)$ e com o caminho alternante ligando $q_{a+1}^{m^{\prime}}$ e $b_{t_{3}}$. De maneira análoga, sejam $q_{b}^{m^{\prime}}$ e $q_{b+1}^{m^{\prime}}$ os vértices superiores tais que o caminho alternante ligando $b_{t_{2}}$ e $b_{t_{4}}$ em $G\left(d, m^{\prime}\right)$ é definido pela concatenação do caminho ligando $b_{t_{2}}$ e $q_{b}^{m^{\prime}}$ com a aresta $\left(q_{b}^{m^{\prime}}, q_{b+1}^{m^{\prime}}\right)$ com o caminho alternante ligando $q_{b+1}^{m^{\prime}}$ e $b_{t_{4}}$ (veja Figura 5.2).

(O único outro caso que deveríamos levar em conta é aquele no qual o caminho ligando $b_{t_{2}} \mathrm{e}$ $b_{t_{4}}$ é definido pela concatenação do caminho alternante ligando $b_{t_{2}}$ e $q_{b+1}^{m^{\prime}}$ com a aresta $\left(q_{b+1}^{m^{\prime}}, q_{b}^{m^{\prime}}\right)$ 
e com o caminho alternante ligando $q_{b}^{m^{\prime}}$ e $b_{t_{4}}$. Entretanto, este caso pode ser tratado da mesma maneira que o anteriormente considerado.)

Quando obtemos $G\left(d, m^{\prime}+r\right)$, a partir de $G\left(d, m^{\prime}\right)$, isto é, quando o número de níveis é incrementado de $r$, o Lema 5.5 mostra que cada aresta $\left(q_{c}^{m^{\prime}}, q_{c+1}^{m^{\prime}}\right), c \in\{1, \ldots, s\} \backslash\{a, b\}$ pode ser substituída pelo caminho alternante ligando esses vértices, enquanto as arestas $\left(q_{a}^{m^{\prime}}, q_{a+1}^{m^{\prime}}\right)$ e $\left(q_{b}^{m^{\prime}}, q_{b+1}^{m^{\prime}}\right)$ podem ser substituídas pelos caminhos alternantes ligando $q_{a}^{m^{\prime}}$ e $q_{b}^{m^{\prime}}$, e $q_{a+1}^{m^{\prime}}$ e $q_{b+1}^{m^{\prime}}$, respectivamente (veja Figura 5.2).

Portanto, se o número de níveis é incrementado de $r$, existem caminhos ligando todos os novos pares na partição. Isto prova o passo de indução e, portanto, o lema.

Para algum inteiro par, definimos $m(d)=\lceil d / 4\rceil(d / 2-1)+1$.

O Procedimento Trans_Euleriano recebe, então, o grafo euleriano $H$ e constrói o grafo $G$ substituindo cada vértice $v$ de $H$ de grau $d$ pelo grafo $G(v)=G(d, m(d))$ e, então, para cada aresta $(v, u)$ de $H$, acrescenta uma aresta vermelha ligando dois vértices bases, um de $G(v)$ e um de $G(u)$. Note que $G$ tem tamanho polinomial em relação ao tamanho de $H$. Além disso, como conseqüência do Lema 5.6, segue que existe uma correspondência um a um entre circuitos de $H$ e circuitos alternantes de $G$, assim como, entre decomposição em circuitos de $H$ e decomposição em circuitos alternantes de $G$, implicando que $c(G)=\hat{c}(H)$.

\subsection{Complexidade de MIN-SBR}

Mostramos a seguir a complexidade do Problema MIN-SBR.

Na Seção 5.4.1 descrevemos o Procedimento Obtem-Permutação que determina, a partir de um grafo de pontos de quebra $G \operatorname{com} n$ vértices, uma permutação $\pi$ com as seguintes propriedades.

- $G=G(\pi)$;

- A permutação $\pi$ pode ser determinada em tempo polinomial em $n$.

Na Seção 5.4.2 descrevemos o Procedimento Dupla-Divisão que constrói, a partir de uma permutação $\pi$ sobre $n$, uma permutação $\sigma$ com as seguintes propriedades.

- $c(\pi)=c(\sigma)$;

- $d(\sigma)=b(\sigma)-c(\sigma)$;

- $\sigma$ pode ser construído em tempo polinomial em $n$.

Dado um grafo de pontos de quebra $G$ com $n$ vértices, o Procedimento Obtem-Permutaçâo determina uma permutação $\pi$ tal que $G=G(\pi)$. Logo, $c(\pi)=c(G)$. A permutação $\pi$, por sua vez, é usada como entrada do Procedimento Dupla-Divisão que constrói uma permutação $\sigma$ sobre $n^{\prime}$, tal que $c(\pi)=c(\sigma)$ e $d(\sigma)=b(\sigma)-c(\sigma)$. Note que o valor de $b(\sigma)$ pode ser encontrado por simples varredura da permutação $\sigma$ (em tempo linear em $n^{\prime}$ ). A permutação $\sigma$ é, então, usada como entrada de um algoritmo para MIN-SBR cuja saída é usada para a solução do Problema MAX-ACD, ou seja, $c(G)=c(\pi)=c(\sigma)=b(\sigma)-d(\sigma)$.

Como os procedimentos Obtem-Permutação e Dupla-Divisão são polinomiais em $n$, temos o seguinte teorema. 
Teorema 5.7 [Cap96] MIN-SBR é NP-difícil.

\subsubsection{Determinando uma Permutação a partir de um Grafo de Pontos de Quebra}

Nesta seção descrevemos o Procedimento Obtem-Permutação que recebe um grafo de pontos de quebra $G \operatorname{com} n$ vértices e devolve uma permutação $\pi$ com as seguintes propriedades.

- $G=G(\pi)$;

- A permutação $\pi$ pode ser determinada em tempo polinomial em $n$.

Seja $G=(W, R \cup B)$ um grafo de pontos de quebra. Considere o conjunto $U(G)$ dos vértices de grau 2 em $G$, isto é, o conjunto de vértices de grau 1 em $G(B)$ e em $G(R)$. Denotamos por $U$ o conjunto $U(G)$ se $G$ estiver claro no contexto. Note que, como cada componente de $G(B)$ e $G(R)$ é um caminho simples, e todo vértice $v \in W$ tem o mesmo grau que é 1 ou 2 em $G(B)$ e em $G(R)$, temos que $|U|$ é par e ou maior ou igual a 2 .

Um emparelhamento perfeito dos vértices de $U$ é um conjunto $M \subset U \times U$, tal que todo $v \in U$ é um elemento de exatamente um par em $M$. Dizemos que um emparelhamento perfeito $M$ é um emparelhamento hamiltoniano, se os grafos $G(B \cup M)$ e $G(R \cup M)$ são circuitos hamiltonianos.

Dado um grafo de pontos de quebra $G$ e um emparelhamento hamiltoniano $M$, determinamos uma permutação $\pi$ tal que $G(\pi)=G$, usando o seguinte procedimento.

\section{Procedimento Obtem-Permutação;}

Entrada: O grafo de pontos de quebra $G=(V, R \cup B)$ e um emparelhamento hamiltoniano $M$. Saída: Uma permutação $\pi$ tal que $G(\pi)=G$.

Seja $h_{0}, h_{1}, \ldots, h_{|V|-1}$ um circuito hamiltoniano $G(B \cup M)$, onde $h_{0}$ tem grau 2 em $G$ e $\left(h_{0}, h_{1}\right) \in B$

para $i \leftarrow 0, \ldots,|V|-1$ faça

$v_{h_{i}} \leftarrow i$

Seja $g_{0}, g_{1}, \ldots, g_{|V|-1}$ o circuito hamiltoniano $G(R \cup M)$, onde $g_{0}=h_{0}$ e $\left(g_{0}, g_{1}\right) \in R$;

para $i \leftarrow 0, \ldots,|V|-1$ faça

$$
\pi_{i} \leftarrow v_{g_{i}}
$$

devolva $\pi$.

Na Figura 5.3 mostramos como determinar um emparelhamento hamiltoniano a partir de um grafo de pontos de quebra $G$.

Caprara [Cap96] mostrou que, de fato, é um emparelhamento hamiltoniano o conjunto $M$ determinado pelo Procedimento Emparelhamento-Hamiltoniano e que, dado um grafo $G$ de pontos de quebra, o Procedimento Obtem-Permutação constrói, de fato, uma permutação $\pi$ tal que $G=G(\pi)$.

\subsubsection{Procedimento Dupla-Divisão}

Na Seção 3.2.2 definimos, para o grafo de pontos de quebra do retrato de uma permutação orientada, os conceitos de arestas convergentes e divergentes. Para uma permutação não-orientada 
Procedimento Emparelhamento-Hamiltoniano;

Entrada: O grafo de pontos de quebra $G=(W, R \cup B)$.

Saída: Um emparelhamento hamiltoniano $M$ dos vértices de grau 2 de $G$.

$U \leftarrow\{v \in W \mid$ o grau de $v$ é 2$\}$;

$M \leftarrow \emptyset$;

$S \leftarrow\{(v, w) \mid v, w \in U$ são vértices de um mesmo caminho em $G(B)\}$;

$C \leftarrow\{(v, w) \mid v, w \in U$ são vértices de um mesmo caminho em $G(R)\}$;

enquanto $|U|>2$ faça

Escolha $i, j \in U$, tais que $(i, j) \notin(S \cup C)$;

Seja $i^{\prime}, j^{\prime} \in U$, tais que $S^{\prime}=\left\{\left(i, i^{\prime}\right),\left(j, j^{\prime}\right)\right\} \subset S$;

Seja $i^{\prime \prime}, j^{\prime \prime} \in U$, tais que $C^{\prime \prime}=\left\{\left(i, i^{\prime \prime}\right),\left(j, j^{\prime \prime}\right)\right\} \subset C$;

$U \leftarrow U \backslash\{i, j\}$

$S \leftarrow\left(S \backslash S^{\prime}\right) \cup\left\{\left(i^{\prime}, j^{\prime}\right)\right\}$

$C \leftarrow\left(C \backslash C^{\prime}\right) \cup\left\{\left(i^{\prime \prime}, j^{\prime \prime}\right)\right\}$

$M \leftarrow M \cup\{(i, j)\}$;

Sejam $i$ e $j$ os elementos remanescentes de $U$;

$M \leftarrow M \cup\{(i, j)\}$;

devolva $M$.

Figura 5.3: Procedimento Emparelhamento-Hamiltoniano.

$\pi$ e uma decomposição máxima em circuitos $D$ do grafo $G(\pi)$, de maneira análoga, podemos definir o conceito de arestas convergentes e divergentes da seguinte forma.

Em um circuito $C$ de $D$, duas arestas vermelhas podem ser comparadas. Imagine por um instante que cada aresta vermelha $\left(\pi_{i}, \pi_{i+1}\right)$ possui orientação de $\pi_{i}$ para $\pi_{i+1}$. Duas arestas vermelhas $p$ e $q$ de $C$ são ditas convergentes, se aorientação das $\operatorname{arestas} p$ e $q$ em relação a $C$ coincidem. Caso contrário, dizemos que elas são divergentes.

Dada uma permutação não-orientada $\pi$ e uma decomposição máxima em circuitos $D$, podemos definir o retrato $\sigma$ de um candidato orientado de $\pi$ tal que $b(\pi)=b(\sigma), c(\pi)=c(\sigma)$, $d(\pi) \leq d(\sigma)$ e existe uma correspondência uma a uma entre os circuitos de $D$ e de $G(\sigma)$, tal que um circuito em $D$ possui um par de arestas divergentes se, e somente se, o circuito correspondente em $G(\sigma)$ possui um par de arestas divergentes. Suponha, então, que todo circuito em $D$ possui um par de arestas divergentes. Neste caso, todo circuito em $G(\sigma)$ possui um par de arestas divergentes, o que implica que não existe componente má em $H(\sigma)$ (Fato 3.3 e Lema 3.6) e, portanto, $d(\sigma)=b(\sigma)-c(\sigma)$ (Teorema 3.38). Segue que

$$
d(\pi) \leq d(\sigma)=b(\sigma)-c(\sigma)=b(\pi)-c(\pi) \leq d(\pi) \text { (Corolário 2.2), }
$$

implicando, portanto que, se todo circuito em uma decomposição máxima em circuitos $D$ possui um par de arestas divergentes, então $d(\pi)=b(\pi)-c(\pi)$.

Dado um grafo de pontos de quebra $G=(V, R \cup B)$, a subdivisão de uma aresta $p=(i, j) \in$ $R \cup B$ é obtida pela adição de dois novos vértices, digamos $a$ e $b$, a $V$ e pela substituição da aresta $p$ pelas arestas $(i, a),(a, b)$ e $(b, j)$, onde $(i, a)$ e $(b, j)$ têm a mesma cor que a aresta $p$ e $(a, b)$ tem cor diferente de $p$ (veja Figura 5.4). 


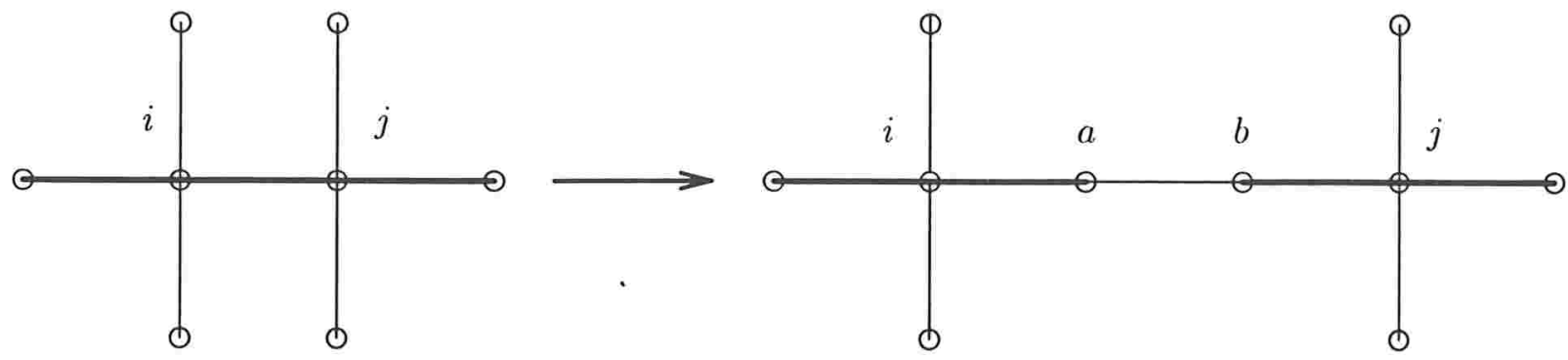

Figura 5.4: A subdivisão da aresta $(i, j)$.

Fato $5.8 O$ grafo $G$ obtido de um grafo de pontos de quebra por subdivisão de arestas é um grafo de pontos de quebra.

Fato 5.9 Existe uma correspondência uma a uma entre as decomposições em circuitos alternantes de um grafo de pontos de quebra $G$ e de um grafo de pontos de quebra $G^{\prime}$ obtido de $G$ por subdivisão de arestas.

A idéia do Procedimento Dupla-Divisão é, ao receber uma permutação $\pi$, subdividir todas as arestas vermelhas de $\pi$, determinando uma permutação $\sigma$ tal que qualquer circuito de qualquer decomposição em circuitos de $G(\sigma)$ posssua um par de arestas vermelhas divergentes.

\section{Procedimento Dupla-Divisão;}

Entrada: Uma permutação $\pi$ sobre $n$.

Saída: Uma permutação $\sigma$ sobre $\{1,2, \ldots, n+4 b(\pi)\}$, tal que $c(\pi)=c(\sigma)$ e $d(\sigma)=b(\sigma)-c(\sigma)$.

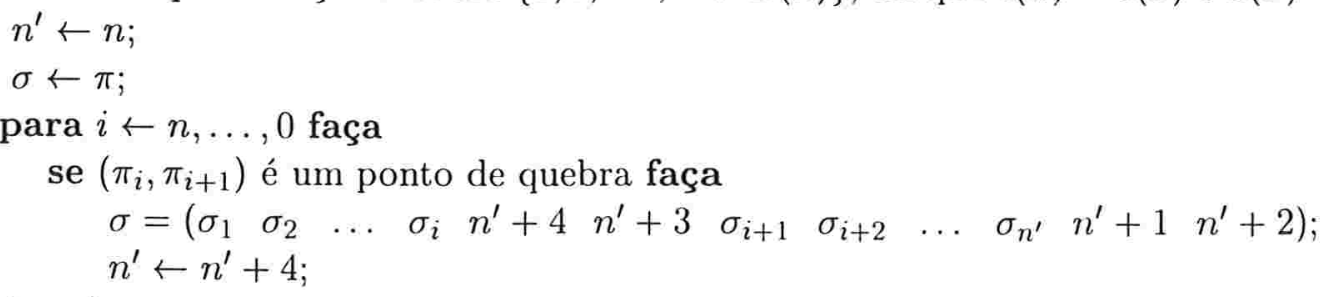

devolva $\sigma$.

Caprara [Cap96] mostrou que o procedimento acima constrói, de fato, uma permutação $\sigma$ com as seguintes propriedades:

- $c(\pi)=c(\sigma)$

- $d(\sigma)=b(\sigma)-c(\sigma)$.

Com isso concluímos a demonstração de que MIN-SBR é $N P$-difícil. 


\section{Capítulo 6}

\section{Conclusão}

Estudamos nesta dissertação alguns algoritmos para os problemas MIN-SBR e MIN-SBR. A seguir mostramos os principais pontos desse trabalho.

No Capítulo 3 formalizamos o Problema MIN- $\overrightarrow{\mathrm{SBR}}$ de maneira diferente daquela apresentada por Hannenhalli e Pevzner [HP95].

Mostramos na Seção 3.4.1 um algoritmo para determinar os conjuntos de vértices de um grafo de pontos de quebra que é executado em tempo $O(n)$, sendo assintóticamente mais rápido que o anteriormente descrito por [HP95] $(O(n \alpha(n)))$.

Durante o estudo percebemos um erro na demonstração do Teorema que prova a Conjectura forte de Gollan [BP93]. Esse erro se deve não ao resultado, que é válido, mas sim à argumentação de que $\mathcal{A} \cap \mathcal{C}=\emptyset$, para todo $n \geq 3$, o que não é verdade desde que a permutação

$$
\left(\begin{array}{lllll}
5 & 2 & 4 & 1 & 3
\end{array}\right) \in \mathcal{A} \cap \mathcal{C} \text {. }
$$

O Lema 4.19 mostra que essa propriedade vale, para todo $n \geq 6$.

No Capítulo 4 verificamos, conforme observado pelo Professor João Meidanis durante a apresentação do Projeto de Qualificação dessa dissertação, que a complexidade de tempo de $O\left(2^{k} n^{3}+n^{4}\right)$, onde $k$ denota o número de correntes da permutação que possuem um único elemento, do algoritmo de Hannenhalli e Pevzner [HP96] pode ser melhorada para $O\left(2^{k} n+n^{2}\right)$ desde que seja substituída a rotina para determinar, a partir de uma permutação orientada, a distância por reversões orientadas e a seqüência de reversões orientadas pelos algoritmos descritos no Capítulo 3.

Mostramos, a seguir, dois resultados recentes que são relevantes nesta dissertação, embora não estejam aqui detalhados.

Um deles, obtido por Berman e Karpinski [BK98], mostra que, para todo $\epsilon>0$, é $N P$-difícil obter um algoritmo polinomial para o Problema MIN-SBR que possua um fator de aproximação $1237 / 1236-\epsilon$.

Outro, é um algoritmo de aproximação para MIN-SBR que possue um fator de aproximação $3 / 2$ descrito por Christie [Chr98].

A seguir mostramos algumas linhas de pesquisa que julgamos interessantes para trabalhos futuros.

Para a versão orientada existem algoritmos polinomiais para determinar a distância de reversões. O melhor deles é de Kaplan, Shamir e Tarjan [KST97] e encontra a distância por 
reversões em tempo quadrático. Seria interessante a obtenção de um algoritmo mais rápido para o problema.

Estamos interessados, também, em pesquisar limitantes inferior e superior da distância esperada por reversões orientadas. Em nosso estudo, não encontramos qualquer referência sobre esse assunto.

Para a versão não-orientada, é sabido que o problema é NP-difícil, não se conhecendo algoritmos polinomiais para o problema. Estamos interessados em implementar e testar algoritmos exatos práticos. Aqui também seria interessante a obtenção de algoritmos mais rápidos do que o de ordem $O\left(2^{k} n+n^{2}\right)$, obtido por Hannenhalli e Pevzner [HP96] para o problema. 


\section{Índice Remissivo}

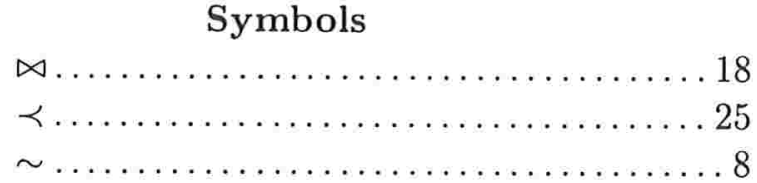

A

adjacência $\ldots \ldots \ldots \ldots \ldots \ldots \ldots \ldots \ldots$

Algoritmo

$K S \ldots \ldots \ldots \ldots \ldots \ldots \ldots \ldots \ldots \ldots \ldots \ldots \ldots \ldots$
AproxMIN-SBR $\ldots \ldots \ldots \ldots \ldots \ldots \ldots \ldots$
SBR-Orienta $\ldots \ldots \ldots \ldots \ldots \ldots \ldots$

permutação não-orientada ........... 3

permutação orientada ............. 5

arco

que define

a proteção de um não-obstáculo . . 29

um obstáculo ................ 27

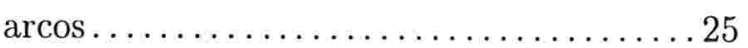

disjuntos .................... 25

opostos .................... 25

arestas

azuis ........................ 9

convergentes...............16, 82

coordenadas.....................63

divergentes ............... 16,82

vermelhas ..................... 9

B

bloco.......................... 58

brecha.......................... 8

C

caminho

direito ....................... 77

esquerdo ...................... 77

zig-zag .................... 77 zig-zag adaptado............... 77

candidato apropriado................64

candidato orientado ...................64 64

circuitos alternantes ................. 9

decomposição em..................9

decomposição máxima em ...........99

clique feliz .................... 47

colados......................... 15

componentes

ativas ....................... 35

boas .......................... 27

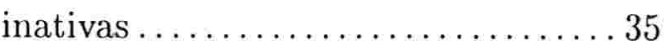

más.......................... 27

corrente....................... 58

cruza.........................27

D

diâmetro

permutações não-orientadas . .......6 68

permutações orientadas . ........... 51

permutações orientadas circulares ... 56 distância

esperada...................... 73

distância par....................... 14

distância por reversões

permutação não-orientada ...........4

permutação orientada .............. 5

permutação orientada circular .......56

$\mathbf{E}$

emparelhamento

hamiltoniano ................... 81

perfeito ...................... 81

entrelaça......................... 18

extremos ........................ 18 


\section{F}

fator de aproximação $\ldots \ldots \ldots \ldots \ldots \ldots 57$

fortaleza ..................... 30

\section{G}

grafo

2-circuito ....................6 61

componentes de um............... 13

de entrelaçamento................20

de pontos de quebra ........... 9, 75

vértices isolados de um............13

L

lista obstáculo-consecutiva...........40

$\mathrm{N}$

não-obstáculo 28

\section{$\mathrm{O}$}

obstáculo

obstáculos

consecutivos .................. 40

que protegem não-obstáculos ....... 28

simples...................... 28

ordenação

permutação não-orientada . . . . . . . . 4

permutação orientada .............. 5

permutação orientada circular ...... 55

ordenação par...................... 14

\section{$\mathbf{P}$}

permutação

de Gollan ......................... 69

não-orientada .................... 3

estendida .................... 8

identidade..................... 3

inversa ..................... 4

orientada.................... 4

circular .................... 55

equivalente...................5 54

identidade................... 5

inversa ...................... 5

ponto de quebra................... 8

precede ......................... 71

Problema
CLIQUE-3 .................... 74

MAX-ACD .................. 75

MAX-ECD .................... 75

MIN-SBR $\ldots \ldots \ldots \ldots \ldots \ldots \ldots \ldots 6$

MIN-SBR-CIRCULAR ............ 56

MIN-SBR .................. 4

Procedimento

Dupla-Divisão ...................83

Emparelhamento-Hamiltoniano . . . . 82

Obtem-Permutação ............... 81

Trans_Euleriano ................ 76

Transforma .................. 62

ConstróiH ....................... 38

R

retrato ........................... 14

reversão

circular ...................... 55

não-orientada ................. 4

orientada....................... 5

par ......................... 14

que age $\ldots \ldots \ldots \ldots \ldots \ldots \ldots \ldots \ldots \ldots \ldots \ldots \ldots$

que age exclusivamente...........23

que corta um obstáculo .......... 40

que intercala obstáculos .......... 40

segura ...................... 34

\section{$\mathrm{S}$}

subdivisão de uma aresta............ 82

super-obstáculo .................... 28

$\mathrm{T}$

tamanho de circuitos ................6 60

\section{V}

vértices

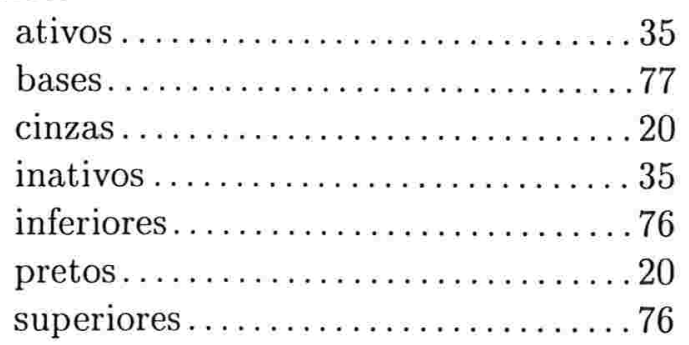

superiores.................... 76 


\section{Referências Bibliográficas}

[BH96] P. Berman and S. Hannenhalli. Fast sorting by reversal. In Combinatorial pattern matching (Laguna Beach, CA, 1996), volume 1075 of Lecture Notes in Comput. Sci., pages 168-185. Springer, Berlin, 1996.

[BK98] P. Berman and M. Karpinski. On some tighter inapproximability results. ftp://ftp.eccc.uni-trier.de/pub/eccc/reports/1998/TR98-029/index.html, 1998.

[BP93] V. Bafna and P. Pevzner. Genome rearrangements and sorting by reversals. In 34th Annual Symposium on Foundations of Computer Science (Palo Alto, CA, 1993), pages 148-157. IEEE Comput. Soc. Press, Los Alamitos, CA, 1993.

[Cap96] A. Caprara. Sorting by reversals is difficult. Technical report, DEIS, University of Bologna, 1996.

[Chr98] D.A. Christie. A 3/2-approximation algorithm for sorting by reversals. In Proceedings of the Ninth Annual ACM-SIAM Symposium on Discrete Algorithms (San Francisco, CA, 1998), pages 244-252, New York, 1998. ACM.

[CLR90] T. H. Cormen, C. E. Leiserson, and R. L. Rivest. Introduction to Algorithms. MIT Press, Cambridge, MA, 1990.

[Hol81] I. Holyer. The NP-completeness of some edge-partition problems. SIAM Journal on Computing, 10:713-717, 1981.

[HP95] S. Hannenhalli and P. Pevzner. Transforming cabbage into turnip (polynomial algorithm for sorting signed permutations by reversals). In Proceedings of the 20th Annual ACM Symposium on Theory of Computing, pages 178-189, 1995.

[HP96] S. Hannenhalli and P. Pevzner. To cut ... or not to cut (applications of comparative physical maps in molecular evolution). In Proceedings of the Seventh Annual ACMSIAM Symposium on Discrete Algorithms (Atlanta, GA, 1996), pages 304-313, New York, 1996. ACM.

[KS95] J. Kececioglu and D. Sankoff. Exact and approximation algorithms for sorting by reversals, with application to genome rearrangement. Algorithmica, 13(1-2):180$210,1995$. 
[KST97] H. Kaplan, R. Shamir, and R. E. Tarjan. Faster and simpler algorithm for sorting signed permutations by reversals. In Proceedings of the Eighth Annual ACM-SIAM Symposium on Discrete Algorithms (New Orleans, LA, 1997), pages 344-351, New York, 1997. ACM.

[MWD97] J. Meidanis, M. E. M. T. Walter, and Z. Dias. Reversal distance of signed circular chromossomes. Manuscrito, 1997.

[SM97] J. C. Setubal and J. Meidanis. Introduction to Computational Molecular Biology. PWS Publishing Co, 1997.

[WEHM82] G. A. Watterson, W. J. Ewens, T. E. Hall, and A. Morgan. The chromosome inversion problem. J. Theor. Biol., 99:1-7, 1982. 